\title{
Combinatoric Properties of Natural Semantic Metalanguage Expressions in Lao
}

\author{
N. J. Enfield \\ Max Planck Institute for Psycholinguistics, Nijmegen
}

\begin{abstract}
The current version of the natural semantic metalanguage (NSM) identifies about 60 semantically basic morpholexical items which are hypothesised to be found in every language of the world. It is argued that these universal semantic units have meanings which are both simple, and identical across languages. Further, it is hypothesised that all language-specific semantic structures are complex, and may be analysed (and translated across languages) by means of complex expressions involving just the 60 or so basic universal semantic units (Wierzbicka 1972, 1996). No other descriptive metalanguage (formal or otherwise) insists on this level of cross-translatability, and so it is apparently the closest thing to a real standard of comparison available for cross-linguistic semantic description. To achieve this, not only must the units of the system be semantically basic and cross-linguistically identical, but their combinatoric properties must also be basic and cross-linguistically identical. The purpose of this study is to evaluate current hypotheses regarding universal combinatoric properties of the putative morpholexical/semantic universals (reviewed in Goddard and Wierzbicka, vol. I, chapter 2), with reference to Lao.
\end{abstract}

\subsection{Preliminary remarks on Lao grammar}

Lao is a Southwestern Tai language with varieties spoken in Laos, Northeast Thailand, and Northeast Cambodia. (For descriptive and pedagogical materials, cf. Roffe and Roffe 1958; Yates and Sayasithsensa 1970; Morev et al. 1972; RLG 1972; Reinhorn 1980; Hoshino and Marcus 1981; Werner 1992; Wright 1994.) While it is the official language of the Lao People's Democratic Republic, there is no well-codified Standard Lao and a certain degree of dialect variation is 
observed (Enfield 1999); this, however, is unlikely to affect generalisations made here. Lao is a tone language (see Abbreviations and Conventions for phonology/transcription), and displays typical isolating/analytical grammatical features, lacking inflectional forms of cross-referencing or case-marking, and displaying limited derivational morphology. Few aspectual/modal distinctions are obligatorily expressed. Grammatical structures are almost exclusively leftheaded: basic word order is AVO/SO, nominal modifiers (including possessives and relative clauses) follow the head, and complementisers and most modals precede the verb. The lexicon shows versatility, with 'adjectives' and most 'adverbs' belonging formally in the same general class as regular verbs, and with various 'prepositions' and tense-aspect-modality markers recruited from among active members of both the noun and verb classes. Nominal structure is characterised by obligatory use of classifier constructions, where most nominals may appear as classifiers, and most classifiers may appear as lexical nouns. The head constituent is arguably the (obligatory) classifier itself rather than the (often optional) lexical noun. Verbal marking includes preverbal negation, as well as aspect/ modality-marking (and adverbial elements) both before and after the verb. Multi-verb compounds and serial verb constructions make up much of the conventional lexicon, as well as being productive in the formation of complex verbal phrases.

Ellipsis is the unmarked form of anaphora. Reference tracking in discourse is highly dependent on pragmatic inference, with little syntactic control of coreference, e.g. across chained clauses. There is slim evidence for a grammatical relation "subject", and it may be that the unmarked constituent order AVO arises from a "highest-argument status" accorded to verb-initial arguments, i.e. depending on factors such as discourse activation and animacy. There is in fact extensive constituent-order variation, usually pragmatically-motivated, with disambiguation of participants' semantic roles being essentially contextdependent. Undergoers often directly precede verbs, either through a combination of object fronting and subject ellipsis, or due to the $S=O$ ambitransitivity of many verbs. Related to this is pervasive Topic-Comment sentence organisation ( $\mathrm{Li}$ and Thompson 1976). A "left position" (cf. Van Valin 1993:6) is available for topical arguments to appear sentence-initially, outside the core of the clause. (The left position may serve other functions, such as hosting a possessor, or an additional core argument in a three-place predication.) Left position constituents may or may not be arguments of the verb, and they serve as (literal or conceptual) 'settings' for the main predication.

To describe the structures for expressing NSM formulas in Lao entails describing most of the significant features of Lao grammar. Indeed, as Goddard (1997) has argued, this exercise may provide a useful starting point for the 
description of the grammar of any language. It is important to bear in mind, however, that this chapter is intended to describe the lexical items and associated grammar required for the articulation of NSM expressions in Lao, and is not intended to be a "grammar of Lao" at any level.

\subsection{Substantives}

\subsection{1 kuu ${ }^{3}$, mùng $g^{2}$ YOU}

Lao has a complex system for personal reference, which includes an array of pronouns encoding various levels of respect (Enfield 2000). The NSM hypothesis includes the claim that all languages have a word meaning 'I' and a word meaning 'you', with each meaning finding precise semantic equivalents cross-linguistically. ' $\mathrm{T} / \mathrm{V}$ ' systems, such as those in many European languages (Trudgill 1974:105ff), provide a choice between two second-person singular pronouns - an "intimate" form and a "respect" form - and thus force the analyst to decide whether or not one of them is semantically basic, and, if so, which one. The issue has been discussed by Wierzbicka (1994:449), with respect to the more elaborated pronominal systems among East and Southeast Asian languages (cf. Huffman 1970, Diller 1994, Onishi 1994). Not only do languages such as Lao, Thai, and Khmer provide a large number of genuine pronominal forms to choose from, but there are also a number of other strategies for personal reference. Huffman (1970:356-357) gives examples of Khmer pronouns with three distinct forms in third-person, and up to seven in each of first and second-person. These do not include other common strategies for personal reference, such as the use of kinship terms ('brother', 'aunty'), occupation/rank terms ('monk', 'teacher'), or plain avoidance (i.e. zero). The situation in Lao is the same. Different speech levels articulated by different pronominals index the relative status of interlocutors, expressing different degrees of familiarity, sometimes related to facts of biography (e.g. respect forms used for strangers, people of specific age differences), or socially determined relative position (e.g. role status of interlocutors, usually most marked in religious settings, such as when speaking with monks). Essentially, the use of different pronouns marks differences in social "height".

The semantically simple forms for ' $I$ ' and 'you' in Lao - i.e. those not semantically encoding any message of social distinction - are $\boldsymbol{k u u}^{3} \mathrm{I}$ and mùng $\mathbf{2}^{2}$ YOU. They are used when speakers do not want to express any difference in "social height" between interlocutors (either because they wish not to, or have no reason to). For example:" 
(1) $k u u^{3}$ jaan $^{4}$ mùng ${ }^{2}$

1SG afraid 2SG

'I was afraid of you.'

(2) $\tilde{n} a k^{\prime} m_{a a^{2}} n i i^{4}$ mùng ${ }^{2} t a a j^{3} d \hat{e} j^{2}$ ogre come here $2 \mathrm{SG}$ die PCL

'(If) the ogre comes here, you'll die you know.'

The first example describes an exchange between close friends in the same class at school (no marking of social distance required), while the second describes the speech of a woman who is trying to chase a man (a junior relative) away, and is showing him none of the respect he would usually be given.

Clear support for the claim that $k u u^{3}$ means plain ' $I$ ' with no social/interactional semantic frills (pragmatic value being another matter) comes from its common use in reported reflexive/inner speech. Example (3) describes a character's exclamation (to himself), having arrived home to find that the spectacles he had bought from a Chinese merchant had not enabled him to read (as he had hoped). In example (4) similarly, the speaker is alone, thinking aloud:

(3) $\quad c \hat{e} k^{2} \quad n i^{0} \quad \operatorname{man}^{2} \operatorname{tom}^{4} \quad k u u^{3} \cdot l e ̀ e ̀ w^{4}$

chinaman TPC.PCL 3SG boil 1SG PFV

'This Chinaman has "boiled" me!' (i.e. has cheated me)

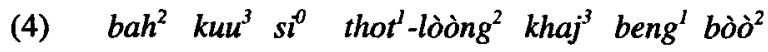

INTJ 1SG IRR test-try open see PCL.Q

'Bah! Should I try opening (it) to have a look?'

The status of mùng ${ }^{2}$ YOU as semantically unmarked for "respect" is demonstrated by the following, in which the speaker is calling out to a dog, who has stolen his sausages. He has no need to linguistically encode social "respect" of any kind:

(5) $\quad$ mùng ${ }^{2} q a w^{3}$ paj $^{3}$ loot $^{4}$

2SG take go without.other.ado

'You go ahead and take (them)!'

In real social interaction, practices of personal reference are influenced by social and situational context, together with personal social sensibilities and specific interactional objectives. Wherever possible, it is preferable to overtly offer an appropriate marking of one's social relationship with one's interlocutor, which explicitly indicates in everyday speech that people are not all on the same level (and thus related in the same way), but are related to each other in a range 
of different ways. Many ways of making personal reference are not reciprocal, embodying a cultural premise that 'certain people may do things that others may not do'. For example, among close family members, one's old grandmother (whose husband and peers are gone) might use the pronoun pair $\mathrm{kuu}^{3} / \mathrm{mùng}^{2}$ 1/YOU with everybody else, but nobody else would have the privilege of using them with her. Others would be required to encode their own "lower" status by using appropriate marked pronouns or kinship terms. Similarly, it is reported that prison wardens use $k u u^{3} /$ mùng $^{2}$ I/YOU with prisoners, encoding no particular respect at all, while the latter are required to encode the highest respect in pronominal choice. This kind of usage is revealed in the following examples, spoken by masters to servants/underlings:

(6) khan ${ }^{2}$ nò̀ng kuu $^{3}$ haaj $^{3} \quad$ mùng $^{2} k^{2} t^{2} \quad h^{3} a^{3}$ mùng $^{2}$ if Y.SIB 1SG disappear 2SG lopped head 2SG

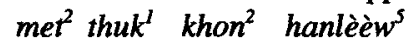
all each people $\mathrm{PCL}$

'If my sister goes missing, you'll have your head lopped, every one of you.'

(7) $k u u^{3}$ bòòk $k^{5}$ ùng ${ }^{2} l a a j^{3}$ thù $a^{I} l \grave{e ̀ w} w^{4}$ 1SG tell 2SG many time PFV 'I've told you many times.'

An apparent problem with identifying the pair $k u u^{3} / m^{2} g^{2}$ as the basic $1 / Y O U$ forms in Lao is their high degree of pragmatic markedness. Given that default rules of "politeness" dictate semantically marked forms in most circumstances, to use the unmarked forms in those circumstances might not be semantically 'saying' anything, but pragmatically it can constitute a very strong statement. For example, between a married couple it is standard to reciprocally use the general respect forms khòjj' 'I' and caw 'you', but it is not uncommon for couples to use $k u u^{3} / m_{i n g}^{2}$ I/YOU in abusive language (e.g. when fighting). (The only relationship in which reciprocal use of $k u u^{3} / \mathrm{mung}^{2}$ is unmarked is between intimate peers of the same age, especially children, or adults who had been together as children.) The semantically unmarked may thus be pragmatically marked, and the use of these forms is highly potent in cases where other forms would be typical. This applies in particular to formal registers, such as in written language, and so the use of $\mathrm{kuu}^{3} / \mathrm{mùng}^{2} \mathrm{I} /$ YOU in written NSM formulas discussed in this chapter is pragmatically very abnormal. In practice, NSM expressions may be better phrased using $k h \dot{\partial} \dot{j}$ ' 'I' and $c a w^{4}$ 'you' the general respect forms, used most widely among strangers and respected friends and relatives (e.g. with one's own parents). 


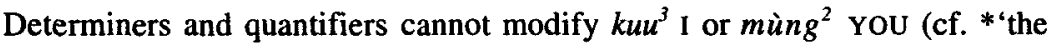
same me', *'one you'), while descriptors and evaluators can only be used predicatively (cf. *'big me', *'bad you'):

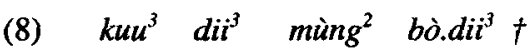

1SG good 2sG bad

'I'm good, you're bad.'

\section{$3.12 p h a j^{3} / p h u$ - SOMEONE/WHO, nang ${ }^{3} / q a n$ - SOMETHING/WHAT}

Expressions involving the primes SOMETHING and SOMEONE show significant grammatical variation, according to pragmatic factors such as specificity and givenness of the argument/participant being referred to. These expressions involve a certain amount of allolexy not only in Lao, but also in the English translations - so it is important to bear in mind throughout the discussion that expressions such as someone, anyone, whoever, and who are considered in the NSM system to be semantically equivalent allolexes of the prime SOMEONE. Let us begin with $p h a j^{3}$ SOMEONE (whose specific translation into English may involve 'whoever', 'who?', 'anyone', or 'someone', and which has a number of lexical variants in addition, while remaining semantically stable). The simplest are non-specific readings.

In (9), in sentence-initial position, $p h a j^{3}$ SOMEONE is a fronted object translated as 'whoever'. In (10), phaj in initial position and with negation is' translated into English as 'nobody'. In (11), with non-specific/non-referential status, $\mathrm{phaj}^{3}$ is translated into English by 'anyone' or 'whoever'.

(9) phaj $^{3} \quad n a m^{2}-q a w^{3}$ nò̀ng ${ }^{4}$ maa $h a j^{5}-s i^{0}$ mò̀̀ ${ }^{4}$ someone go.after-take Y.SIB come give IRR hand.over mùang ${ }^{2}$ haj $^{5}$ loot $^{4}$ kingdom give without.further.ado 'Whoever brings my sister to (me), (I) will hand over the kingdom to (them) right away.'

(10) phaj $^{3} \quad b \dot{o}^{0} k a a^{4}$ phaan ${ }^{1}-k h a a m^{5} b a k^{2}-$ siang $^{2}$ daj $^{0}$ thòo ${ }^{1} \tilde{n} a j^{2}$ someone NEG dare pass-cross M.PRFX-S. EXT extent web 'Nobody dared to cross Siang even the width of a spider web.'

(11) thaam $^{3} \mathrm{phaj}^{3} \quad b o^{0} \mathrm{mii}^{2} \quad \mathrm{phaj}^{3} \quad \mathrm{daj}^{4}$ ask someone NEG there.is someone can 'Whoever (you) asked, nobody was able.' 
$P h a j^{3}$ may also have interrogative readings ('who?') in certain contexts, but confusion with the non-interrogative non-specific/referential uses described so far does not arise. The following example shows that in a simple clause, phaj $j^{3}$ may be read as 'who?':

(12) $\mathrm{caw}^{4} \mathrm{hên}^{3} \mathrm{phaj}^{3} \mathrm{juu}^{\mathbf{l}}$ talaat $^{5}+$

2SG see who be.at market

'Who did you see at the market?'

Addition of a sentence-final polar-question particle forces a non-interrogative reading for $p h a j^{3}$ :

(13) caw $^{4}$ hên ${ }^{3}$ phajj juul talaat ${ }^{3}$ bòò ${ }^{3}+$

2SG see who be.at market PCL

'Did you see anyone at the market?'

So far, $\mathrm{phaj}^{3}$ has been used for non-referential "someones". When the said SOMEONE is specific/referential (as when marked by a specifier or determiner SOMEONE ELSE, THIS SOMEONE) more complex constructions are required. We now turn to these.

The expression $p h a j^{3}$ is related to a morphologically complex expression phu$d a j^{3}$, in which $d a j^{3}$ is a determiner meaning 'which?/any (one)', and phu- (a reduced form of phuu 'person') is a nominal head, a pseudo-classifier quite restricted in its grammatical behaviour, meaning 'someone' or 'person'. (In NSM terms, phu- may be described as an allolex of $p h a j^{3}$ SOMEONE.) While in a number of Tai languages, cognates of phuu ${ }^{5}$ are used as free nominals, phu- or $p h u u^{5}$ in Lao is never available as a main free nominal (i.e. without an attached specifier/determiner). It appears very frequently in descriptions of participants with specific and referential status, taking postnominal descriptive phrases, or determiners such as nii ${ }^{3}$ THIS, qùùn ${ }^{l}$ OTHER, diaw ${ }^{3}-k^{3} n^{3}$ THE SAME, and nùng ${ }^{1}$ ONE:

(14) phu-nït mè̀n ${ }^{1}$ phuu ${ }^{5} \quad c a^{0}$ suu $^{5}-$ son $^{2}$ someone-this be someone IRR fight-clash 'This fellow is the one who will fight.'

(15) $h_{a a^{5}} k_{h o n^{2}} n^{0} \quad q a w^{3}$ haj $j^{5}$ phu-nùng' $\quad$... lèèw five people TPC.PCL take give someone-one ... PFV phu-qùùn' ${ }^{1}$ han $^{5} q^{2} t^{2} q a w^{3}$ nòq $^{1}$ someone-other TPC.PCL go.without take PCL 'Five people would give (rice) to one... the others would go without, right?' 
However, phu-SOMEONE differs from regular classifiers in that it may not take prenominal modification, such as sòong ${ }^{3}$ Two (or any other numerals higher than one) or baang ${ }^{3}$ SOME. So: *sò̀ng ${ }^{3}$ phuu ${ }^{5}$ 'two someone'; *baang phuu' 'some someone'. Note, however, that sòong ${ }^{3}$ phu-nii [two someone-this] is fine for 'these two (people)'.

When "SOMEONE expressions" have specific reference or are intended to introduce referential participants into a discourse, certain grammatical mechanisms may, and sometimes must, come into play in marking this. In general, new arguments appear postverbally, either as object arguments or in a special construction involving the verb $\mathrm{mii}^{2}$ THERE IS in a presentational sentence-initial role. First, note that $p h a j^{3}$ 'who' or $p h u-d a j^{3}$ 'someonewhich/any' is almost never used alone to refer to referential/specific arguments. As in the above examples, they are usually used in questions ('who?'), generic statements ('whoever/ anybody'), and negative statements ('nobody'). Referential/specific expressions like 'I saw someone in the house' typically involve the numeral nùng ${ }^{l}$ ONE, as a specifier for $p h u$ - SOMEONE, often in further combination with $p h u-d a j^{3}$ 'who/whoever'. In the following example, the expression phu-nùng ${ }^{l}$ ONE SOMEONE is used postnominally to express specificity of the new nominals ('a country person' and 'an uncle') and to introduce them into the discourse:

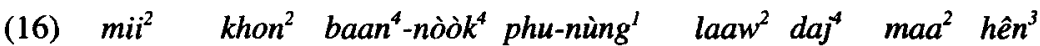
there.is people village-out someone-one 3SG ACHV come see qannaa $^{l}$ phò-luung ${ }^{2}$ phu-nùng ${ }^{l}$ saj $^{l}$ vèèn ${ }^{l}$ taa $^{3}$ qaan $^{1}$ nangsùù $^{3}$ HES.PCL uncle someone-one put spectacles read writing 'There was a country person, (and) he came and saw one uncle putting on spectacles to read.'

Compare the contrast between interrogative and specific readings, distinguished by the presence of the specifier/determiner nùng ${ }^{\prime}$ ONE:

(17) (a) $\operatorname{man}^{2} h e \hat{n}{ }^{3} p h u-d a j^{3} j u u^{I}$ talaat ${ }^{5} \dagger$

3SG see who be.at market

'Who did s/he see at the market?'

(NOT: 'S/he saw someone at the market.')

(b) $\operatorname{man}^{2}$ hên ${ }^{3}$ phu-daj-nùng ${ }^{1} \quad j u u^{l}$ talaat $^{5} \dagger$

3SG see someone-which-one be.at market

'S/he saw someone at the market.'

(NOT: 'Who did s/he see at the market?') 
The structure in (17b) can be made more explicit with phu- appearing twice, separately, once with the determiner $d a j^{3}$ 'which?/any' and once with the determiner nùng ${ }^{\prime}$ ONE (in that order), as in (18). And, as noted above, a further variation involves contraction of $p h u-d a j^{3}$ to $p h a j^{3}$, as in (19).

(18) $\operatorname{man}^{2}$ hên ${ }^{3}$ phu-daj ${ }^{3}$ phu-nùng ${ }^{1}$ juu $^{I}$ talaat $^{5} \dagger$ 3SG see someone-which someone-one be.at market 'S/he saw someone at the market.'

(19) $\operatorname{man}^{2} h e \hat{n}{ }^{3} p^{2} j^{3}$ phu-nùng ${ }^{1}$ juu ${ }^{I}$ talaat $^{5} \dagger$ 3SG see someone someone-one be.at market 'S/he saw someone at the market.'

The element $\tilde{n} a n g^{3}$ SOMETHING/WHAT patterns in the same way as $p h a j^{3}$ SOMEONE/WHO - its specific translation into English may involve whatever, what?, anything, or something (while this does not signify semantic variation). In (20) and (21), nang ${ }^{3}$ SOMETHING is unmarked, denoting non-referential/nonspecific discourse participants. In (22), it is a question word 'what?':

(20) bò ${ }^{0} \quad h e n^{3} \tilde{n} a n g^{3}$

NEG see something

'(They) didn't see anything.'

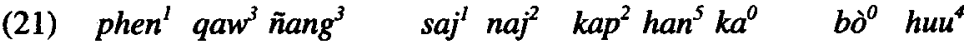
3HON take something put inside box that FOC.PCL NEG know 'What he put in that box, (I) don't know.'

(22) $d a j^{0}$ hêt $t^{l} \tilde{n} a n g^{3} d \grave{e} \grave{e}^{l}$ ACHV do what PCL 'What did you do?'

A common variant of $\tilde{n} a n g^{3}$ SOMETHING/WHAT is $q i-\tilde{n} a n g^{3}$. This involves a reduced form of the non-respect feminine prefix $q \ddot{i}^{I}-$, otherwise used as a nonrespect prefix for women's names or as a non-respect nominal head for demonstratives referring to women. It is unclear what the import of this variant is, but it seems to lend it some phonological weight where no specifiers or other marking are used:

(23) $q a w^{3} q i-\tilde{n} a n g^{3} \operatorname{maa}^{2} \tan ^{3} \quad v a j^{4}$ take something come block keep/fix

'(He) took something to block (the door).' 


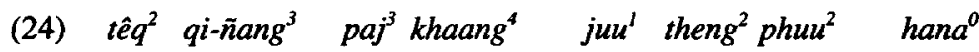
kick something go stuck.on.top be.at top mountain PCL 'What was it that (he) kicked up onto the mountain?'

$\tilde{N} a n g^{3}$ SOMETHING/WHAT is semantically identical to the bimorphemic expression $q a n-d a j^{3}$ (formally 'which thing'), and the two are related in the same way as $p h a j^{3}$ SOMEONE/WHO and $p h u$-daj 'which-someone', discussed above. Expressions using specifiers such as nii ${ }^{3}$ THIS, qùùn ${ }^{1}$ OTHER, diaw ${ }^{3}-k_{a n}{ }^{3}$ THE SAME, and nùng ${ }^{l}$ ONE do not involve $\tilde{n} a n g^{3}$, but use the classifier $q a n^{3}$ THING/WHAT (usually unstressed, represented here as qan-). Like phu- SOMEONE, qan- with this meaning cannot appear as a lone nominal, i.e. it must take a specifier of some kind. However, unlike $p h u$-SOMEONE, $q a n^{3}$ THING/WHAT may take prenominal modifiers, such as numeral expressions like sòòng ${ }^{3}$ TWO, baang ${ }^{3}$ SOME, and $c a k^{2}$ 'how many'.

The nominal heads $p h u$-SOMEONE and -qan SOMETHING combine with modifiers such as maj' 'new', kaw $^{l}$ 'old', and from the NSM set dii $^{3}$ GOOD, bò.dii ${ }^{3} \mathrm{~B} \mathrm{AD}, \tilde{n} a j^{l} \mathrm{BIG}$, and nòoj SMALL (in these roles they may merely be grammatical props for the relevant specifiers; see below):

(25) lèèw mùù $^{4}-n i i^{4} s i^{0} v a w^{4}$ qan-kaw ${ }^{1}$ hanlèq ${ }^{1}$ so day-this IRR say thing-old PCL. 'So today, (I)'ll tell the old one [i.e. story].'

(26) baang ${ }^{3}-t h u ̀ a^{1} \quad k a^{0} \quad m i^{2} \quad q a n-\tilde{n} u n g^{5}-\tilde{n} a a k^{4}$ some-occasion FOC.PCL there.is thing-tangled-difficult 'Sometimes there are difficulties.'

\subsection{3 khon ${ }^{2}$ PEOPLE}

The word khon ${ }^{2}$ refers to PEOPLE as a general social category or to PEOPLE as individuals. Here are some examples in which $k h o n^{2}$ PEOPLE refers nonspecifically:

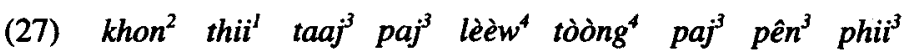
people REL die go PFV must go be spirit 'People who have died must become spirits.' 


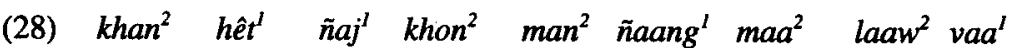
if make big people 3SG walk come. 3SG say man $^{2}$ saj $^{4}$ thaa ${ }^{1}-$ thii $^{2} \quad k h e ̀ e ̀ n g^{3}-k a d a a n g^{4}$ 3SG use attitude hard-coarse 'If (he) made (it [i.e. his house]) big, people would walk here, and they'd say that he used a coarse attitude.'

(29) khon ${ }^{2}$ suan $^{1} \mathrm{laaj}^{3} \quad \mathrm{ni}^{0} \quad \mathrm{ka}^{0} \quad \mathrm{jaak}^{5} \mathrm{hian}^{2} \mathrm{phaa}^{2} . \mathrm{saa}^{3} \mathrm{lat}^{1} . \mathrm{sia}^{2}$ people part much TPC.PCL FOC.PCL want study language Russia 'Most people wanted to learn Russian.'

The next example uses $k^{2}{ }^{2}$ PEOPLE with no obvious difference in meaning from $p h a j^{3} / p h u$ - SOMEONE. In this example, $k h o n^{2}$ PEOPLE may be replaced by phu-SOMEONE, and no obvious meaning difference would result.

(30) tòòn $^{3}$ suaj $^{3} \quad \mathrm{maa}^{2} \mathrm{ka}^{o} \quad \mathrm{mil}^{2} \quad \mathrm{khon}^{2}$ tèèng ${ }^{1} \mathrm{kin}^{3} \mathrm{haj}^{5}$ time lunchtime come FOC.PCL there.is people prepare eat give 'When lunchtime came around, there'd be someone who'd cook for (us).'

The notion of PEOPLE as a social plurality is important in NSM explications referring to cultural kinds ('things made by people'), aspects of psychological and social life ('what people know/think/want/say'), human emotions ('how people feel'), as well as language (for discussion, see Wierzbicka 1996:40-42). In typical NSM expressions involving PEOPLE, khon ${ }^{2}$ is treated as "given" (i.e. it does not require a verb to introduce it into discourse; see below on mii $^{2}$ ) due to its reference being exhaustive of the complete set (for this treatment of generics, see Givón 1984:407, Chafe 1994:102-103, Langacker 1991:101). Typical NSM expressions involving PEOPLE are phrased as follows:

(31) khon ${ }^{2}$ khùt $t^{1} v a a^{l}$ qan-nii ${ }^{4}$ bò.dii ${ }^{3} \dagger$ people think COMP something-this bad 'People think this is bad.'

(32) khon ${ }^{2} \quad j a a k^{5} h a j^{5} \quad m i i^{2} \quad$ qan-dii ${ }^{3} \quad k e e t^{5} . k h u ̀ n^{5} \dagger$ people want give there.is something-good happen 'People want something good (good things) to happen.'

$K h n^{2}$ PEOPLE combines with determiners and quantifiers such as $n i i^{4}$ THIS, diaw $^{3}-\mathrm{kan}^{3}$ THE SAME, baang ${ }^{3}$ SOME, sòòng ${ }^{3}$ TWO, laaj ${ }^{3}$ MANY, and qùùn ${ }^{l}$ OTHER, and also forms a productive nominal head for nationality expressions (cf. English -ish, -ese, -an, as in Scottish, Vietnamese, Tibetan): 


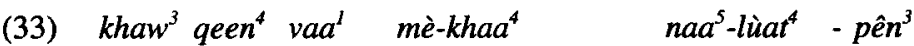

3PL call COMP F.PRFX-commerce face-blood be

mè-khaa ${ }^{4} \quad$ thii $^{I} \quad$ khuut.hiit ${ }^{4} \quad$ khon $^{2}$-qùùn ${ }^{I}$

F.PRFX-commerce which exploit/oppress people-other

'They call (them) 'blood-faced market women' - they're market women who exploit other people.'

(34) baang $^{3}$ khon $^{2} \mathrm{ka}^{0} \quad \mathrm{paj}^{3}$ falang $^{l}$ baang $^{3} \mathrm{khon}^{2} \mathrm{ka}^{0}$ some people FOC.PCL go France some people FOC.PCL paj $^{3}$ qamê $\hat{e}^{2} \cdot l i k a a^{3}$

go America

'Some people went to France, some people went to America.'

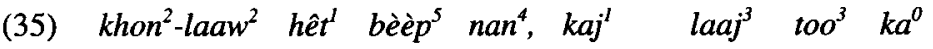
people-Lao do way that chicken many CLF FOC.PCL

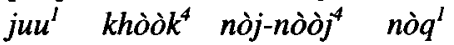
be.at pen small-RDP PCL

'Lao people do it like that, lots of chickens in a small pen.'

Khon ${ }^{2}$ PEOPLE may be used in contrast with non-humans such as spirits, gods, or ogres (who may nonetheless also be categorised as 'someones'). Here is an example from a scene in a world of ogres, in which no humans normally live. The protagonist - a human incarcerated in this place - hears the voice of another human (who has come to get her). The speaker at first uses khon ${ }^{2}$ PEOPLE to refer to a 'human' (as opposed to an ogre), then switching to manut ${ }^{l}$, a more formal term meaning 'human being':

(36) man $^{2}$ siang $^{3}$ khon $^{2}-$ siang $^{3}$ manut $t^{1}-p e ̂ n-\tilde{n} a n g^{3}$ mil $^{2} \quad$ siang $^{3}$ manut ${ }^{1}$ 3SG voice people-voice human-why there.is voice human 'That's the voice of a person - the voice of a human - why is there the voice of a human (here)?'

Both $k h o n^{2}$ PEOPLE and $p h u$ - SOMEONE are appropriate as classifiers for people. In (37), khon ${ }^{2}$ PEOPLE is a classifier for 'child'. Indeed, as shown in (38), $k h o n^{2}$ PEOPLE may be a classifier for khon ${ }^{2}$ itself.

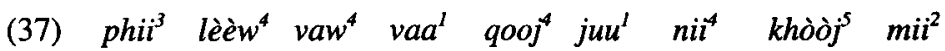
spirit PFV say COMP INTJ be.at here 1SG have

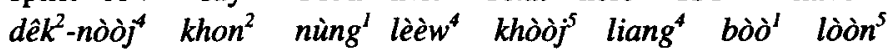
child-small people one PFV 1SG feed NEG complete 'The spirit said "Oh, here I have one child, and I can't feed it."” 
(38) $\mathrm{baat}^{5}-n i^{0} \mathrm{ka}^{0} \quad \mathrm{haj}^{5} \mathrm{khon}^{2} \mathrm{saam}^{3} \mathrm{khon}^{2} \mathrm{paj}^{3}$ qiik $^{5} \mathrm{paj}^{3}$ now FOC.PCL give people three people go more go tòo $\grave{o}^{I} \quad$ fùùn ${ }^{2} \quad$ tò̀ $^{I} \quad f a j^{2}$ hanlè $q^{5}$

connect firewood connect fire PCL

'Now, (he) got three people to go and set up a fire.'

And also commonly, $p h u$ - SOMEONE may serve as a classifier for $k_{h o n^{2}}$ PEOPLE. Here phu- may be considered a grammatical device for hosting nominal modification, rather than expressing the meaning 'someone'.

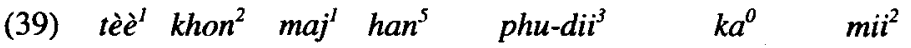
but people new TPC.PCL someone-good FOC.PCL there.is phu-bò.dii ${ }^{3} \quad k a^{0} \quad m i i^{2}$ someone-bad FOC.PCL there.is

'But (as for the) new people, there are good ones, and there are (bad) ones.'

(40) khon ${ }^{2}$ phu-nùng ${ }^{I} \quad$ dajj $^{0} \quad$ kin $^{3}$ khaw $^{5}$ pèèt ${ }^{5}$ lòòj people someone-one ACHV eat rice eight hundred kaam $^{3}$ tò̀ ${ }^{l}$ nùng ${ }^{l}$ mùù ${ }^{4}$ gram connect one day

'One person would get to eat 800 grams of rice per day.'

The grammatical behaviour of $p^{2} j^{3} / p h u$ - SOMEONE/WHO is more restricted than $k_{h o n^{2}}$ PEOPLE, in that the former cannot take preposed determiners or quantifiers, ruling out combinations like 'many someones', 'two someones', and 'some someones' (laaj ${ }^{3}$ MANY, sòong ${ }^{3}$ TWO, and baang ${ }^{3}$ SOME appear before their nominal head). The former ( $p h$ aj $^{3} / p h u$ - SOMEONE/WHO) is okay with a different determiner accompanying it:
(a) *hên ${ }^{3}$ sòòng ${ }^{3}$ phuu ${ }^{5}+$
see two someone
'((I) saw two "someones".)'
(b) hên ${ }^{3}$ sòòng ${ }^{3}$ phu-nii ${ }^{4} \dagger$
see two someone-this
'(I) saw these two "someones".'

In sum, khon ${ }^{2}$ PEOPLE is a free main nominal referring to 'people', most naturally as a group or social category. Like most nominals, it often appears also in a classifier function. The SOMEONE/WHO term $p h a j^{3} / p h u$ - is a more individuated notion, and while it has a broader reference than $k h o \dot{n}^{2}$ PEOPLE (i.e. 
it may refer to non-human 'someones' like ogres), it is more restricted in grammatical behaviour, and indeed has unique restrictions in the language unlike normal classifiers, it does not take preposed specifiers.

The use of a classifier construction in which the classifier takes the determiner/numeral nùng ${ }^{l}$ ONE helps to achieve singularity, since without it we don't know the number of the referent. In the next example, our first mention of the nominal $\mathrm{kaj}^{l}$ 'chicken' tells us nothing of number. While the first clause could mean 'He turned himself into a chicken', in fact it turns out to mean 'He turned himself into chickens':

(42) $\operatorname{man}^{2}$ nimit $^{I} \quad t_{o}^{3} \quad o^{3} n^{3} k a j^{l}-p \hat{e n}{ }^{3} k a j^{I}-p a a^{I} \quad n i^{D}$ 3SG transform body be chicken be chicken-forest TPC.PCL pên ${ }^{3} \operatorname{sè̀n}^{3}$ too $^{3}$ phun $^{4}$ be $100,000 \mathrm{CLF}$ PCL

'He transformed himself into chickens - into wild chickens - into a hundred thousand of them!'

For individuation of nominals, Lao commonly employs a construction of the form 'NP classifier-one', and the most common classifier to perform this role is qan- THING (as the "default" or general classifier). The following examples show qan- as a "prop" for the determiner, and not as a substantive meaning SOMETHING:

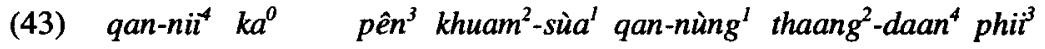
thing-this FOC.PCL be NSR-believe thing-one way-side spirits 'This is one belief concerning spirits.'

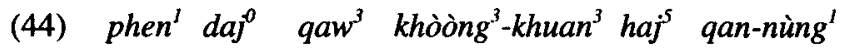
3HON ACHV take gift give thing-one 'They gave (him) a gift.'

Examples (45a) and (45b) show interrogative/non-specific and numeralspecific nominal phrases, respectively:

(45) (a) $\operatorname{maa}^{3} t_{0 o}^{3} d a j^{3} \dagger$

dog CLF any/which

i. 'which dog?'

ii. 'any dog, whichever dog'

(b) $\mathrm{maa}^{3}$ too $^{3}$ nùng ${ }^{\prime}+$

$\operatorname{dog}$ CLF one

'one dog' 
More simply, the two structures shown above may be combined as follows, allowing a 'particular' reading (i.e. 'a certain $\mathrm{X}$ '):

(46) maa $^{3}$ to-daj-nùng ${ }^{l} \dagger$

dog body-any-one

'a dog' (some dog, a certain dog)

In some circumstances, when clarity is required, NSM expressions including SOMETHING and SOMEONE may have to be expressed in Lao using the structure of the complex classifier phrase in (47):

(47) (a) qan-daj-nùng ${ }^{I} \dagger$

thing-any-one

'something' ('one anything')

(b) phu-daj-nùng ${ }^{l} \dagger$

someone-any-one

'someone' ('one anyone')

Unlike $k u u^{3}$ I, mùng ${ }^{2}$ YOU, $p h a j^{3}$ SOMEONE, and $k h o n^{2}$ PEOPLE, $\tilde{n} a n g^{3}$ SOMETHING/ WHAT cannot appear as a preverbal argument of $v a w^{4} S A Y$ or any mental predicate. It can, however, (and often must, cf. Section 5, below) appear postverbally. Compare:

(48) mii $^{2} \quad \tilde{n} a n g^{3} \quad * h u u^{4} / *^{*} v w^{4} \quad v a a^{l} \ldots \dagger$ there.is something know/say say(COMP) '*Something knew/said that...'

(49) mùng $^{2}$ huu $^{4} /$ vaw $^{4}$ nang ${ }^{3} \dagger$ 2SG know/say something

'You knew/said something.' (or: 'What did you know/say?')

While $\tilde{n} a n g^{3}$ (gan- SOMETHING can fill the valency slot opened by $\mathrm{kap}^{2}$ 'to' in

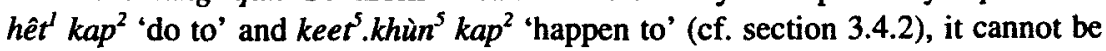
the object of $\mathrm{kap}^{2}$ 'to' in $\mathrm{vaw}^{4} \mathrm{kap}^{2}$ 'say to'. It may, however, be placed in a peripheral about-phrase (as in 'say something about something', cf. section 3.3.1).

Before summarising the situation with SOMETHING and SOMEONE, we will first look at some functions of the verb $m i^{2}$, which apart from its main verb functions with the meanings HAVE and THERE IS, is also involved in a common grammatical construction introducing new participants to discourse. In certain contexts this directly affects the expression of SOMEONE and SOMETHING. 


\subsubsection{Syntactic treatment of sentence-initial NPs: Functions of mit ${ }^{2}$ HAVE/THERE IS}

A significant feature of Lao grammar is the association of sentence-initial NPs with "given" or "activated" discourse status. When an NP in subject position is new, it cannot appear sentence-initially, and speakers use $m i^{2}$ HAVE/THERE IS to introduce it by putting it into a non-initial position. This strategy is common among Southeast Asian languages. Compare the following examples in which the absence of $m i i^{2}$ corresponds to definite marking in English, while its presence corresponds to indefinite marking in a presentative construction using 'there is':

$$
\begin{aligned}
& \text { (a) } \quad k a c \grave{e} \grave{e}^{3} \quad j u u^{l} \quad n a j^{2} \quad l i n^{4}-s a k^{2} \dagger \\
& \text { key be.at inside drawer } \\
& \text { 'The key's in the drawer.' } \\
& \text { (b) } \cdot m i i^{2} \quad k a c \grave{e} e^{3} j u u^{1} \quad n a j^{2} \quad l i n^{4}-s a k^{2} \dagger \\
& \text { there.is key be.at inside drawer } \\
& \text { 'There's a key in the drawer.' }
\end{aligned}
$$

In (50b), mii ${ }^{2}$ THERE IS is the main verb, taking any attendant aspect-modality marking. It is necessary to identify two distinct functions of $m i^{2}{ }^{2}$ in this grammatical role. The first is to predicate existence of an entity or class of entities. The second is to mark first mentions of referential/specific arguments. These are closely related functions, and obviously overlap to some degree. First, here are examples of what I will refer to as a "presentational" use, where a new argument (a person) is introduced into the discourse:

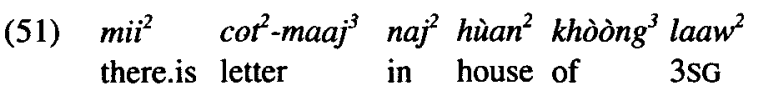

'There was a letter in his house.'

(52) $m \ddot{i i}^{2} \quad$ khon $^{2} \quad b a a n^{4}-n o ̀ ̀ k^{4} \quad$ phu-nùng ${ }^{l}$

there.is people village-outside someone-one

'There was (once) a country fellow.'

The next example shows something slightly different, in that the participant introduced by $m i i^{2}$ is also subject of a full clause within the same sentence:

(53) mii $^{2}$ khon ${ }^{2}$ maa $^{2}$ tat $^{2}$ qaw ${ }^{3}$ khèèn ${ }^{3}$ paj̀ $^{3}$ khèèn ${ }^{3}$ nùng ${ }^{I}$ there.is people come cut take arm go arm one 'Someone came and cut one of his arms off.' 
This could conceivably (but wrongly, I argue) be translated using 'there is' in combination with a relative clause - 'There was someone who VP-ed'. But example (53) does not predicate the existence of any 'someone'. (It merely presupposes it.) In this position and with this discourse status, $\mathrm{mii}^{2}$ khon ${ }^{2}$ simply means SOMEONE (as I argue in more detail below). Here we see a close relationship between genuine predication of existence THERE IS, and simple grammatical machinery associated with discourse status of arguments.

Given the role of sentence-initial $m i^{2}$ as a marker of non-given preverbal NPs, it is not surprising that the NSM expressions SOMETHING and SOMEONE require this marking when in preverbal position:

(54) mii $^{2} \quad \tilde{n} a n g^{3} \quad \tilde{n} a j^{1} j u u^{1}$ theng ${ }^{2}$ toq $^{2} \dagger$ there.is something big be.at on table

i. 'There is something big on the table.'

ii. 'What big thing is on the table?'

Consider, further, the following, in which the inherently definite $\mathrm{dam}^{3}$ 'Dam' (a personal name) cannot take sentence-initial $\mathrm{mii}^{2}$, but the non-given $\mathrm{phaj}^{3}$ SOMEONE/WHO must (if it is to be referential):

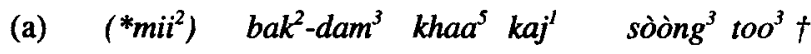

$$
\begin{aligned}
& \text { there.is M.PRFX-D. kill chicken two body } \\
& \text { 'Dam killed two chickens.' }
\end{aligned}
$$

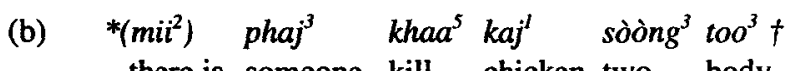
there.is someone kill chicken two body 'Someone killed two chickens.'

Without sentence-initial $m i^{2}$ ('literally', but not semantically, 'there is'), (55b) is not interpreted as a declarative sentence. It would be either a question 'Who killed two chickens?', or a relativised nominal construction 'someone who killed two chickens', or perhaps 'whoever kills two chickens'.

Let us now consider some examples of $m i^{2}$ THERE IS as genuinely predicating existence (or non-existence, under negation). (56) is an example of mii ${ }^{2}$ THERE IS negated, predicating non-existence. (57) shows $m i^{2}$ THERE IS predicating existence of something in a certain time:

(56) $b \grave{o}^{0} \quad \mathrm{mil}^{2} \quad b \grave{o ̀ n}{ }^{l}$ nang $^{l}$ NEG there.is place sit 'There was no place to sit.' 


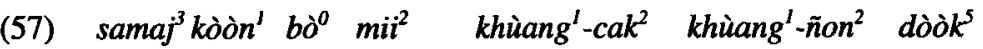
era before NEG there.is machine-engine machine-plane PCL 'In the old days, there weren't engines or aeroplanes.'

When $m i^{2}$ does mean THERE IS in this sense, it need not appear initially (when postposed, it usually takes the focus particle $k a^{0}$ ):

(58)
(a) $\quad \mathrm{mii}^{2} \quad \mathrm{cia}^{3} \mathrm{juu}^{l} \quad \mathrm{laaw}^{2}+$
there.is bat be.at Laos
'There are bats in Laos.'

(b) $\mathrm{juu}^{1} \mathrm{laaw}^{2} \mathrm{mil}^{2} \quad \mathrm{cia}^{3} \dagger$

be.at Laos there.is bat

'In Laos there are bats.'

(c) $\mathrm{cia}^{3} \mathrm{juu}^{\prime} \quad \mathrm{laaw}^{2}\left(\mathrm{ka} \mathrm{a}^{\mathrm{o}}\right) \quad \mathrm{mii}^{2}+$

bat be.at Laos FOC.PCL there.is

'Bats in Laos, there are.'

(59) (a) $\mathrm{mii}^{2} \quad \mathrm{cia}^{3} \mathrm{saam}^{3}$ sanit $^{l}+$

there.is bat three kind

'There are three kinds of bat.'

(b) $\mathrm{cia}^{3} \mathrm{mii}^{2} \quad \mathrm{saam}^{3}$ sanit $^{I} \dagger$

bat there.is three kind

'Bats, there are three kinds.'

(c) $\mathrm{cia}^{3} \mathrm{saam}^{3}$ sanit $^{1}\left(\mathrm{ka}^{0}\right) \quad \mathrm{mii}^{2}+$

bat three kind FOC.PCL there

'Bats of three kinds, there are.'

Now, a question regarding the status of sentence-initial $m i i^{2}$ arises for the grammar of NSM formulas. Consider expressions such as 'Something is happening in this place' and 'Something is moving in this place'.

(60) mii ${ }^{2}$ qan-daj-nùng ${ }^{3}$ keet ${ }^{5}-k h u ̀ n^{5}$ juu ${ }^{I}$ bòòn ${ }^{I}$ nit $\dagger$

there.is something happen be.at place this

'There is something happening in this place.'

'Something is happening in this place.' 


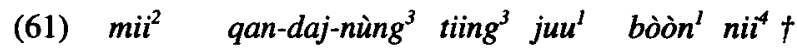
there.is something move be.at place this 'There is something moving in this place.'

'Something is moving in this place.'

The issue is the status of 'something' here as a discourse "participant". In these examples does $\mathrm{mil}^{2}$ introduce some participant in the sense discussed above, or does it predicate the existence of some entity, or is it merely part of the grammatical machinery required for expression of SOMETHING in subject position? I think the third possibility is closest to the truth. Such a usage of $m i^{2}$ is grammatically distinct from the existential uses in (58) and (59), in that the (b, c) permutations are not available; for example, $\mathrm{mii}^{2}$ in (61) cannot be postposed:

(62)

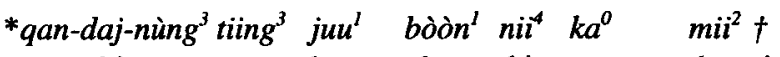
something move be.at place this FOC.PCL there.is

('There is something moving in this place.')

A similar problem occurs with SOMETHING/WHAT as an inherent subject of HAPPEN in the NSM system. If this inherent SOMETHING argument is being mentioned for the first time (i.e. where it would appear in English as something), then (a) sentence-initial $m i i^{2}$ is obligatory, and (b) no permutations putting $m i i^{2}$ into non-initial position are permissible (unlike existential $\mathrm{mii}^{2}$ constructions):

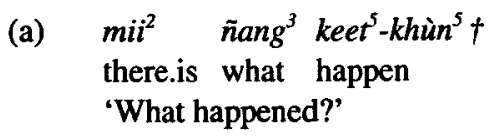

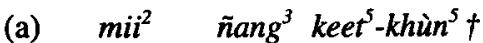
there.is what happen 'What happened?'

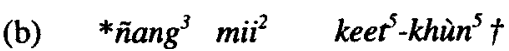
what there.is happen (What happened?)

There is yet another distinct meaning for sentence-initial $m i^{2}$, involving something like a relative clause structure, and the attributable meaning is SOME rather than THERE IS. The following example is polysemous, depending on whether we construe it to be a presentational statement about a specific group of people, with $m i^{2}$ meaning THERE IS (64i), or whether we take it as a general statement about a subset of all people, where $\mathrm{mii}^{2}$ means SOME (64ii): 
(64) $\mathrm{mil}^{2} \quad \mathrm{khon}^{2} \mathrm{kin}^{3} \mathrm{sin}^{4} \mathrm{maa}^{3}+$ there.is people eat flesh dog i. 'There are people eating dog flesh (somewhere).'

ii. 'Some people eat dog flesh.' ('There are people who eat dog flesh.')

If $m i i^{2}$ is omitted from this example, then $k h o n^{2}$ PEOPLE must be taken as a generic argument or as the (definite) nominal head of relative clause:

(65) khon ${ }^{2} \mathrm{kin}^{3} \sin ^{4} \mathrm{maa}^{3}+$

people eat flesh dog

i. 'People eat dog flesh.'

ii. 'people who eat dog flesh'

Similarly, the next example, without sentence-initial $m i i^{2}$, shows three possible "given" readings of the sentence-initial NP phu.saaj 'man': as a generic ("given" by speakers' shared knowledge of the "reference mass"); as "already mentioned" (clearly referential, as well as specific, resulting from prior discourse); and as the head of a relative clause:

(66) phu.saaj mak $^{l}$ lin $^{5}$ phaj ${ }^{4}+$

man like play cards

i. 'Men like to play cards.'

ii. 'The men like to play cards.'

iii. 'men who like to play cards'

As described above, addition of sentence-initial $m i i^{2}$ indicates either introduction to the discourse of a new participant, as in (67i) (cf. (50b) above), or means SOME, as in (67ii):

(67) $m i^{2} \quad$ phu.saaj mak $^{I} \operatorname{lin}^{5}$ phaj +

there.is man like play cards

i. 'There is/was a man who likes/liked to play cards.'

ii. 'Some men like to play cards.'

('There are men who like to play cards.')

There is a formal difference between these two readings, namely that only the second reading allows insertion of a sentence-final particle after mii $^{2}$, putting the remaining into an "afterthought" position, as shown below. The restriction against this type of permutation involving the construction with the first reading is presumably due to the more "constructional" status of $m i i^{2}$ in its role as a "grammatical prop" introducing new discourse participants. 
(68) mii $^{2}$ dêj ${ }^{2}$ phu.saaj mak $^{l}$ lin $^{5} \quad$ phaj $\dagger$ there.is PCL man like play cards 'There are, you know - men who like to play cards.'

(NOT: There is/was, you know - a man who likes/liked to play cards.)

Another major role for $m i i^{2}$ is as a main verb HAVE, used basically as a twoplace predicate, in clause-medial position:

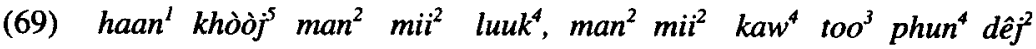
geese 1SG 3SG have child 3SG have nine CLF PCL PCL 'My goose, it has goslings, it has nine, you know.'

(70) $m i i^{2} \quad \tilde{n} a n g^{3} \quad k a^{0} \quad l \grave{e} k^{4}-$ pian $^{\prime} k a n^{3}-p h u^{0}-n a n^{4} \quad m i^{2}$ have something FOC.PCL exchange RCP - someone-that have phak ${ }^{2} \quad$ bò ${ }^{3} \quad$ phu $^{0}-n i i^{4} \quad m i i^{2} \quad$ ngua ${ }^{2}-k h u a j^{2} \ldots$ vegetable PCL someone-this have cattle-buffalo 'Whatever (they) had, (they'd) exchange with each other - that person might have vegetables, this person has cattle and buffaloes...'

$M i i^{2}$ HAVE can sometimes take a verb object:

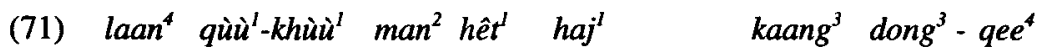
bald EXPR 3SG make swidden.field middle forest INTJ

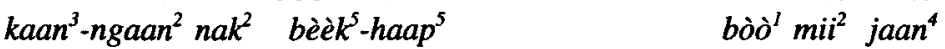
labour heavy carry.on.back-carry.on.shoulder NEG have afraid 'Those who are qùù $\grave{u}^{l}-k h \grave{u} \grave{u}^{l}$ bald make a swidden clearing in the forest - yeah, heavy labour, they have no fear of.'

The following examples provide syntactic evidence that a distinction between THERE IS and HAVE predicated by $\mathrm{mii}^{2}$ is not merely one of variance in English translation. They show that a locative "preposition" (i.e. juu 'be at') is optional where $m i i^{2}$ means THERE is (and the subject is a location), but not applicable where $m i i^{2}$ means HAVE (and the subject is a true possessor):

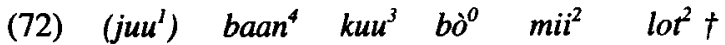
(be.at) village 1SG NEG there.is vehicle '(In/at) my village there are no cars.' (without sentence-initial $\mathrm{juu}$ ': 'My village 'has' no cars.') 
(73) $\left(* j u u^{l}\right) \mathrm{dam}^{3} b \grave{\delta}^{\circ} \quad \mathrm{mii}^{2} \quad l o t^{2} \dagger$ (be.at) D. NEG have vehicle 'Dam doesn't have a car.' (with sentence-initial $j u u^{\prime}: *^{\prime}$ (In/at) Dam there is no car'.)

In example (72), baan ${ }^{4}$ 'village' is optionally preceded by $j u u^{I}$ 'be at', which indicates that it is a location, and of a different grammatical status to dam $^{3}$ 'Dam' with respect to the verb in (73). Further, the status of 'my village' as a locative setting rather than a possessor in (72) is supported by the fact that the noun phrase in preverbal position need not be coreferential with the left-detached noun phrase (note there is no equivalent option for (73)):

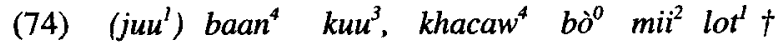
be.at village 1SG 3PL NEG have vehicle '(In) my village, they don't have cars.'

From the discussion so far, it is clear that the word $m i i^{2}$ has a range of distinct meanings and functions, and it happens that several of these are important in NSM expressions. The different functions of $m i^{2}$ are separately identifiable, by distinctions in syntactic environment and behaviour. The relevant distinctions are (a) SOME, (b) grammatical marking of arguments new to the discourse, (c) THERE IS/EXIST, and (d) HAVE. These, along with the grammatical frames that distinguish them, are summarised in Table 3.1. Notice that while frames 1 and 2 are identical in overt form, they are distinguished by the possibility (in 1 but not in 2) of $m i^{2}$ appearing other than in the sentence-initial position.

Table 3.1: Meanings of Lao $\mathrm{mii}^{2}$ in different grammatical frames

\begin{tabular}{|c|c|c|c|c|}
\hline & Frame & Meaning & $\begin{array}{c}\text { Is } m i^{2} \text { okay } \\
\text { non-initially? }\end{array}$ & Example \\
\hline 1 & - NP VP & 'Some NPs VP.' & Yes & $\begin{array}{l}\text { mii' khon }^{2} \text { kin }^{3} \text { bia }^{3} \text { [_ _ people drink beer] } \\
\text { 'Some people drink beer.' }\end{array}$ \\
\hline 2 & - NP VP & 'NP $\mathrm{NEW}$ VP.' & No & $\begin{array}{l}\text { mili }^{2} \text { khon }^{2} \text { kin }^{3} \text { bia }^{3} \text { [_ people drink beer] } \\
\text { 'Somebody is drinking beer (somewhere),' }\end{array}$ \\
\hline 3 & - NP & 'There is NP.' & Yes & 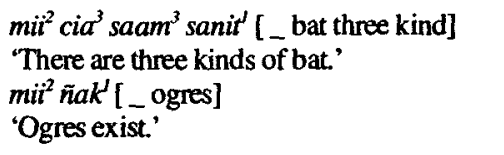 \\
\hline 4 & $N_{\text {_ }} \mathrm{NP}$ & 'NP has NP.' & Yes & $\begin{array}{l}\text { sòòn }{ }^{3} \text { mit' lot' ñaj' }[\text { S. _ car big] } \\
\text { 'Sone has a big car.' }\end{array}$ \\
\hline
\end{tabular}




\subsubsection{Review}

Having reviewed various roles of $m i^{2}$, we may summarise the formal variation in the NSM terms SOMETHING/WHAT and SOMEONE/WHO as expressed in Lao. Expressing these ideas in Lao NSM involves a number of different lexical items and grammatical constructions, depending on grammatical and discourse context. I will discuss the SOMETHING words $\tilde{n} a g^{3}$ and qan- only. The generalisations correspond directly (mutatis mutandis) to $p h a j^{3}$ and phu-, respectively.

First, the form nang ${ }^{3}$ sometHING is restricted to contexts in which the discourse status of the argument is non-specific or indefinite. It is used in non main-subject position of simple clauses as a content question word 'what?':

(75) mùng $^{2}$ sùŭ $^{4}$ nang ${ }^{3}$ juu ${ }^{l}$ talaat $^{5}+$

2SG buy what be.at market

'What did you buy at the market?'

The interrogative reading for $\tilde{n} a n g^{3}$ in (75) is not entailed by $\tilde{n} a n g^{3}$ itself, but arises from its use in that particular construction as an independent sentence. In the same manner as English what, the question form in a subordinated frame results in a (non-interrogative) relative clause head reading:

\section{(76) $k u u^{3} \quad b \grave{o}^{0} \quad h u u^{4} \quad v a a^{1} \quad m u ̀ n g^{2} \quad s u ̀ u^{4} \quad \tilde{n} a n g^{3} \quad j u u^{1}$ talaat $^{5} \dagger$ 1SG NEG know COMP 2SG buy what be.at market 'I don't know what you bought at the market.'}

Further, if a sentence-final polar-question particle is added to the simple interrogative frame, $\tilde{n} a n g^{3}$ no longer expresses a content question, and instead means 'anything' (retaining its non-referential, non-specific status):

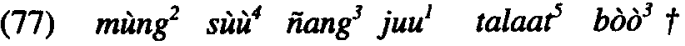 2SG buy what be.at market PCL 'Did you buy anything at the market?'

When the referent is specific or referential, some kind of determiner/specifier must be used to indicate this, and $\tilde{n} a g^{3}$ is unable to host such grammatical marking. In these cases, qan- THING is used. The markings of relevance to NSM formulas are specifiers like qùùn ${ }^{l}$ OTHER, $n i^{4}$ THIS, and $n u ̀ n g^{l}$ ONE, and attributives like $d i^{3}$ GOOD and bò.dit ${ }^{3} \mathrm{BAD}$. The facts are summarised in Table 3.2.

Table 3.3 describes the situation in more detail (for nang $^{3} / q a n$ - SOMETHING only), with statements of context-specific readings, i.e. English translations: 
Table 3.2: Grammatical variants of exponents of SOMEONE, SOMETHING, and SOMEWHERE in Lao

\begin{tabular}{|c|c|c|c|}
\hline Role & $\begin{array}{l}\text { Indefinite/ } \\
\text { interrogative }\end{array}$ & $\begin{array}{l}\text { Free simple } \\
\text { nominal }\end{array}$ & $\begin{array}{l}\text { Head for combination } \\
\text { with determiners }\end{array}$ \\
\hline SOMEONE & $p h a j^{3} / p h u-d a j^{3}$ & & phu- \\
\hline SOMETHING & $\tilde{n} a n g^{3} / q a n-d a j^{3}$ & $q a n^{3}$ & qan- \\
\hline SOMEWHERE & $s a j^{3} \not b o ̀ o n^{\prime}-d a j^{3}$ & bòòn' & bòn- \\
\hline
\end{tabular}

Table 3.3: Surface expression of the prime SOMETHING/WHAT in different grammatical and discourse contexts in Lao

\begin{tabular}{|c|c|c|c|c|}
\hline Syntactic context & $\begin{array}{l}\text { Discourse } \\
\text { status }\end{array}$ & Form & Translation & Examples \\
\hline $\begin{array}{l}\text { As non main-S core ARG, } \\
\text { no SPEC, no IF marked }\end{array}$ & $\begin{array}{c}\text { non-specific, } \\
\text { non-referential }\end{array}$ & $\bar{n} a n g^{3}$ & 'what?' & $\begin{array}{l}\text { hên }{ }^{3} \tilde{n} a n g^{3} \text { [see_] } \\
\text { 'What do you see?' }\end{array}$ \\
\hline $\begin{array}{l}\text { As non main-S core ARG } \\
\text { of loose suboid as, no } \\
\text { SPEC, no IF marked }\end{array}$ & $\begin{array}{l}\text { non-specific, } \\
\text { non-referential }\end{array}$ & $\tilde{n} a n g^{3}$ & 'what' & $\begin{array}{l}\text { kaul }^{3} \text { huut vad ming }{ }^{2} \text { hên }{ }^{3} \text { ñang } \\
\text { [1sG know COMP 2sG see_] } \\
\text { 'I know what you saw.' }\end{array}$ \\
\hline $\begin{array}{l}\text { As non main-S core ARG, } \\
\text { no SPEC, IF NEG or polar-Q } \\
\text { or under irrealis "will'/if'/ } \\
\text { "when'/can' }\end{array}$ & $\begin{array}{l}\text { non-specific, } \\
\text { non-referential }\end{array}$ & $\tilde{n} a n g^{3}$ & $\begin{array}{l}\text { 'something/ } \\
\text { anything' }\end{array}$ & $\begin{array}{l}\text { mùng }{ }^{2} h \hat{n^{3}}{ }^{3} \text { nang }{ }^{3} b \grave{o} \grave{o}^{3} \\
\text { [2sG see_PC_(polar-q)] } \\
\text { 'Do you see anything?' }\end{array}$ \\
\hline $\begin{array}{l}\text { As main } S \text {, no SPEC, no IF } \\
\text { marked }\end{array}$ & new, referential & $m i^{2} \tilde{n} a n g^{3}$ & 'something' & $\begin{array}{l}\text { mit }^{2} \text { nang }{ }^{3} \text { tïng }{ }^{3} j u u^{\prime} \text { han' } \\
\text { [there.is_move be.at there] } \\
\text { 'Something is moving there.' }\end{array}$ \\
\hline $\begin{array}{l}\text { As main } S \text {, no SPEC, no IF } \\
\text { marked }\end{array}$ & non-referential & $m \ddot{i} i^{2} \tilde{n} a n g^{3}$ & 'what?' & $\begin{array}{l}m_{i i^{2}} \tilde{n} a n g^{3} t i ̈ n g^{3} j u u^{l} h a n^{5} \\
\text { [there.is_move be.at there] } \\
\text { 'What is moving there?' }\end{array}$ \\
\hline $\begin{array}{l}\text { As any } S \text {, no SPEC, IF NEG } \\
\text { or polar-Q }\end{array}$ & $\begin{array}{l}\text { non-specific, } \\
\text { non-referential }\end{array}$ & mit ñang ${ }^{3}$ & $\begin{array}{l}\text { 'something/ } \\
\text { anything' }\end{array}$ & $\begin{array}{l}\text { mit' }^{2} \text { ñang }{ }^{3} \text { tüng }{ }^{3} b \partial \partial \partial^{3} \\
\text { [there.is_move Pa]] } \\
\text { 'Did something move? }\end{array}$ \\
\hline As any ARG, with SFEC & $\begin{array}{l}\text { specific, } \\
\text { referential }\end{array}$ & qan- & $\begin{array}{l}\text { 'thing' } \\
\text { something' }\end{array}$ & $\begin{array}{l}\text { qan-nï' [_-this] } \\
\text { 'this thing' } \\
\text { qan-quìion' [_other] } \\
\text { 'something else' } \\
\text { qan-ning' [_-one] } \\
\text { 'one thing' } \\
\text { sódong' qan' [two_] } \\
\text { 'wo things' }\end{array}$ \\
\hline
\end{tabular}

Abbreviations: $A R G$ 'argument'; $C L S$ 'clause'; IF 'illocutionary force'; NEG 'negative'; $Q$ 'question'; $S$ 'subject'; SPEC 'specifier' 


\subsection{Mental predicates}

\subsection{1 khùt ${ }^{\prime} / k h t^{l}$ THINK}

THINK is expressed in Lao by either $k h u ̀ t^{l}$ or $k h i t^{\prime}$, which are essentially interchangeable with this meaning. $K \mathrm{Kit}^{l}$ has a further meaning of 'calculate, reckon', often in a "synonym compound" with laj $^{l}$ 'calculate', as follows:

(78) $k h \grave{o} \grave{o j} j^{5} k h i t^{l}-l a j^{l} \quad p h i t^{2}$ 1SG think-calculate incorrect 'I calculated incorrectly (and didn't have enough money to finish off the house I am building).'

$K h \grave{u} t^{I}$ does not appear in this kind of context. Hereafter, for convenience I will discuss $k h u t^{l}$ only, but my remarks similarly apply to $k$ hit (with the meaning THINK, not 'calculate'), as many of the text examples show.

$K h \grave{u} t^{\text {l }}$ THINK optionally takes a direct postverbal complement, a "locutionary topic" or about-argument, and/or a sentential complement clause. We first address nominal complements of khüt ${ }^{l}$ THINK, which are in fact rare in natural discourse. Of over 100 examples of khùt ${ }^{I}$ THINK in my source texts, the only ones taking direct nominal complements are the following two:

(79) khùt $t^{I} q i-\tilde{n} a n g^{3}$, law $^{I} m \grave{e} \grave{e}^{l}$ think what tell PCL

'Whatever (story) you think of, go ahead and tell it!'

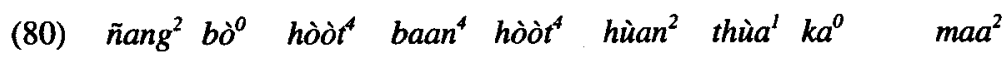
still NEG reach home reach house yet FOC.PCL come khit $^{l}$ lùangl kaw $^{l}$ han $^{5}$ think story old that '(He) still hadn't yet reached his home, and he came to think (about) the same story as before.'

Despite the rarity of these constructions in real discourse, expressions with THINK in NSM formulas commonly take direct nominal complements. The following example is fine in Lao:

(81) (tò̀n ${ }^{3}$ nan $\left.^{4}\right)$ dam ${ }^{3}$ khùt ${ }^{I}$ qan-bò.dii ${ }^{3}+$ (time that) D. think thing-bad

'(At that time) Dam thought something bad.' 
Locutionary topics are marked by $k^{2}{ }^{l} w^{l}-k_{a p}{ }^{2}$ 'about' (where kiaw ${ }^{l}$ means 'concerning' or 'having to do with', and $\mathrm{kap}^{2}$ is a preposition 'to/with'), as in (82). Direct complements may be combined, as in (83).

(82) dam $^{3}$ khùt kiaw $^{l}-\mathrm{kap}^{2}$ mùng ${ }^{2} \dagger$

D. think about 2SG

'Dam thought about you.'

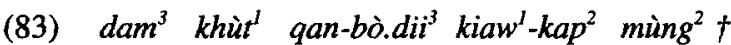

D. think thing-bad about 2SG

'Dam thought something bad about you.'

More often, nominal complements of khùt $t^{\prime}$ are marked as oblique, by a "coverb" such as hò̀t 't 'reach/to', theng ${ }^{3}$ 'reach/to', hên ${ }^{3}$ 'see', haa 'seek', phò $\partial^{4}$ 'meet', as in the following examples:

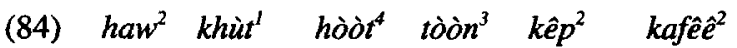

1SG think reach time gather coffee

'I miss the time when (I) was harvesting coffee.'

(85) tè $e^{l}$ phen ${ }^{l} k a^{0} \quad s i^{0} \quad k h i t^{l}$ theng $^{3}$ qan ${ }^{0} \quad$ khuam $^{2}$-phit ${ }^{2}$ but 3HON FOC.PCL IRR think reach HES.PCL NSR-wrong khòòng ${ }^{3}$ phen' juul of 3HON PCL

'But she would have thought about - um - her wrong-doings.'

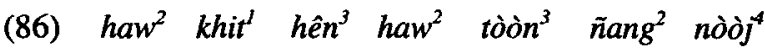

1SG think see 1SG time still small

'I think of myself when I was still small.'

(87) $m \grave{e} e^{l} \quad n g u a^{2} t_{0 o}^{3} \operatorname{nan}^{4} \mathrm{ka}^{0} \quad$ tok $^{2} . \mathrm{caj}^{3} \mathrm{ka}^{0}$ mother cow CLF that FOC.PCL shocked FOC.PCL

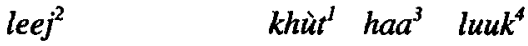

without.other.ado think seek child

'That mother cow was shocked, and then thought of her child.'

(88) $h a w^{2} \quad l a^{0} \quad k h i t^{l} \quad p h o ̀ \partial^{4}$ qan-nan ${ }^{4}$

ISG PCL think meet thing-that

'(So) that came to my mind.' 


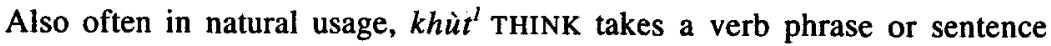
complement, marked by the complementiser vaa' (elsewhere 'say'):

(89) laaw $^{2}$ leej ${ }^{2}$ khit $^{\prime}$ vaa ${ }^{1}$ vèèn-taa ${ }^{3}$ phaa ${ }^{2}$ haj qaan $^{l}$

3SG PCL think COMP spectacles lead give read

nangsùù ${ }^{3} \quad \mathrm{daj}^{4}$

writing can

'So he thought that spectacles led one to be able to read.'

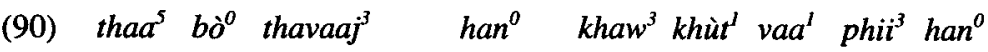
if NEG make.offering TPC.PCL 3PL think COMP spirit TPC.PCL ca $a^{0}$ maa $^{2}$ kuan $^{3}$ khò̀ ${ }^{4}-k h u a^{2}$ hùan ${ }^{2}-$ saan $^{2} \quad k h a w^{3}$ IRR come disturb family home 3PL 'If (they) don't make offerings, they think that the spirits will come and disturb their family and their home.'

The complement introduced by $v a a^{I}$ may also be a nominal if this is a "mention" of an actual thought (cf. English 'The butler', he thought). The following example comes from a description of an old man's attempt to give his grandchild a clue as to how to read the third letter of the Lao alphabet, by pointing at his neck (the name of the said letter - khò $\grave{\partial}^{2}$ - is homophonous with the word for 'neck'):

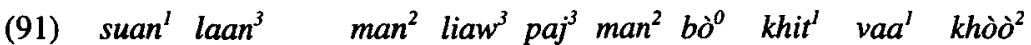
part grandchild 3SG turn go 3SG NEG think COMP neck 'As for the child, it turned around, (but) it didn't think "neck".'

(The punch line of the story is that the boy's attention is on the tendons in his grandfather's neck, and he announces that the name of the letter must be qên ${ }^{3}$ 'tendons' - homophonous with the name of the English letter ' $n$ '.)

An associated issue here is that of direct quotative frames for specific thoughts introduced by khùt' THINK. In directly quoting natural speech (with main verbs like SAY; see section 3.3), speakers introduce, and also often close off, the section of quoted speech with a discourse marker such as an interjection (which is understood to be part of the quoted conversation), with the function of indexing the interactional context of the utterance being described. This strategy is also used for direct quotation of the wording of someone's thoughts: 


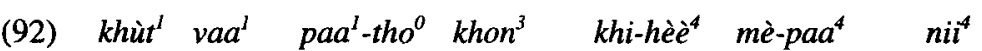
think COMP INTJ body.hair underarm F.PRFX-aunty this $m a a^{2} \tilde{n} a a w^{2}$ thè $\grave{e}^{4}$ come long indeed '(He) thought, "Wow, this old lady's underarm hair is so long!"'

(93) $h a w^{2} \mathrm{ka}^{0}$ tòòng ${ }^{4} \mathrm{khit}^{l} \mathrm{vaa}^{1} \mathrm{bah}^{2} \mathrm{khaw}^{3} \mathrm{si}^{0} \mathrm{qaw}^{3} \mathrm{paj}^{3}$ 1SG FOC.PCL must think COMP INTJ 3PL IRR take go $s a j^{3} \quad$ diaw $^{3}-n i i^{4}$ where now 'I had to think "Bah, where are they going to take me now?"

A further "quotative" frame in the NSM system for THINK is " $\mathrm{X}$ thought something like this:__', which is readily expressed in Lao:

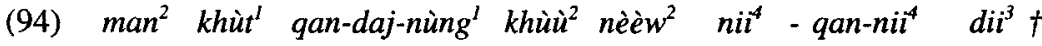
3SG think something like manner this thing-this good 'S/he thought something like this: this (thing) is good.'

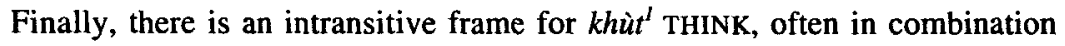
with some adverbial material:

(95) tòòng ${ }^{4}$ haj ${ }^{5}$ laaw ${ }^{2} k h i t^{\prime}$ khak-khak $k^{l}$ hian $^{3}$ vaj sa-kòòn ${ }^{4}$ must give $3 \mathrm{sG}$ think clear-RDP write keep PCL

'(We) must let him think clearly, and then write (it) down first.'

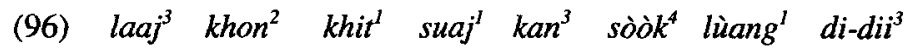
many people think help RCP seek story good-RDP muan-muan ${ }^{1}$ maa $^{2}$ haj ${ }^{5}$ naa $^{3}$ fun-RDP come give PCL

'Many (of us should) help each other to think, and find good fun stories to give (him).'

\subsection{2 $h u u^{4} / h u u^{4} \cdot c a k^{2} \mathrm{KNOW}$}

$H u u^{4}$ KNOW takes direct nominal complements more readily than $k h u ̀ t^{\prime}$ THINK, and does not appear with the oblique-marked objects (marked by coverbs such as

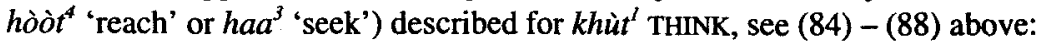




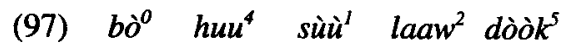

NEG know name 3SG PCL

'(I) don't know his name.'

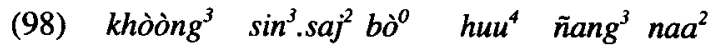

of $S$. NEG know what PCL

'As for Sinsay, (he) didn't know anything.'

Sentential complements of $h u u^{4}$ KNOW are also common, and are also introduced by the complementiser $v a a^{l}$ :

(99) nòòng ${ }^{4}-$ saaw $^{3} h u u^{4} \quad v a a^{l} \quad k h o ̀ o j j ~ m a a^{2}$ y.sib-girl know COMP 1SG come

'(My) sister knew that I had come (here).'

The idea of 'knowing someone' is usually expressed in Lao by the term $h u u^{4} . c a k^{2}$, a compound of $h u u^{4}$ KNOW and $c a k^{2}$, which also means 'know' or 'recognise', and is considered either archaic or typical of Southern dialects. The speaker of example (100), in which $c a k^{2}$ alone means $\mathrm{KNOW}$, is from the Southernmost district of Laos. The following two examples show $h u u^{4} . c a k^{2}$ as a verb to 'know someone'.

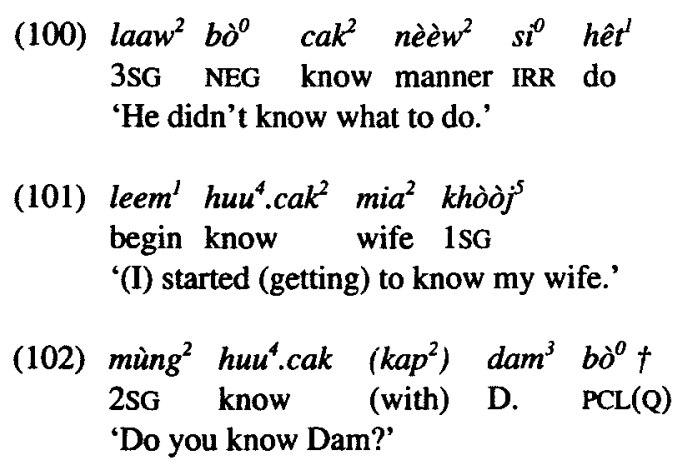

Semantically, both $h u u^{4}$ and $h u u^{4} . c a k^{2}$ may serve as 'recognise' and 'know' alike. However, $h u u^{4} . c a k^{2}$ more usually refers to 'knowing someone', and this is reflected in a grammatical limitation on $h u u^{4}$, namely that $h u u^{4}$ alone cannot take an oblique nominal marked by $\mathrm{kap}^{2}$ (in contrast to $h u u^{4} . c a k^{2}$ in (102)). $\mathrm{Huu}^{4} . c a k^{2}$ may easily refer to 'knowing something', or 'knowing that' something is the case. In the following example, a man has asked his wife why his mother-in-law 
has been constantly absent from the house of late. She replies:

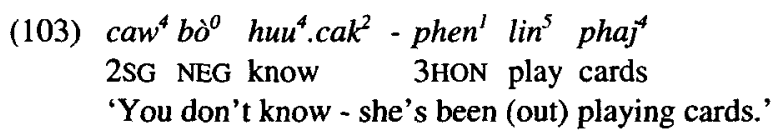

Conversely, while $h u u^{4}$ alone as KNOW is probably more basically thought of as referring to 'knowing things', and 'knowing that' something is the case, it may nevertheless also be used in the sense of 'knowing someone':

(104) mùng $^{2}$ huu ${ }^{4}$ phò̀ $\grave{m a n}^{2} b \grave{o}^{0}+$

2SG know father 3SG PCL(Q)

'Do you know her father?'

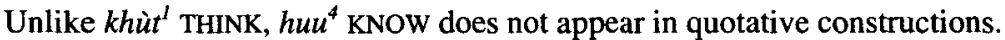

$\mathrm{Hu}^{4} \mathrm{KNOW}$ also may take an about-phrase marked by $\mathrm{kiaw}^{2}-\mathrm{kap}^{2}$ (as for khùt ${ }^{l}$ THINK):

(105) dam $^{3} h u u^{4}$ qan-bò.dii ${ }^{3}$ kiaw $^{1}-k a p^{2}$ mùng ${ }^{2}+$

D. know thing-bad about 2SG

'Dam knows something bad about you.'

I regard the expressions 'to know about something/someone' and 'to think about something/someone' as not structurally equivalent. 'Dam thought about you' is a complete predication, while 'Dam knows about you' is elliptical, and presumably must mean 'Dam knows something about you'.

Finally, it is worth noting that $h u u^{4}$ KNOW does not take a locative adjunct, perhaps because it would be irrelevant in delimiting states of knowing. Could one know something at a certain location, but not know it at another location? It is time, not space, which is the factor in moving from a state of not-knowing into a state of knowing. Accordingly, while THINK, WANT, and FEEL are compatible with locative phrases, expressions like 'At that place I felt good' or 'I wanted to do something in that place' are strongly suggestive also of temporal "placement". It is conceivable that 'in/at that place' in these examples is a reduced form of 'when in/at that place'.

\subsection{3 jaak ${ }^{5}$ WANT}

$J_{a a k}{ }^{5}$ WANT is a complement-taking predicate, with a strict same-subject coreference constraint between main and subordinate verb: 
(106) $b^{\circ}{ }^{o} j a a k^{5}$ caaj $^{1}$ ngen $^{2}$

NEG want pay money

'(He) didn't want to pay the money (for his room).'

(107) $\mathrm{paa}^{3} \quad \mathrm{ka}^{0} \quad \mathrm{jaak}^{5} d a j^{4}-\mathrm{siin}^{4} \quad \mathrm{ka}^{0} \quad j a a k^{5} \mathrm{daj}^{4}$ fish FOC.PCL want acquire meat FOC.PCL want acquire 'The fish, (she) wanted to get - the meat, (she) wanted to get.'

When main and lower subjects are non-coreferential (as in 'He didn't want him to open it'), $h a j^{5}$ 'give' is used as the direct complement of jaak' WANT, resulting in obligatory non-coreference between lower subject (optionally expressed), and main subject (i.e. the "want-er"):

(108) mè $\grave{e}^{I} \quad k a^{o} \quad b \grave{o}^{o} \quad j a a k^{5} \quad h a j^{5} \quad l u u k^{4} \quad t a a j^{3}-l u u k^{4} \quad k a^{o} \quad b \grave{o}^{o}$ mother FOC.PCL NEG want give child die child IRR NEG jaak $h a j^{5}$. mè̀ ${ }^{l}$ taaj $^{3}$ want give mother die

'The mother didn't want her child to die - the child didn't want its mother to die.'

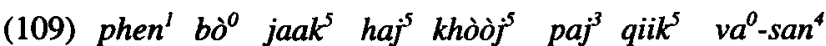
3HON NEG want give 1SG go more say-thus 'They didn't want me to go again, they said.'

Elsewhere, haj' 'give' can appear as a complement-taking permissive/ causative verb, 'let someone $\mathrm{V}$ '/'get someone to $\mathrm{V}$ ', with (in direct contrast to jaak $k^{5}$ WANT) a strict different-subject constraint with subordinate verbs. (Note also that ellipsis of lower clause subject is optional with haj 'give', but obligatory with jaak ${ }^{5}$ WANT.) Thus, there may be alternative readings of these constructions involving jaak ${ }^{5}$ WANT and $h a j{ }^{5}$ 'give' in combination, depending on whether $h a j^{5}$ is regarded as a true permissive/causative verb or a mere structural mechanism for switching reference of main and lower subjects:

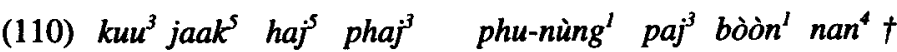
1SG want give someone CLF-one go place that

i. 'I want to get someone to go to that place.'

ii. 'I want someone to go to that place.'

The (i) reading assumes $h a j$ ' 'give' to be a genuine permissive/causative. The (ii) reading, where no causal relation between main subject and subordinate clause is 
intended (i.e. the speaker does not want to do anything), suggests that $h a j^{5}$ 'give' has a purely syntactic function. This is supported by (111), where it could not reasonably be argued that a permissive/causative meaning for $h a j^{5}$ is intended:

(111) $k u u^{3} j a a k^{5} h a j^{5}$ fon $^{3}$ tok $^{2} \dagger$

1SG want give rain fall

'I want it to rain.'

Finally, the following examples show a range of NSM predicates - $h u u^{4}$

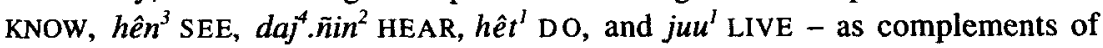
$j a a k^{5}$ WANT (with example (114) using $h a j^{5}$ 'give' in switch-reference function):

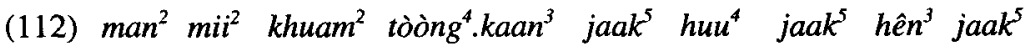
3PL have NSR require want know want see want

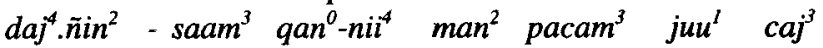
hear three thing-this 3SG stationed be.at heart/mind $k_{\text {khòng }}{ }^{3} \quad$ khon $^{2} \quad$ haw $^{2}$ of people $1 \mathrm{PL}$ 'They have the need to want to know, to want to see, to want to hear these three things are established in the hearts of we people.'

(113) $\operatorname{man}^{2} j^{2 a a k}$ maa $^{2}$ het $t^{\prime} q i i k^{5} h^{0}$ 3PL want come do more PCL

'They wanted to come and do (it [i.e. go fishing in that river]) some more,'

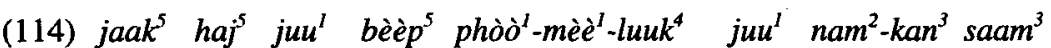
want give be.at way father-mother-child live together three khon ${ }^{2} \quad$ leej $^{2} \quad \mathrm{na}^{3}$ people without.other.ado PCL.

'(I) want (us) to live as father, mother and child, living together just the three of us.'

\subsection{4 huu $u^{4}$ sùk $k^{2}$ FEEL}

The Lao exponent of FEEL $h u u^{4} . s u k^{2}$ includes the morpheme $h u u^{4}$ (elsewhere 'know'), but the expression is not semantically analysable into 'know' plus something else. The element sùk ${ }^{2}$ is said to mean 'feel', but it only appears bound in this expression, never on its own. (See Diller (1994:153) on the closely related form in Thai, as well as Pawley's (1994:392-401) general treatment of surface morphological complexity in Kalam exponents for NSM primes, especially mental predicates; also Wierzbicka (1994:461-465).) 
The following example shows one speaker asking another how she feels, which elicits an emotion term as a grammatical complement of $h u u^{4} . s \grave{u} k^{2}$ FEEL:

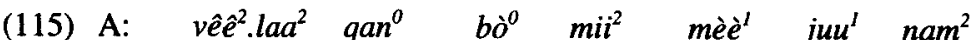

time HES.PCL NEG there.is mother be.at with

$h_{a n}{ }^{0} \quad \operatorname{caw}^{4} \quad h u u^{4} . \operatorname{sùk}^{2} \quad \mathrm{pen}^{3} \quad \mathrm{cang}^{l}-d a j^{3}$

TPC.PCL 2SG feel be how

'When - um - (you) don't have (your) mother with (you), how do (you) feel?'

$$
\begin{array}{llll}
\text { B: } & h u u^{4} \cdot s \grave{k} k^{2} & b \grave{o}^{0} & d i i^{3}-c a j^{3} \\
& \text { feel } & \text { NEG } & \text { good-heart }
\end{array}
$$

'(I) feel unhappy.'

This is the only case in my texts in which $h u u^{4} . s u k^{2}$ FEEL takes a direct complement. All other examples feature clausal complements (usually introduced by complementiser $v a a^{l}$ 'say'), and in these examples, $h u u^{4}$.sùk $k^{2}$ does not mean FEEL in the sense intended for NSM formulas, but takes on a more complex semantic structure comparable to English 'feel that (such and such is the case)'. This seems to incorporate notions of both FEEL and THINK, and it is presumably the presence of THINK in the semantics which explains why such examples may feature direct quotative frames (i.e. inclusion of an introductory discourse particle or interjection) for the subordinate clauses. For example:

(116) cang $^{l} v a a^{l} h^{2}$ qêêng ${ }^{3} a^{o} \quad h u u^{4} . s u ̀ k^{2} \quad v a a^{I} q o o^{4} h a a^{3}$ thus COMP 1SG self FOC.PCL feel COMP INTJ seek

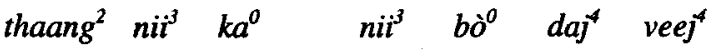

way flee FOC.PCL flee NEG can PCL

'That's why I myself felt that "Oh, a way to escape cannot be found!"

Returning to direct nominal complement constructions needed for NSM formulas, while constructions like 'I feel this' or 'I feel something bad' are rare in real discourse, they are perfectly acceptable and clear. NSM formulas with 'feel something' can be expressed in Lao using $h u u^{4}$.sùk ${ }^{2}$ FEEL and a postverbal nominal complement ñang ${ }^{3}$ SOMETHING, or qan- SOMETHING if specifiers or other modifiers - such as bo.dii ${ }^{3} \mathrm{BAD}$ - are required:

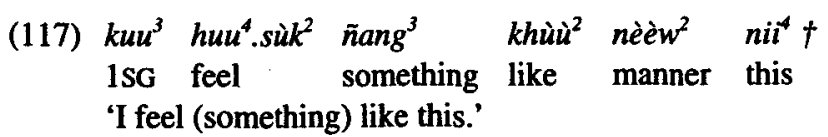




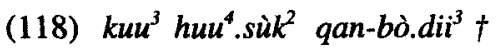
1SG feel something-bad 'I feel (something) bad.'

There is also a sense of location for FEEL which refers not to the location of the subject or the event as a whole, but to the locus of what is felt:

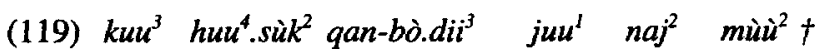

$$
\begin{aligned}
& \text { 1SG feel something-bad be.at inside hand } \\
& \text { 'I feel something bad in (my) hand.' }
\end{aligned}
$$

The 'hand' in this example is not necessarily construed as that of the speaker (e.g. this could be the speech of a doctor who is manually examining someone's hand, and feels something bad in there, in which case the unexpressed possessor

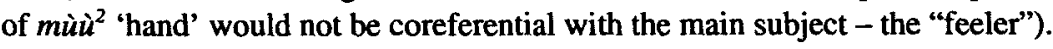

\subsection{5 hên ${ }^{3}$ SEE, $d a j^{+} . \tilde{n}$ in $^{2}$ HEAR}

The perceptual pair $h \hat{e} n^{3}$ SEE and $d a \jmath^{4} \cdot \tilde{n} i n^{2}$ HEAR may take three kinds of complements. First, simple nominals:

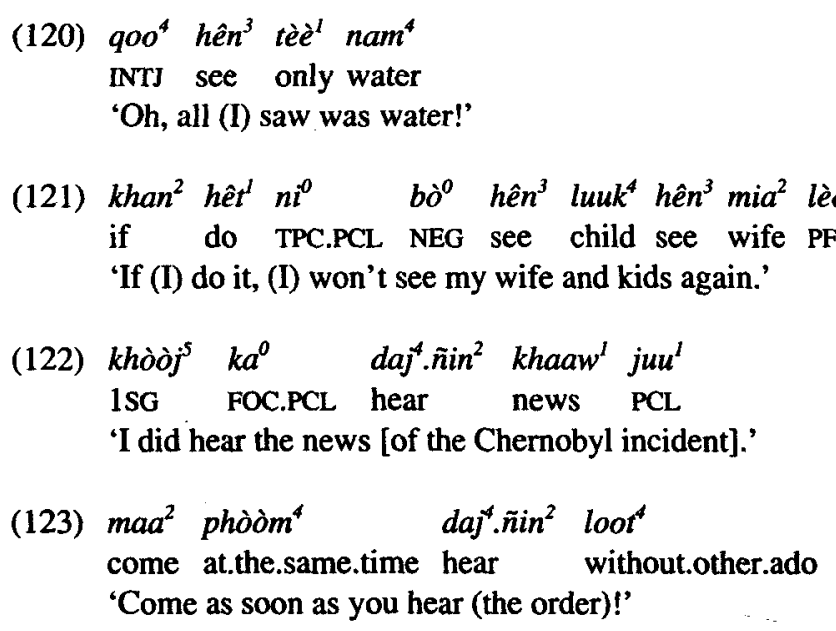

Second, $h \hat{e} n^{3}$ SEE and $d a \jmath^{4} \cdot \tilde{n} i^{2}$ HEAR may take simple sentential complements, where the lower subject is non-coreferential with the main clause subject (unless lower subject is reflexive/logophoric pronoun to-qêeng ${ }^{3}$ 'self'), 
and where tense-aspect of the lower clause is identical with that of the main clause:

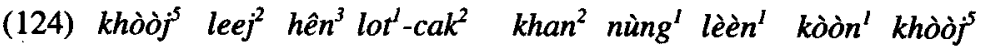
1SG so see motorcycle CLF one run before 1SG 'So, I saw one motorcycle riding ahead of me.'

(125) liaw $^{3}$ maa $^{2}$ haa $^{3}$ thong $^{3}$ lot ${ }^{0}$ hên ${ }^{3}$ maa $^{3}$ to $^{0}$-nùng ${ }^{\prime}$ turn come seek bag then see dog CLF-one

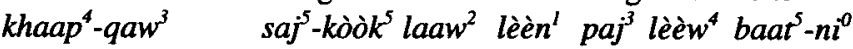
hold.in.mouth-take sausages $3 \mathrm{SG}$ run go PFV PCL

'(He) turned around towards the bag, and then saw a dog carrying away in its mouth the sausages, and running away.'

(126) $h a w^{2} k h e e j^{2} d a j^{4} . \tilde{n} i n^{2} \quad k h a c a w^{4} \quad v a w^{4} n a j^{2}$ thoo ${ }^{2}$ lathat $1 \mathrm{PL}$ ever hear 3PL say in television 'I've heard them speaking (it) on the television.'

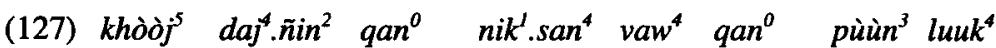
1SG hear HES.PCL N. say HES.PCL gun bullet diaw $^{3}$ ning ${ }^{2}$ nok $^{l}$ sòòng $^{3}$ too $^{3}$ single shoot bird two CLF

'I heard - um - Nixon say - um - "Kill two birds with one shot."'

Third, hên ${ }^{3}$ SEE and $d a j^{4} . \tilde{n} i n^{2}$ HEAR may take looser complements, marked by the complementiser vaa ${ }^{l}$.

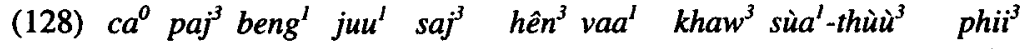
IRR go look be.at where see COMP 3PL believe-hold spirits 'Wherever (you) may look, you'll see that people believe in spirits.'

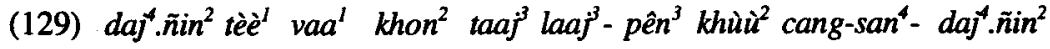
hear only COMP people die many be like thus hear

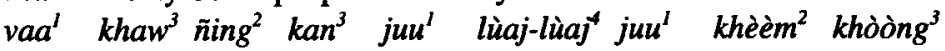
COMP 3PL shoot RCP be.at regularly be.at bank Mekong 'All (I) heard is that lots of people died, that's how it was - (I) heard that they were fighting regularly on the banks of the Mekong.'

The presence of the complementiser $v a a^{l}$ indicates that the perception is not first-hand. Consider the contrast of presence versus absence of $v a a^{l}$ : 
$(130)$
(a) $k u u^{3} \quad d a j^{4} . \tilde{n} i n^{2} / h e \hat{e} n^{3}$ phu-nùng ${ }^{1} \quad k h a a^{5} k a j^{l}+$ 1SG hear/see someone-one kill chicken 'I heard/saw someone kill a chicken.'
(b) $k u u^{3} \quad d a j^{4} . \tilde{n} i n^{2} / h e n^{3} \quad v a a^{l} \quad p h u-n u ̀ n g^{l} \quad k h a a^{5}, k a j j^{I} \dagger$ 1SG hear/see COMP someone kill chicken 'I heard/saw that someone killed a chicken.'

In (130a), the speaker heard/saw the event himself, whereas what the speaker heard/saw in (130b) was second-hand, either by hearsay or inferred from observed evidence. The distinction between direct perception and hearsay is encoded here iconically (in the sense of Haiman 1985), with the complement of hearsay/evidence further distanced - literally - from the main verb.

\subsection{Speech}

\subsection{1 $v a w^{4}$ SAY}

The grammar of $v a w^{4}$ SAY parallels that of khùt $t^{t}$ THINK. It may firstly take SOMETHING as a direct nominal complement, and secondly a "locutionary topic" marked with an about-phrase (i.e. 'say something (good/bad) about someone/ something'). In the following example, both these valency options are filled:

$$
\begin{aligned}
& \text { (131) mùng } \left.{ }^{2} \text { vaw qan-daj-nùng }{ }^{4} \text { (bò.dii }{ }^{3}\right) k i a w^{\prime} . k^{2}{ }^{2} k u u^{3} \dagger \\
& \text { 2SG say something-which-one (bad) about ISG } \\
& \text { 'You said something (bad) about me.' }
\end{aligned}
$$

Further, vaw $w^{4}$ SAY offers a third valency option, that of 'say something to someone', with the addressee argument marked by the linker $k_{a p}{ }^{2}$ 'with/to' (cf. extended valency options for DO and HAPPEN, section 3.4), as in the following:

(132) $v a w^{4} \mathrm{kap}^{2} \mathrm{mia}^{2} \mathrm{vaa}^{l} h^{2} w^{2}$ qòo $k^{5}$ say with wife COMP 1PL exit '(I) said to (my) wife, "We're leaving."”

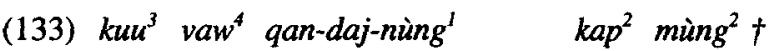 ISG say something-which-one with $2 S G$ 'I said something to you.'


The following examples show a more idiomatic (but semantically more complex) expression, involving a verb complex with a verb of saying (e.g. vaw ${ }^{4}$ SAY or $l a w^{l}$ 'relate/tell') in combination with a benefactive/causative phrase 'give/reach you listen' (i.e. 'for you to listen'). Similar constructions appear in other Southeast Asian languages (e.g. Cantonese; Matthews \& Yip 1994:308).

(134) $k u u^{3} v a w^{4}$ qan-daj-nùng ${ }^{I} \quad h a j^{5}$ mùng $^{2}$ fang $^{2}+$ ISG say something-which-one give $2 \mathrm{SG}$ listen 'I said something to you (I told you sth, I related sth. to you).'

(135) $q e e^{4}$ khòòj $^{5}$ lùùm ${ }^{2}$ law $^{l}$ suu $^{l}$ caw $^{4}$ fang $^{2}$ INTJ 1SG forget tell reach 2SG listen 'Oh, I forgot to tell you.'

The following example shows $v a w^{4}$ SAY with all three valency options filled:

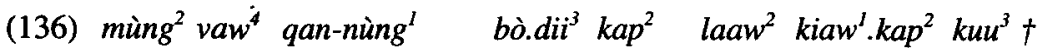
2SG say something-one bad with/to 3SG about 1SG 'You said something (bad) to them about me.'

The next grammatical issue for $v a w^{4}$ SAY is quotative complementation. First, this must involve the complementiser $v a a^{l}$, which basically means 'say', but with greater grammatical restrictions than $v a w^{4} \mathrm{SAY}$. (For example, it cannot take an about-phrase, as $v a w^{4}$ SAY does in (131) and (136) above.) In many cases, when $v a a^{l}$ introduces a speech complement, no main verb of saying is expressed. Consider the following example:

(137) $\operatorname{laaw}^{2}\left(v a w^{4}\right) v a a^{l}$ mùng ${ }^{2} b^{0} k^{0}$ huan ${ }^{2} \mathrm{paj}^{3} \dagger$ 3SG say COMP 2SG NEG should go 'He said you shouldn't go.'

Without some kind of marked intonation between the complementiser and the complement clause, this would not be construed as a direct quotation. More commonly, as described above for mental predicates involving 'saying' at some level (i.e. khùt $t^{l}$ THINK), direct quotation is formally marked by introduction of the clausal complement of $v a a^{l}$ with an interactional discourse marker, usually an interjection such as $q o o^{4}$ or $q 00 j^{4}$. The following examples illustrate this "embedded discourse marker" quotative strategy, involving main verbs of saying such as $v a w^{4}$ SAY, thaam ${ }^{3}$ 'ask', tòop $p^{5}$ 'answer', and bare use of the complementiser $v a a^{I}$ 'say' itself: 
(138) muu $^{l}$ vaa ${ }^{l}$ qooj $j^{4}$ jaan $^{4} \operatorname{man}^{2} \operatorname{taaj}^{3}$ lèèw $w^{4} l e ̀ w^{4}$ friends say INTJ afraid 3SG die PFV PCL '(His) friends said "Oh, (we're) afraid he's died!"'

(139) $\mathrm{mia}^{2}$ phañaa $\mathrm{ka}^{0} \quad$ thaam $^{3} \mathrm{vaa}^{1}$ qoo $\mathrm{o}^{4} \mathrm{qaj}^{4}$ wife lord FOC.PCL ask COMP INTJ o.bro

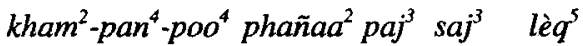
$\mathrm{K}$. lord go where $\mathrm{PCL}$

'So the lord's wife asked "Oh, Khampanpoo, where has the lord gone?"'

It is also common in direct quotation, especially in narrative sequences, to add at the end of the quoted material a particle $v a$-san ${ }^{4}$, a reduced combination of $v a a^{l}$ 'say' and $\operatorname{san}^{4}$ 'thus' (although the presence of $v a-s a n^{4}$ does not entail direct quotation; cf. example (109) above):

(140) $q a w^{2}-q a a n^{l}$ nam $^{2}-$ lang $^{3}$ phò-tuu $u^{4}$ dee va-san INTJ read after grandfather PCL say-thus

“"All right - read after grandpa, y'hear!", he said.'

(141) $\mathrm{cak}^{2} \quad \mathrm{si}^{0} \quad h \hat{e} \mathrm{t}^{1}$ cang-daj ${ }^{3} \mathrm{kin}^{3} \mathrm{va}-\mathrm{san}^{4}+$

what.on.earth IRR do how eat say-thus

"'What on earth am I going to make to eat?", he thought.'

\subsection{2 $\mathrm{kham}^{2} \cdot \operatorname{sap}^{2}$ WORDS}

The Lao exponent for wORDS $\mathrm{kham}^{2} . \mathrm{sap}^{2}$ is morphologically a compound of $\mathrm{kham}^{2}$ 'mouthful (e.g. of food), word' and $\mathrm{sap}^{2}$ 'word' (a loan from Sanskrit $s a b d a$ ). It is a nominal, and may be used as an object of $v a w^{4} \mathrm{SAY}$, as well as in a number of other contexts. The following examples demonstrate simple instances of $\mathrm{kham}^{2} \cdot \mathrm{sap}^{2}$ :

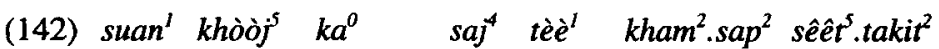
part 1SG FOC.PCL use only words economics

'As for me, (I) only used economics vocabulary.'

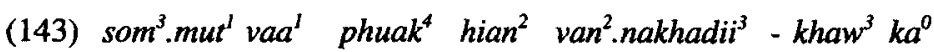
suppose COMP group study literature 3PL FOC.PCL saj $^{4}$ kham $^{2} . \mathrm{sap}^{2}$ khòòng $\mathrm{khaw}^{3}$ san $^{0} . n a a^{3}$ use words of . 3PL PCL

'Suppose those who study literature - they would use their (own) vocabulary.' 
The following examples show that either $s a p^{2}$ or $\mathrm{kham}^{2}$ may be used alone to mean WORDS:

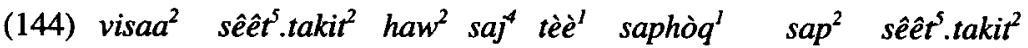
subject economics 1PL use only specifically words economics '(In) the subject of economics, we use only economics words.'

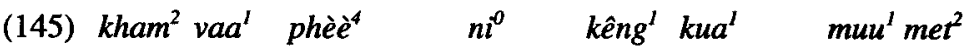
word COMP be.victorious TPC.PCL adept more.than peer all "This word phèè (means) "more adept than the rest".'

$\mathrm{Kham}^{2}$ WORDS functions productively as a nominaliser, as in $\mathrm{kham}^{2}$ $n e ̀ q^{l} \cdot$ nam $^{2}$ [word-advise] 'advice', kham $^{2}$-tùan ${ }^{3}$ [word-warn] 'warning', kham ${ }^{2}$ sang ${ }^{1}$ [word-order] 'order', $\mathrm{kham}^{2}$-khuan ${ }^{3}$ [word-spirit/morale] 'slogan'. Here are some sample NSM expressions involving WORDS as a nominal argument:

(146) dam $^{3} v a w^{4} t \grave{e}^{0}$ sòòng ${ }^{3}$ kham $^{2}$ sap $^{2} \dagger$

D say only two word

'Dam said only two words.'

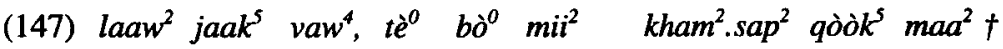
3P want say but NEG there.is word exit come 'S/he wanted to speak, but no words came out.'

The presence of both SAY and wORDS in the NSM system enables a contrast between judgements about what people say as opposed to the words they use to say it. The following example expresses the idea of using 'bad words' (as distinct from saying something with bad 'content'; cf. Wierzbicka 1996:107):

(148) laaw $^{2}$ vaw kham $^{2}$ bò.dii ${ }^{3} \mathrm{kap}^{2} \mathrm{kuu}^{3} \dagger$

3SG say word bad to 1SG

'S/he said a bad word/some bad words to me.'

An important frame for wORDS in NSM formulas is associated with the idea of translation, either of 'putting things in other words' (i.e. within a single language), or of translating from one language to another. Thus, it is useful to have a frame along the lines of English 'The word for $X$ (in Language $A$ ) is $Y$ '. There are two relevant constructions in Lao. First, when talking about the word for a thing, the verb qeen 'call' is used: 
(149) qan-nii $\quad\left(p h a a^{2} . s a a^{3} \quad l a a w^{2}\right) q e e n^{4} \tilde{n a n g}{ }^{3}+$ thing-this language Lao call what 'What's this thing called in Lao?'

Second, when talking about 'the word for' another word, Lao speakers use the term $p \grave{e} \grave{e}^{3}$ 'translate, put into other words' with the complementiser $v a a^{\text {' }}$ :

$$
\begin{aligned}
& \text { (150) 'table' (phaa }{ }^{2} \text { saa }^{3} \text { laaw }^{2} \text { ) pè̀ } \grave{3}^{3} \text { vaal } \text { toq }^{2}+ \\
& \text { 'table' language Lao translate coMP table } \\
& \text { 'Table (in Lao) is toq.', (or: 'The word for table (in Lao) is } t o q^{2} . \text { ') }
\end{aligned}
$$

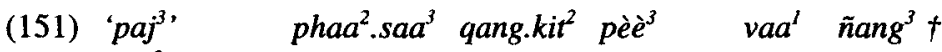

$$
\begin{aligned}
& \text { 'paj']' ['go'] language English translate COMP what } \\
& \text { 'How is 'paj' ['go'] translated into English?' } \\
& \text { (or: 'What is the word for ' } \mathrm{paj}^{3} \text { ' ['go'] in English?) }
\end{aligned}
$$

This is the normal way of expressing the idea of 'the word for something', or putting something 'in other words'. It would not be normal to use kham ${ }^{2}$.sap WORDS in expressions such as these. (Note that the term pè $\grave{e}^{3}$ 'translate, put into other words' is an everyday word on a par with English in other words, rather than the more technical sounding term translate.)

It is possible, in addition, to use $\mathrm{kham}^{2} . \mathrm{sap}^{2}$ wORDs in combination with qùùn' OTHER to express the idea of paraphrase:

(152) man $^{2} v a w^{4}$ qan-diaw ${ }^{3} \cdot \mathrm{kan}^{3}$ tè̀ $\grave{e}^{1} \operatorname{man}^{2} \mathrm{saj}^{4} \quad \mathrm{sap}^{2}$ qùùn ${ }^{1}+$ 3SG say thing-same but 3sG use word other 'He said the same thing, but he used other words.'

\subsection{3 mii ${ }^{2}$ khuam $^{2}$-cing ${ }^{3}$ TRUE}

The notion of a statement being TRUE is expressed in Lao by a complex phrase mii $^{2}$ khuam $^{2}$-cing ${ }^{3}$, literally 'have truth' (where khuam ${ }^{2}$ is a productive nominaliser, as in khuam ${ }^{2}$-dii ${ }^{3}$ [NSR-to.be.good] 'goodness' or khuam ${ }^{2}$-hak' [NSRto.love] 'love'). While $\operatorname{cing}^{3}$ itself fits into a simple verb slot in this nominalising construction, it does not have free verb properties. Unlike $d i i^{3}$ GOOD or $h a k^{l}$ 'love', it does not appear alone with its own main verb meaning (i.e. 'to be true'). Here are two examples: 


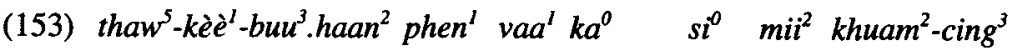
old-aged-ancient thè $\grave{e}^{4} l \grave{u} \grave{u}^{3} b \grave{o} \grave{o}^{l}$ really or NEG

'The old people say (this), (but) is it really true?'

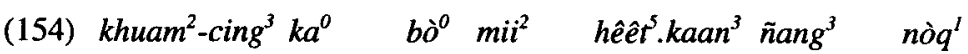
NSR-true FOC.PCL NEG there.is incident whatever PCL - tang $^{4}-\operatorname{tang}^{4}$ maw $^{2}$ intend intend drunk

'The truth is (that) there wasn't any particular incident - (they were) just intentionally - intentionally drunk.'

In NSM expressions, we may get strings like the following:

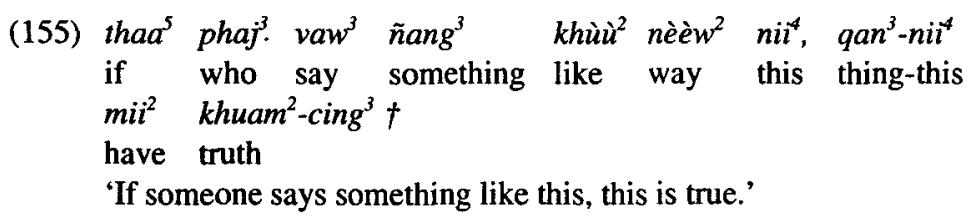

\subsection{Actions, events and movement}

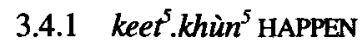

HAPPEN is expressed by the formally bimorphemic expression keet $^{5}$. khùn $^{5}$, consisting of keet 'be.born' and khùn ${ }^{5}$ 'ascend'. As 'born', keet is ambitransitive, where $S=O$ (Dixon 1991:286ff), while khùn' 'ascend' is ambitransitive, where $S=A$.

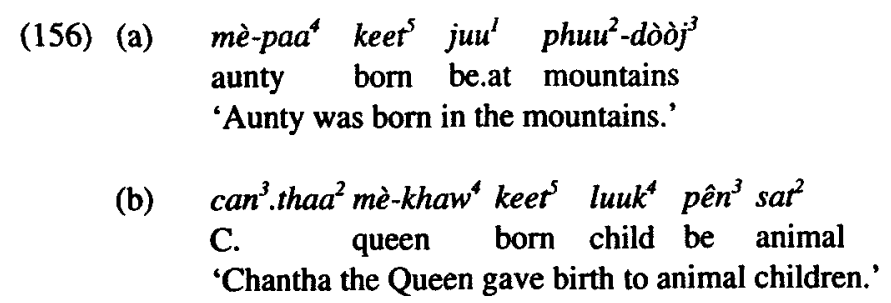




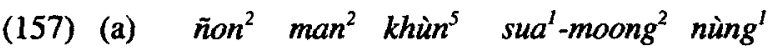
plane 3SG ascend hour one 'The plane went up for one hour.'

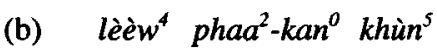
PFV together ascend 'And so together they went up (the riverbank).'

In the following example, keet' 'born', and khùn' 'ascend' appear in a compound meaning 'appear', 'be manifest':

(158) lèèw ${ }^{4}$ val bun $^{3}$ nan ${ }^{0} s^{0}$ keet $^{5}-k h u ̀ n^{5}$ pên $n^{3} k h a w^{5}$ pên PFV say merit TPC.PCL IRR born-ascend be rice be paa $^{3}$ pên ${ }^{3}$ ngen ${ }^{2}$ pên kham $^{2}$ lèèw fish be money be gold PFV

'And so (they) say that the merit will be manifest as rice and fish and money and gold.'

More commonly, the meaning of this combination - keet $t^{5} . k h u n^{5}-$ is HAPPEN:

(159) (tòòn ${ }^{3}$ nan $\left.^{4}\right)$ mii $^{2} \quad$ qan-daj-nùng ${ }^{l} \quad$ keet $^{5}$. khùn $^{5}$ (juu (time that) there.is something-which-one happen (be.at bòòn ${ }^{l}$ nan $\left.^{4}\right) \dagger$

place that)

'(At that time) something happened (in that place).'

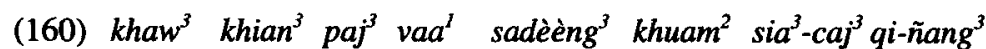
3PL write go COMP show NSR sorry something

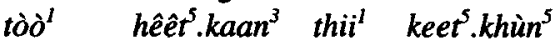
connect incident which happen 'They wrote to (them), expressing their sadness and whatever at the incident which (had) happened.'

Sometimes keet $^{5}$ alone does this job in initial position:

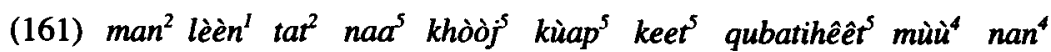
$3 S G$ run cut front $1 \mathrm{SG}$ nearly born accident day that 'He cut across in front, an accident almost occurred that day.' 
The following example shows a similar construction, in which khùn ${ }^{5}$ 'ascend' appears, but comes after the object of keet ' 'born', revealing that while HAPPEN is considered semantically basic, in Lao it is morphologically discontinuous:

(162) $\mathrm{ka}^{0} \quad \mathrm{leej}^{2} \mathrm{keet}^{5} \mathrm{kaan}^{3} \mathrm{tò̀}^{\prime}$-suu $\mathrm{kan}^{3} \mathrm{khùn}^{5}$

FOC.PCL so born NSR fight RCP arise

'And so there occurred fighting (between them).'

In the NSM system, while SOMETHING is the only subject argument possible for HAPPEN, any nominal may appear as an undergoer (i.e. as object of 'something happened to _'; see below).

\subsection{2 hêt $t^{\prime} \mathrm{DO}$}

DO is expressed in Lao by the verb hêt ${ }^{l}$ :

(163) $h a w^{2} s i^{0}$ hêt $t^{l}$ cang-daj baat $^{5}-n i^{0}$

1PL IRR do how PCL.

'What are we going to do?'

(164) thaa ${ }^{5}-h a a k^{5}$ vaa ${ }^{1} h^{2} w^{2}$ paj $^{3}$ hêt $t^{1}$ nang ${ }^{3}$ qanaa phit if COMP 1PL go do whatever HES.PCL wrong tò̀ $^{l} \quad q a n^{0} \quad$ hiit $^{4}$-khòòng ${ }^{2}$ khòòng $^{3}$ khacaw ${ }^{4}$ connect HES.PCL traditions of 3PL

'If we go and do anything - um - wrong against - um - their customs...'

$H e \hat{t} t^{t}$ has a number of other functions as well. As a main verb it may also mean 'make', as in (165). As a main complement-taking predicate, hêt' has a causative meaning 'make (something happen)', as in (166). It can also mean 'perform/act as', as in (167).

(165) haw hêt patuu $^{3}$ saj $^{l}$

1PL make door put

'We make a door to put in (there).'

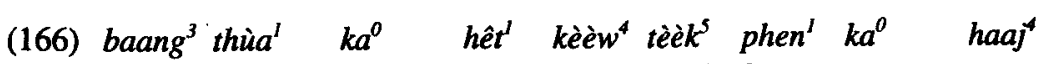
some occasion FOC.PCL make glass break 3HON FOC.PCL angry 'Sometimes I break a glass (and) so she will be angry.' 
(167) too $^{3}$ kheej $j^{2}$ hêt to-talok ${ }^{2}$ 2SG EXP do comedian 'You've been a comedian.'

In the NSM system, DO specifies an obligatory "action complement" SOMETHING (i.e. ñang ${ }^{3}$ WHAT or qan- THING), as illustrated below:

(168) jaak ${ }^{5} h \hat{e}^{t} \tilde{n} a n g^{3} \quad k a^{0} \quad b \grave{o}^{0}$ daj $^{4}$ lèèw $w^{4}$ want do something FOC.PCL NEG can PFV 'What(ever) (you) wanted to do, you couldn't (do it).'

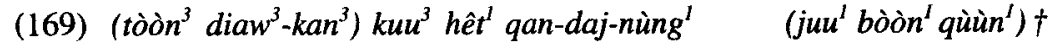
(time same) 1SG do something-which-one (be.at place other) '(At the same time), I did something (in another place).'

Modification of the 'something'-complement is also possible, such as in example (170), in which the SOMETHING done is 'bad'. In this kind of expression, the complement SOMETHING is often omitted and bo.dit ${ }^{3} \mathrm{BAD}$ remains, with adverbial function. In example (171), hêt ${ }^{l}$ DO appears with an adverbial modifier - phit ' 'wrong' - and no nominal complement:

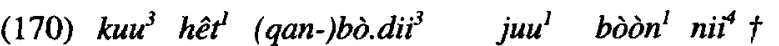
ISG do (something-)bad be.at place this 'I did (something) bad in this place.'

(171) bò sùa $\grave{a}^{1} h^{2}-j a a n^{4}$ haw ${ }^{2}$ hêt ${ }^{l}$ phit $^{2}$ qiik NEG believe 1SG afraid 1SG do wrong more '(He) didn't believe me - (he) was afraid I would do (something) wrong again.'

The optional undergoer arguments of $k e e t^{5}-k h u ̀ n^{5}$ HAPPEN and het $t^{\prime}$ D O ("extended valency options", Wierzbicka (1996:122-3)) include all NSM substantives. These are expressed as post-verbal obliques, marked either by the linker kap ' 'with/to' or the verb saj' 'put'.

First, $s^{\prime} j^{\prime}$ 'put' is used as a peripheral-marking "coverb" only to mark a SOMEONE undergoer of $\mathrm{DO}$, as in the following examples:

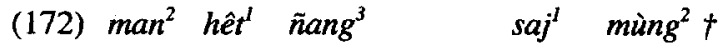

3SG do something/what put/to 2SG

'What did s/he/it do to you?' 
(173) mùng $^{2} b \grave{o}^{o}$ daj ${ }^{0} \quad h e t^{l}$ qan-bò.dii ${ }^{3}$ saj $^{l} \quad k u u^{3} \dagger$ 2SG NEG ACHV do thing-bad put/to 1SG 'You didn't do anything bad to me.'

The linker $k a p^{2}$, which applies to all other 'undergoers', has more widespread usage. It can function as a simple coordinative nominal linker 'and/with', as in (174), and to mark the object argument of reciprocal verbs such as $s u u^{5}$ 'fight' and $\operatorname{soo}^{3}$ 'confer'.

(174) sihoo $^{3}$ kap $^{2}$ sangthòòng ${ }^{2}$ mùa ${ }^{2}$ haa $a^{3}$ mè̀ ${ }^{l}$ juu ${ }^{I}$ paa $^{l}$ phun ${ }^{4}$ S. with S. go seek mother be.at forest PCL 'Siho and Sangthong went back to see (their) mother in the forest.'

(175) man $^{2} \mathrm{paj}^{3} \mathrm{suu}^{5} \mathrm{kap}^{2}$ manut ${ }^{1} \mathrm{naa}^{3}$ 3SG go fight with humans PCL 'He went and fought with humans, you know.'

For keet $^{5} . \mathrm{khùn}^{5}$ HAPPEN, any kind of undergoer argument (SOMEONE or SOMETHING) is marked by $k a p^{2}$ 'with':

(176) mii $^{2} \quad$ qan.daj.nùng ${ }^{I}$ bò.dii ${ }^{3}$ keet $^{5}$. khùn $^{5}$ kap ${ }^{2}$ qan-nili ${ }^{4}+$ there.is something bad happen with thing-this 'Something bad happened to this thing.'

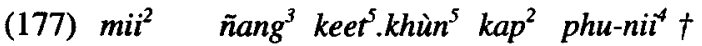
there.is what happen with someone-this 'What happened to this person?'

However, in expressions involving DO, $k a p^{2}$ as an oblique marker of an undergoer is ambiguous, also allowing comitative and instrumental readings:

(178) mùng ${ }^{2}$ hêt ${ }^{\prime}$ qan.daj.nùngl bò.dii ${ }^{3}$ kap $^{2}$ khon ${ }^{2}$ nì $^{4}+$ 2SG do something bad to people this

i. 'You did something bad to this person.'

ii. 'You did something bad with this person.'

The distinction between 'doing something with someone' and 'doing something to someone' must be maintained in the NSM. Lao speakers can maintain this distinction by avoiding $\mathrm{kap}^{2}$ 'with', and instead using $\mathrm{saj}^{l}$ 'put' to mark SOMEONE undergoers of DO, and nam $^{2}$ 'retrieve, go-get' to mark comitative arguments. 
Comitative complements of $h \hat{e}^{l}$ DO may be marked by nam 'accompany, lead along, go after, retrieve'. The next example shows nam $^{2}$ as a main verb 'go after':

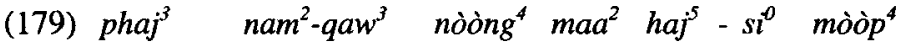
someone go.after-take Y.SIB come give IRR hand.over mùang ${ }^{2}$ haj loot $^{4}$

kingdom give without.further.ado

'Whoever brings my sister to (me), (I) will hand over the kingdom to (them) right away.'

The following examples show the comitative function of $\mathrm{nam}^{2}$ which appears in NSM formulas:

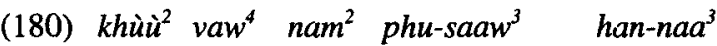
like speak with unmarried.girl PCL

'(You talk) like (you're) talking with an unmarried girl.'

(181) bòò ${ }^{I} h a j^{5} \quad h e ̂ t ~ v i a k^{4}$ nam $^{2}$ muu NEG give do work with peers '(They) are not allowed to work with others.'

(182) $k h \grave{o ̀ j} \dot{j}^{5} b \grave{\partial} \grave{o}^{l} p_{a j}$ nam $^{2} \quad c a w^{4}$ 1SG NEG go with $2 \mathrm{SG}$ 'I'm not going with you.'

It seems clear that comitative expressions in NSM formulas would use $\mathrm{nam}^{2}$ in Lao. Often $k a p^{2}$ could mark the same relationship ('do with'), but it is usually also open to a 'do to' interpretation. In order to keep these ideas distinct, we may do best to avoid $k a p^{2}$ altogether.

Instrumental complements of $h e t^{l}$ DO may be marked by duaj 'with':

(183) $k u u^{3} h e t^{l} q^{3} n^{3} i l^{4} d u a j^{4}$ miit $^{4}+$ 1SG do thing this with knife

'I did this (thing) with a knife.'

(184) khan $^{2}$ mung $^{2}$ duaj sang $^{3} \mathrm{kasii}^{3} \quad n i^{0} \quad$ qaat $^{5} \quad s i^{0} \quad h e t^{\circ}$ if roof with corrugated.iron TPC.PCL might IRR do suung $^{3}$ dè $\grave{l}^{\prime}$ caak $^{5}$ phùùn ${ }^{4}$ high PCL from floor 'If (we) roof it with corrugated iron, we might make it high off the floor.' 
More idiomatically, instruments are included in a serial verb construction using $s a j$ ' 'use' or $q a w^{3}$ 'take' in V1 position:

(185) $\mathrm{kuu}^{3} \mathrm{saj}^{4} \mathrm{miit}^{4}$ hêt $\mathrm{qan}^{3} \mathrm{nit}^{4} \dagger$

1SG use knife do thing this

'I used a knife to do this (thing).'

(186) $\mathrm{kuu}^{3} q a w^{3}$ miit' hêt $q a n^{3} n i i^{4}+$

1SG take knife do thing this

'I took a knife and did this (thing).'

Thus, in a Lao version of the NSM, comitative relationship is always marked by nam $^{2}$ and only arises occurs where SOMEONE is the peripheral argument and the main verb is LIVE or DO. Instrument relationship is always marked by duaj and only occurs where the peripheral argument is SOMETHING and the main verb is DO. The non-subject nominal is marked by $k a p^{2}$ (or $s a j^{l}$ 'put') in the case of SAY (restricted to SOMEONE addressees), and HAPPEN (with any undergoer nominal), and is marked by saj for any lower argument when the main verb is DO. Table 3.4 provides a summary.

Table 3.4: Oblique markers for extended valency options of HAPPEN, SAY and DO in Lao

\begin{tabular}{|c|c|c|c|}
\hline & Object is 'someone' & & Object is 'something' \\
\hline $\begin{array}{l}\text { 'happen to_' } \\
\text { 'say to_' } \\
\text { 'do to_' } \\
\text { 'do with_' }\end{array}$ & $\begin{array}{c}\operatorname{kap}^{\prime}\left(s a j^{\prime}\right) \\
n a m^{2} \\
\text { ('comitative') }\end{array}$ & $\begin{array}{l}k a p^{2} \\
s a j^{\prime}\end{array}$ & $\begin{array}{c}- \\
\text { duaj' } \\
\text { ('instrumental') }\end{array}$ \\
\hline
\end{tabular}

\subsection{3 tiing $3 / n \hat{e n g}^{3}$ MOVE}

MOVE is expressed in Lao by $n \hat{e} n g^{3}$ or tiing ${ }^{3}$, the two words being apparently synonymous and interchangeable in every context. The only restriction seems to be that when used in a compound combination, the order is always nên ${ }^{3}$-tiing ${ }^{3}$. Arbitrarily, I will refer only to tiing ${ }^{3}$ in this description (it is slightly more common in my texts), although $n \hat{e} n g^{3}$-tiing ${ }^{3}$ or $n \hat{e}$ g $^{3}$ would be semantically equivalent in all the examples. The following two examples describe a scene in which a tiger, having made an attack on a field hut, has just been thwarted by a 
small child who has thrown a pot of boiling bamboo-shoot soup over its head. The tiger is lying still, unconscious or dead:

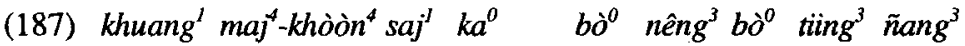
throw wood-bat put FOC.PCL NEG move NEG move anything '(They) threw pieces of wood at (it), and (it) didn't move at all.'

(188) thè $\grave{e}^{4}$ han-naa ${ }^{3} a^{0} \quad b \grave{o}^{0}$ nêng $^{3}$-tiing ${ }^{3}$ nang ${ }^{3}$ really PCL FOC.PCL NEG move-move anything 'Really, it didn't move at all.'

In the next example, MOVE is used in a more general, almost figurative sense, to refer to severe restrictions of general social freedom (including travel) during the early period of the current government:

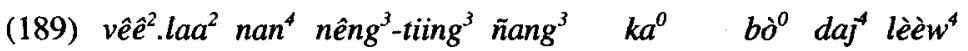
time that move-move anything FOC.PCL NEG can PFV '(At) that time, one couldn't 'move' at all.'

While English move suggests change of location - or "translocational" movement - and accordingly is compatible with directional complements ("It moved from A to B'), Lao tiing ${ }^{3}$ MOVE describes only movement of something relative to itself, i.e. with no entailment of change of location at all. The following typical example (attested), is a speaker's description of busily patterned wallpaper which was creating an illusion of "shimmering" in low light:

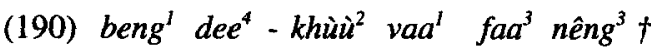
look PCL like COMP wall move 'Look - it's like the wall is moving!'

In the next example, a character has noticed an intruder outside her room, who is at the time staying completely still so as to avoid detection:

(191) phaj $j^{3}$ phu-liit ${ }^{4} \quad j u u^{l} n i^{4}-h e ̂ n^{3} l e ̀ e ̀ w^{4} b o^{0}$ tiing $^{3}$ who someone-hide be.at here - see PFV NEG move 'Who's hiding here, (I) see (you), (you're) not moving.'

These examples show that tiing ${ }^{3}$ MOVE refers to non-translocational movement in a place. Unlike, say, paj $^{3}$ 'go' or lè̀n ' 'run', tïing ${ }^{3}$ MOVE cannot be used to describe movement from one place to another: 


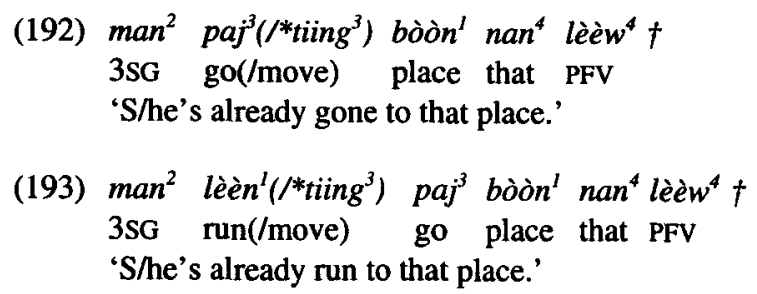

The next example presents an apparent exception in that tiing ${ }^{3}$ MOVE takes a complement thaang ${ }^{2} \mathrm{daj}^{3}$ 'any direction', which is usually a complement of directional verbs such as $p^{\prime} j^{3}$ ' $g o$ ', and which is usually thus given an interpretation 'in any direction'. In the scene being described, a man's arms are tied by long ropes, each held out to his sides, with a crew of men holding each rope, tightly and in opposite directions:

$$
\begin{aligned}
& \text { (194) } \operatorname{tii}^{3} \text { loot }^{4} \quad l \grave{e} e ̀ w^{4}-v a a^{1} \text { tè̀ } \grave{e}^{1} \operatorname{man}^{2} \text { tiing }^{3} \text { thaang }{ }^{2} \text { daj } \dot{j}^{3} \\
& \text { hit without.other.ado PFV COMP only } 3 \text { SG move way which } \\
& \text { 'Go right ahead and hit (him) - right whenever he moves at any side.' }
\end{aligned}
$$

The translation 'moves at any side' reflects the non-translocational meaning of tiing $^{3}$ MOVE in this case. Here, the speaker is not talking about movement to either side, but on either side. Similarly, the following describes shaking or wiggling of one's hand, with no necessary change of location:

(195) laaw $^{2}$ hêt $t^{1}$ mùù $^{2}$ tiing $^{3} \dagger$

3SG make hand move

'(S)he moved his/her hand.'

One informant remarked that the word $\tilde{n} a a j^{4}$, expressing the translocational sense of MOVE, would be inapplicable for describing mere wiggling of the hand, giving the following explanation:

(196) $\operatorname{man}^{2} \tilde{n} a n g^{2} \quad j u u^{l}$ bòòn ${ }^{l} k^{2} w^{l} \dagger$

3sG still be.at place old

'It (i.e. the hand) is still in the old/former place.'

(i.e. it's still in the same place as before)

Thus, while translocational ñaaj 'move (from one place to another)' entails change of location, tiing ${ }^{3}$ MOVE entails only "internal" or "local" movement, in a single place.

Possible preverbal arguments of tiing $^{3}$ MOVE include all the NSM nominals 
except PLACE. Although 'move' may be a two-place predicate in Lao (e.g. taking body-part "undergoers"), none of the NSM nominals occur postverbally in NSM expressions (except perhaps the newly proposed prime BODY).

I have referred to non-translocational "internal" or "local" movement, by which I mean movement within something, or motion of its parts, independent of any change of location. There are many verbs specifically involving location change, including $\mathrm{paj}^{3}$ ' $\mathrm{go}$ ', ñaaj 'move, transport, shift', and lùùn 'slip, slide' but these do not necessarily include any sense of internal or local movement (as a cause of translocational movement or not). A possible source of confusion in nailing down the concept of the putative prime MOVE is the fact that events involving translocational movement (i.e. 'from A to B') are very often accompanied by (causal) internal/local movement. For example, 'walking' involves internal/local movement (of the legs), and resultant change of location (of the whole body): By contrast, however, compare the "movement" of 'sliding', which involves only translocational movement (no necessary causational internal movement), with "movement" such as 'shaking' or 'revolving', which makes no reference to (caused or coincidental) translocational movement. Thus, English 'move' is polysemous, and any apparent vagueness (e.g. in Don't anybody move!) arises only from the fact that the two kinds of movement (translocational vs. internal/local) are apparently inseparable (pragmatically) in some contexts.

Unlike English move, Lao tiing ${ }^{3}$ MOVE is in no way vague as to whether it depicts translocational or local/internal movement. Tiing ${ }^{3}$ MOVE cannot appear in a source/goal construction, nor can it appear with any directional serial verb complement (i.e. in a construction analogous with English move away, move across, or move down). Compatibility of a tiing ${ }^{3}$ MOVE expression with translocational movement is metonymic - local movement is often associated with translocational movement, and the latter is hard to imagine without the former.

Concepts referring to translocational movement should be explicable in terms of change of location, with or without reference (as required) to local/internal movement as a causational event. Indeed, change of location does not entail MOVE. If something were to change place instantly, by magic - for example on a TV screen in a typical illusion - the event could not be described in Lao using tiing ${ }^{3}$ MOVE, but by naaj 'move (changing location)' or by a circumlocution like 'change place' or 'be in a different place'.

\subsection{Existence and possession}

The primes THERE IS and HAVE are both expressed in Lao by the verb $m i i^{2}$, 
distinguished by different grammatical contexts. See section 3.1.4 above for a description of $m i^{2}$ in these and other functions.

\subsection{Life and death}

\subsection{1 $\operatorname{taaj}^{3} \mathrm{DIE}$}

The Lao exponent for DIE is $t a a j$ :

(197) $l u u k^{4}-n \grave{o ̀ n g} g^{4} \operatorname{man}^{2} \quad k a^{0} \quad \operatorname{taaj}^{3} \mathrm{met}^{2}$ child-Y.SIB 3SG TPC.PCL die all

'His underlings all died.'

(198) khan $^{2}$ san $^{4}$ lèèw $w^{4}$ tòòng taaj $^{3}$

if thus PFV must die

'If that's the case [i.e. if one had to fight], then (one would) surely die.'

As the following examples show, dying happens in a place, and thus expressions with taaj $^{3}$ DIE may refer to location by asking 'where?', or by including locative adjuncts:

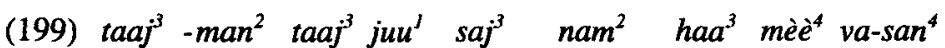
die 3SG die be.at where go.after seek PCL say-thus "“(He's) died?! Where has he died? Go and look for him!", (he) said.'

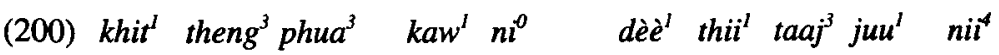
think reach husband old TPC.PCL PCL rel die be.at here '(She) thought about (her) old husband, (the one) who died here.'

Also, dying happens at a time. It is common for $t a a j^{3} \mathrm{DIE}$ to be used with a range of time-related aspect/modality marking, as in the following examples:

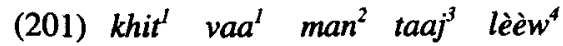

think COMP 3SG die PFV

'(I) think he's already died.'

(202) $c a w^{4}$ nang ${ }^{2} b^{0}$ than $^{2} \operatorname{taaj}^{3}$ paan $^{3}$ nil $^{4} v^{2} h^{2}$ 2SG still NEG yet die extent this PCL 'Haven't you died yet?!' 
There are no examples in my texts of $\operatorname{taaj}^{3}$ DIE appearing with a specific temporal adjunct, but expressions like the following are both clear and idiomatic:

(203) $\operatorname{man}^{2} \operatorname{taaj}^{3}$ tòòn ${ }^{3} d a j^{3} \dagger$

3SG die time which

'When did s/he die?'

(204) man $^{2}$ taaj $^{3}$ tòòn $h^{3}$ ha $^{5}$ moong ${ }^{5} \dagger$

3SG die time five hour/clock

'S/he died at five o'clock.'

3.6.2 $j u u^{l}$ LIVE

The Lao exponent for LIVE is $j u u^{l}$ :

(205) $p h u-d a j^{3} \quad d i i^{3} \quad p h u^{0}-n a n^{4} \quad j u u^{l}$ someone-which good someone-that live

'Whoever was good [in that fight], that one would live.'

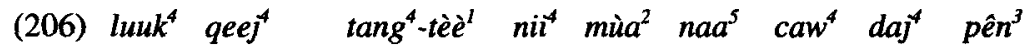
child VOC.PCL since/from this go ahead 2SG ACHV be kam $^{1}$.phaa ${ }^{4}$ juu tua $^{3}$-diaw ${ }^{3}$ lèèw orphan live CLF-single PFV

'Child, from this (time) on, you'll become an orphan, living on your own.'

(207) $b \grave{o}^{\circ} h \hat{e} n^{3}, j u u^{I} b \grave{o}^{o} d a j^{4}$

NEG see live NEG can

'(If he) didn't see (his former wife), (he) couldn't live.'

$J u u^{l}$ as LIVE can be modified by adverbials, providing descriptions of living in a certain way, for example living 'well' or living 'cool':

(208) phen ${ }^{I}$ juu ${ }^{I} \mathrm{dit}^{3}+$

3HON live good

'S/he lives well.'

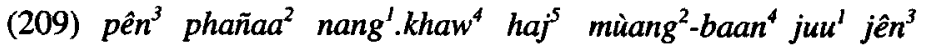
be lord rule give city-village live cool '(He) was the lord, ruling, enabling the (people of the) city to live well/calmly/peacefully.' 
Naturally, one may live 'in a place', as shown by these examples in which juu ${ }^{I}$ LIVE takes a location as direct object:

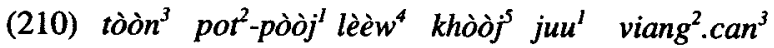

time liberate PFV 1SG be.at V.

'When the liberation was complete I was living in Vientiane.'

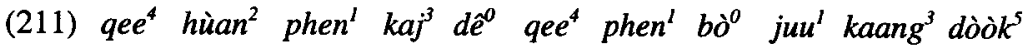
INTJ house 3HON far PCL INTJ 3HON NEG live middle PCL 'Yeah, his house was far, you know - he didn't live in the centre.'

Another valency option for $j u u^{l}$ LIVE involves living with someone. In Lao, the oblique argument is marked by the coverb nam ${ }^{2}$ 'with' (elsewhere a main verb 'accompany, go.after'), as in the following example:

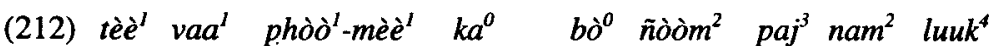
but COMP father-mother FOC.PCL NEG yield go with child phu-nan ${ }^{4}$ phu-hang ${ }^{l}$ phu-mii ${ }^{2}$ han ${ }^{5}$ maa $^{2}$ juu $^{l}$ nam $^{2}$ CLF-that CLF-rich CLF-have TPC.PCL come live with phu-thuk ${ }^{I} \quad$ phu-ñaak ${ }^{4}$ phil $^{4}$ CLF-miserable CLF-difficult here

'But the parents won't go with that rich child, (they'll) come and live with the miserable and poor ones over here.'

One difficulty here is that $j u u^{\prime}$ may also predicate existence in a location, rather than 'living' as such. Example (213), with a place in object position, is not about 'living' but about location. In example (214), it is not clear from the context whether 'living together' or 'being together (at that place)' is intended:

(213) tè̀ $\grave{e}^{l}$ saphòq $q^{2} \sin ^{3} s a j^{2} j u u^{l}$ naj' thòòng ${ }^{4} \grave{o}^{\circ}$ than $^{2} d a j^{0}$ keet $^{5}$ thù $a^{l}$ but specifically S. be.at inside belly NEG yet ACHV be.bornyet 'But as for Sinxay, (he) was in (his mother's) belly - (he) wasn't born yet.'

(214) juul hùan ${ }^{2}$ nan $^{4}$ mil $^{2}$ phò-thaw ${ }^{5}$ dè̀ lèka ${ }^{o} \quad m i^{2}$ be.at house that there.is old.man PCL CLS.LNK there.is laan ${ }^{3} d \grave{e} e^{l} \mathrm{juu}^{l} \mathrm{nam}^{2}$. $\mathrm{kan}^{3}$ grandchild PCL be.at together RCP.PCL

'At that house there was an old man, and there was a grandchild, there together.' 
The context does not tell us whether the two characters actually live together, or just happen to be in the house together on this occasion. I am unable to say how these interpretations are distinguished.

Further, when the subject is not a living thing, and the oblique "location" is a person, the same construction sees $j u u^{I}$ as a locative verb, with nam ${ }^{2}$ required to mark the 'person location':

(215) $\mathrm{tam}^{3} . \mathrm{lag}^{2} \mathrm{juu}^{1} \mathrm{nam}^{2} \mathrm{kuu}^{3} \mathrm{phil}^{4}$ recipe be.at with $1 \mathrm{SG}$ here 'The recipe's here with me.'

In a further locative function, $j u u^{l}$ is used as a secondary verb or "verbpreposition", marking the location of action expressed in a main clause (and translatable by in/at):

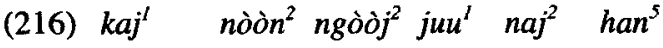
chicken lie roost be.at inside there 'The chickens roost in there.'

(217) $\mathrm{ca}^{0} \quad \mathrm{saw}^{2}$ juu $\mathrm{saj}^{\mathrm{s}} \quad \mathrm{baat}^{5}-n \mathrm{i}^{0}$ IRR stop be.at where PCL 'Now, where shall (we) stop?'

\subsection{Determiners}

\subsection{1 $n i i^{4}$ THIS, diaw $^{3} . \mathrm{kan}^{3}$ THE SAME, qùùn $n^{1}$ OTHER}

Determiners are expressed as part of the nominal phrase in Lao, usually involving classifier constructions. They attach to the head nominal, which will be the classifier, if one is present. The patterns for determiners are [noundeterminer] or [noun classifier-determiner]. $\mathrm{Nii}^{4} \mathrm{THIS}, \mathrm{diaw}^{3} . \mathrm{kan}^{3} \mathrm{THE}$ SAME, and qùùn ${ }^{l}$ OTHER are straightforward in this regard. Examples include: $t \grave{o o ̀ n}{ }^{3} n i^{4}$ [time this] '(at) this time'; khon ${ }^{2}$ diaw $^{3} . \mathrm{kan}^{3}$ [people same] 'the same person/people'; suan qùùn ${ }^{l}$ [part other] 'another part/other parts'. Many other examples can be found throughout this chapter.

Note that $n i i^{4}$ 'this' is the semantically unmarked member of a set of demonstrative expressions, including one other genuine demonstrative adjective nan $^{4}$ 'that', along with three spatially deictic adverbials phii 'here', han ${ }^{5}$ 'there', and phun 'yonder'. By being in opposition with the 'distal' demonstrative nan ${ }^{4}$ 'that', $n i i^{4}$ 'this' pragmatically adopts a 'proximal' meaning. 
The term $\mathrm{diaw}^{3} . \mathrm{kan}^{3}$ THE SAME (morphemically analysable as a combination of diaw $^{3}$ 'single, alone' - cf. example (206) above - and the reciprocal particle $\mathrm{kan}^{3}$ ) is a specifier most importantly used in NSM formulas as a modifier of nominals, in the frame 'the same person/thing/place/time'. Here are two examples:

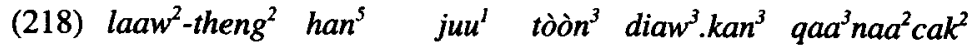 Lao-above TPC.PCL be.at place same kingdom

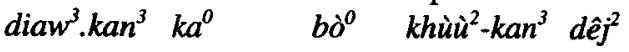 same FOC.PCL NEG like-RCP PCL

'The Lao Theung live in the same place (as us), the same kingdom (as us), (but we are) not alike, you know.'

(219) lèq saa maat $^{4}$ pèè ${ }^{3} \quad p \hat{e} n^{3} \operatorname{sap}^{2}$ vithañasaat ${ }^{5}$ qùùn $k a^{0}$ and able translate be words science other FOC.PCL

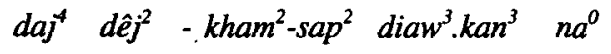
can PCL words same PCL

'And it's possible to translate (them) as terms from other sciences, you know - the same words.'

There is one common usage of the English expression the same - in the frames ' $\mathrm{X}$ is the same as $\mathrm{Y}$ ' and ' $\mathrm{X}$ and $\mathrm{Y}$ are the same' - which should not be regarded as part of the NSM system. English the same in this adverbial frame refers not to identity but to close likeness in some or all respects. This cannot be expressed in Lao using diaw ${ }^{3} . \mathrm{kan}^{3}$. It is expressed instead using khùù ${ }^{2}$ LIKE. When in English we say John is the same as Bill or John and Bill are the same, we mean that they are 'alike' in some respect, e.g. temperament. This latter sense of English the same means something like 'it is like they are the same person/ thing', or 'one could say the same thing about them'.

In Lao, diaw . $^{3} \mathrm{nn}^{3}$ THE SAME cannot appear in this kind of adverbial frame, and instead must appear attached to a nominal head (cf. next section). The following two examples illustrate this, the first being ungrammatical, the second simply pragmatically odd:

(220) *mùngl diaw ${ }^{3} . \mathrm{kan}^{3} \mathrm{kap}^{2} \mathrm{kuu}^{3} \dagger$

2SG same with $1 \mathrm{SG}$

(You are the same as me.)

(221) ??mùng pên $^{3}$ phu-diaw $w^{3} . \mathrm{kan}^{3} \mathrm{kap}^{2} \mathrm{kuu}^{3} \dagger$

2SG be someone-same with 1SG

('You are the same person as me.') 
Compare the following using khùù $\grave{L}^{2}$ LIKE corresponding to English the same.

(222) mùng ${ }^{2} k h \grave{u} \grave{u}^{2} k u u^{3} \dagger$

2SG like 1SG

'You are like me.' (or English: You are the same as me.)

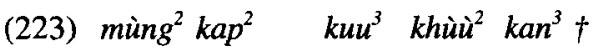

2SG with/and 1SG like RCP

'You and I are alike.' (or English: You and I are the same.)

\subsection{2 "Quasi-substantive" use of determiners}

It is worth considering whether the obligatory use of nominal heads with determiners can constrain the semantic possibilities of NSM expressions. One problem arises in NSM expressions which feature determiners (especially THIS) as "substantives" (i.e. as lone complements of hêt $t^{l}$ DO, keet . khùn $n^{5}$ HAPPEN, vaw"

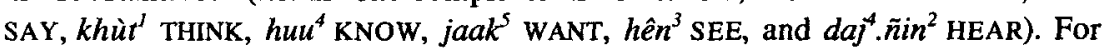
example, to translate People think this is good into Lao, the element nil ${ }^{4}$ THIS can only appear as a dependent determiner, attached to some nominal head, i.e. a classifier. The Lao speaker cannot simply use $n i i^{4}$ THIS alone in this context. (This no doubt helps to account for a common error in Lao speakers' use of English, namely the tendency to use this one where English speakers would normally just say this.)

Most commonly, the nominal head to which determiners attach is the maximally general classifier qan $^{3}$ 'thing'. The resulting form, which corresponds to THIS as a "substantive" in NSM formulas, is thus qan-niil (literally "this thing').

(224) khon ${ }^{2}$ khùt ${ }^{I} \quad v a a^{I} \quad q a n-n i i^{4} / * n i i^{4} d i i^{3}+$ people think COMP thing-this/this good 'People think this (thing) is good.'

(225) $k u u^{3} \quad v a w^{4} \quad q a n-n i i^{4} / * n i i^{4}+$ $1 \mathrm{SG}$ say thing-this/this

'I said this (thing).'

While $n i i^{4}$ never appears alone meaning THIS, it may appear alone with other meanings. For example, as a complement of $j u u^{l}$ 'be at' or $\mathrm{maa}^{2}$ 'come', niil may mean 'here', as in the following examples: 
(226) $\mathrm{maa}^{2} \mathrm{nit}^{4}+$

come this/here

'Come here!'

(227) laaw $^{2}$ bò ${ }^{o}$ daj ${ }^{0}$ hêt $t^{l} j u u^{1}$ nil ${ }^{4}+$ 3P NEG ACHV do be.at this/here 'S/he didn't do (it) here.'

$\mathrm{Nil}^{4}$ sometimes appears as a lone substantive 'this here' in preverbal position, usually with strong prosodic marking (stressed, often followed by a marked pause). Such usage picks out a salient referent, usually present in the physical context. In the following examples, the sentence-initial $n i i^{4}$ has an overt demonstrative function, referring to something physically present:

(228) $n i i^{4} \quad l a^{0}$ phu-nil $\quad s i^{0} \quad d a j^{4}$

this PCL someone-this IRR can

'Here, this person will be able (to do it).'

(229) nil $^{4}$ mè̀̀n ${ }^{1}$ nam-jaa ${ }^{3} \quad$ qoo ${ }^{3}$ lalit $^{\prime} \dagger$

this be water-medicine $O$.

'This here is Oralite medicine.'

Example (229) is attested (Unicef Lao 1991), spoken by a puppeteer holding up sachets of 'Oralite' brand rehydration salts in front of a vast audience of school children, and introducing a demonstration of how they are used.

THE SAME is another determiner which Wierzbicka (1996:127) has argued should be able to occur as a "quasi-substantive", as in 'I did the same'. However, in Lao, diaw $w^{3} . \mathrm{kan}^{3}$ THE SAME shares the grammatical property with $n i^{4}$ THIS that it may not appear without being attached to a nominal head - i.e. one cannot say 'I did the same', but instead must say 'I did the same thing':

(230) $\mathrm{kuu}^{3}$ hêt $t^{\prime}$ *(qan) diaw ${ }^{3} \cdot \mathrm{kan}^{3} \dagger$

ISG do thing same

'I did the same (thing).'

Further, Wierzbicka suggests that in THE SAME expressions, languages should be expected to "open a syntactic slot for the second member of the equation" (i.e. 'I did the same as you'). In Lao, this second argument is marked with the addition of the relational particle $\mathrm{kap}^{2}$ "with' (as for "undergoer" arguments of keet $^{5}$.khùn ${ }^{5}$ HAPPEN or vaw $w^{4}$ SAY): 
(231) $k u u^{3} h e t^{l} *(q a n) d i a w^{3} \cdot k^{3} k^{3}{ }^{2}$ mùng ${ }^{2}+$

$1 \mathrm{SG}$ do thing same with 2SG

'I did the same (thing) as you.'

The evidence from Lao shows that determiners such as THIS and THE SAME cannot be universally used as "quasi-substantives", pace Wierzbicka (1996:126127); cf. also Diller (1994:155ff) on the same matter with regard to Thai.

\subsection{Quantifiers}

\subsection{1 baang $^{3}$ SOME, nùng ${ }^{1} \mathrm{ONE}$, sòòng $^{3}$ TWO}

The quantifiers baang ${ }^{3}$ SOME, nùng ${ }^{I}$ ONE, and sòòng ${ }^{3}$ TWO, (as well as laaj ${ }^{3}$ MUCH/MANY and $m e t^{2}$ ALL; see below) combine freely with the substantives $k^{2}{ }^{2}$ PEOPLE and qan- THING, as well as with suan' PART. Baang ${ }^{3}$ SOME, sòong ${ }^{3}$ TWO, and $l a a j^{3}$ MUCH/MANY precede the nominal, while $n u n^{l}$ ONE may precede or follow ( et $^{2}$ ALL is an adverbial with distinct grammar; see below):
(232) baang $^{3}$ qan $^{3}$ nùng $^{1}$ khon $^{2}$ khon ${ }^{2}$ ùng ${ }^{l}$ sòòng ${ }^{3}$ suan $^{1}$ $\operatorname{laaj}^{3}$ qan $^{3}$

$$
\begin{aligned}
& \text { [some thing] } \\
& \text { [one people] } \\
& \text { [people one] } \\
& \text { [two part] } \\
& \text { [many thing] }
\end{aligned}
$$$$
\begin{aligned}
& \text { 'some things' } \\
& \text { 'one person' } \\
& \text { 'one person' } \\
& \text { 'two parts' } \\
& \text { 'many things' }
\end{aligned}
$$

The first two examples below are text examples of baang ${ }^{3}$ some, which precedes the nominal it quantifies. The second two are examples of nùng ${ }^{l}$ ONE, in the more common pattern of appearing after the nominal it modifies (in contrast to the other quantifiers).

(233) baang ${ }^{3}$ khon $^{2} k h a w^{3} k^{0} \quad n i i^{3}$ paj $^{3}$ mùang ${ }^{2}$-thaj baang $^{3}$ khon $^{2}$ some people 3PL FOC.PCL flee go country-Thai some people $k a^{0} \quad \mathrm{paj}^{3}$ falang $^{1}$ baang ${ }^{3} \mathrm{khon}^{2} \mathrm{ka}^{0} \quad \mathrm{paj}^{3} \mathrm{gaa}^{3} \mathrm{mê}^{2} \mathrm{e}^{\mathrm{l}} \mathrm{likaa^{3 }}$ FOC.PCL go France some people FOC.PCL go America 'Some people, they fled to Thailand, some people went to France, some people went to America.'

(234) baang ${ }^{3}$ bòòn khacaw $^{4}$ bò $^{0}$ kin $^{3}$ pèèng $-n u a^{2} n a^{o}$ some place 3PL NEG eat MSG PCL '(In) some places they don't eat MSG.' 
(235) pasaa son $^{2}$ kheej ${ }^{2}$ hêt pì $^{3}$ nùngl khang ${ }^{4}$ diaw $^{3}$ citizens ever do year one occasion single 'The people are accustomed to doing (it [i.e. harvesting rice]) a single time in one year.'

(236) $s i k^{2}$

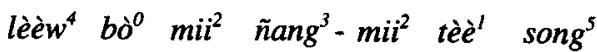
exit.monkhood PFV NEG have what have only pants to-nùng ${ }^{1}$ qee $e^{4}$ sùa $a^{5}$ to-nùng ${ }^{I}$ qee $^{4}$ CLF-one INTJ shirt CLF-one INTJ 'Having left the monkhood, (I) didn't have anything - (I) only had one pair of pants, yeah, and one shirt, yeah.'

Here are some text examples of sòong ${ }^{3}$ Two as a quantifier, appearing before the nominal it quantifies (the first example showing that the attached nominal is the classifier, if one is present):

(237) $q a w^{3}$ huup ${ }^{4}$ sò̀ng ${ }^{3} \quad b a j^{3}$ kap $^{2}$ ngen $^{2}$ take picture two CLF with money

'(I) take (along) two photographs, and money (to arrange a visa).'

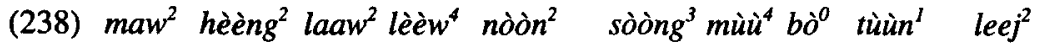
drunk strong 3SG PFV lie/sleep two day NEG awaken at.all 'And (he) was really drunk, and so he slept for two days, without waking up at all.'

Like $n i^{4}$ THIS, and $\operatorname{diaw}^{3} . \mathrm{kan}^{3}$ THE SAME, discussed above, neither nùng ${ }^{l}$ ONE nor sòòng ${ }^{3}$ Two can be used in Lao as "quasi-substantives". Expressions like mii. sòong ${ }^{3}$ 'There are two' are possible, but must have a contextually retrievable (i.e. given/accessible) referent for the thing being counted.

"Selective" expressions like 'two of these people' or 'one of these things' utilise the left position in a kind of topic-comment construction ( $\mathrm{Li} \&$ Thompson $1976,1981)$. A common use of the topic-comment construction involves a possessive relation, with the possessor in left (topic) position, and the possessed being the subject of the verb in the comment clause:

(239) phò̀ ${ }^{I} k h \grave{o ̀ j}{ }^{5} k h a a^{3} h a k^{2} \dagger$ father 1SG leg break 'My father's leg is broken.' (lit. '(Of) my father, the leg is broken.') 
The same structure forms a selective expression, where the full set (from which the subset will be selected) appears in left position, and the subset is specified immediately after, in preverbal subject position:

(240) khon ${ }^{2}$ (law $\left.{ }^{1}\right)$ nilt $^{4}$ sòòng $^{3}$ khon $^{2}$ jaak $^{5}$ vaw $^{4}$ qan-nùng ${ }^{1}$ kap $^{2}$ mùng $^{2}$ people (group) this two people want say something-one with 2SG 'Two of these people want to say something to you.' $\dagger$ (lit: '(Of) these people, two people want to say something to you.')

Note that the quantifiers nùng ${ }^{l}$ ONE and sòng ${ }^{3}$ TwO (as well as the determiner qùùn ${ }^{I}$ OTHER) can be easily combined with $n i^{4}$ THIS, with a maximal expansion 'NUMBER-THING/PERSON-OTHER-THIS':

(241) $k_{\text {hon }}^{2}$ qùùn ${ }^{1} \operatorname{nit}^{4}+$

people other this

'these other people'

(242) phu-qùùn ${ }^{1} \quad n i i^{4}+$ someone-other this

"this other "someone""

(243) sòòng ${ }^{3}$ qan-nii $i^{4} \dagger$

two thing-this

'these two things'

(244) sòòng ${ }^{3}$ khon $^{2}$ qùùn' nil̀ $^{4}$

two people other this

'these two other people'

\subsection{2 $\operatorname{la}^{3} j^{3} \mathrm{MUCH} / \mathrm{MANY}$}

The Lao exponent of MUCH/MANY is $\operatorname{laaj}^{3}$. It commonly functions as a regular quantifier, appearing before the nominal (usually the classifier) it quantifies, as in (245). However, it also may function as a regular verb 'to be much/many', as in (246).

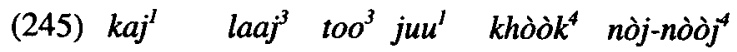
chicken many CLF be.at pen small-RDP 'Many chickens are in a small-ish pen.' 
(246) $j u u^{I} \quad n i i^{4} \quad k_{h o n^{2}} l a a j^{3} \dagger$

be.at here people many

'There are a lot of people here.' (Lit. 'Here, the people are many.')

Also, $\operatorname{laaj}^{3} \mathrm{MUCH} / \mathrm{MANY}$ may appear separated from the nominal it refers to, with an adverbial function, as follows:

(247) $\operatorname{man}^{2} \operatorname{mil}^{2} \quad q e \hat{n} n^{3} \quad j u u^{l} n i i^{4} \quad l a a j^{3} n a^{0}$

3SG have/there.is tendon be.at here much PCL

'It had lots of tendons there.' [i.e. on an old man's neck.]

Since $l a a j^{3}$ MUCH/MANY can have the properties of a verb, it may appear in noun phrases after the noun quantified, in a kind of adjectival function. For example, 'many people' may be expressed as either laaj $^{3}$ khon $^{2}$ 'many people' or $k{ }^{2}{ }^{2}{ }^{2} a a j^{3}$ 'people (which are) many'. (The latter could appear as a complete sentence meaning 'There are many people'.) Consider the contrast between $l a a j{ }^{3}$ MANY as an independent "adverbial" complement and as a nominal modifier:

(248)
(a) khon $^{2} \quad n i i^{4} \operatorname{vaw}^{4} \quad \operatorname{laaj}^{3}+$ people this say much 'This person spoke a lot.'

(b) khon $^{2} \mathrm{nil}^{4} \mathrm{vaw}^{4} \mathrm{laaj}^{3} \mathrm{qan}^{3} \dagger$ people this say many thing 'This person said many things.'

The adverbial function cannot arise when $l a a j^{3}$ comes before the nominal head.

There is apparently no real identifiable semantic distinction between laaj $^{3}$ as MUCH and $l a a j^{3}$ as MANY, and the difference in English translation seems to depend on the nature (or construal) of the nominal being quantified. Thus, a mass noun combination such as $\mathrm{khaw}^{5} \mathrm{laaj}^{3}$ [rice much/many] is translated as 'much rice' (or 'a lot of rice'), while a count noun combination such as lot $^{I}$ laaj $^{3}$ [vehicle much/many] is translated as 'many vehicles'. Nominals which are open to both mass and count interpretations may allow either translation, depending on the interpretation. For example, $\mathrm{kaj}^{\prime} \mathrm{laaj}^{3}$ [chicken much/many] could be translated as either 'many chickens' or 'much chicken' ('a lot of chicken').

One grammatical constraint which emerges from the inherent lexical class distinction between mass and count nouns involves the use of $l a a j^{3} \mathrm{MUCH} / \mathrm{MANY}$ in pre-nominal position, where it may only mean 'many (of a countable thing)'. Thus, the countable nominal $l o t$ ' 'vehicle' may take $l a a j{ }^{3}$ MUCH/MANY either pre- 
or post-nominally (but note that $(249 \mathrm{~b})$ is less idiomatic than $\operatorname{lot}^{1}$ laaj $^{3}$ khan $^{2}$ [vehicle many CLF] 'many vehicles'):

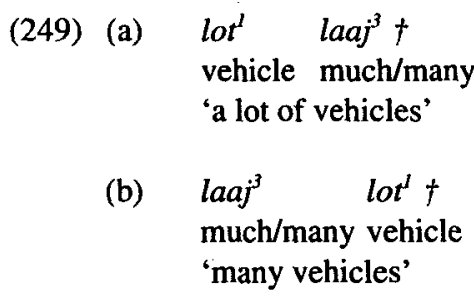

However, to express the idea of a large quantity of some non-countable mass, such as $k h a w^{5}$ 'rice', laaj $j^{3}$ MUCH/MANY may only be used post-nominally. If $l a a j^{3}$ MUCH/MANY were to appear pre-nominally with such a mass noun, the only possible reading would involve reconstrual of the mass noun as something countable, cf. English many rices, - i.e. 'many (kinds of) rice':

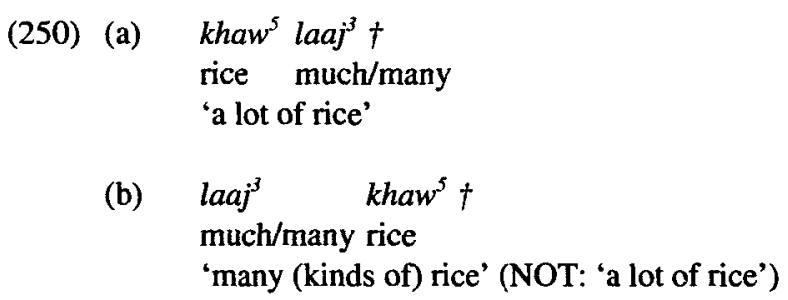

This behaviour does not demonstrate that $\mathrm{laaj}^{3}$ itself has multiple meanings, but rather appears to be due to inherent properties of different types of nominals (i.e. mass versus count).

\subsection{3 $m e t^{2}$ ALL}

The Lao exponent of ALL is $m e t^{2}$, which as an independent verb means 'run out, finished, exhausted, complete' as in (251). With the meaning ALL, met $^{2}$ often has an adverbial function, appearing after the verb phrase it has scope over, as in (252) and (253).

$$
\begin{aligned}
& \text { (251) } \text { hhaw }^{5} \text { met }^{2} \quad \text { lèèw } \\
& \text { rice exhausted PFV } \\
& \text { '(The) rice is all finished.' }
\end{aligned}
$$


(252) bò̀ $k^{5}$ nè-nam ${ }^{2} \mathrm{met}^{2}$

tell advise all

'(He) gave (them) all instructions.'

(253) $\mathrm{muu}^{\prime} \operatorname{taaj}^{3} \mathrm{met}^{2}$

peer die all

'All (his) peers died.'

To express notions like 'everything' and 'everyone', $m e t^{2}$ ALL appears with the nominals nang ${ }^{3}$ SOMETHING and $p h a j^{3}$ SOMEONE, but cannot be used as a specifier with the 'classifier' heads phu- SOMEONE and qan- THING:

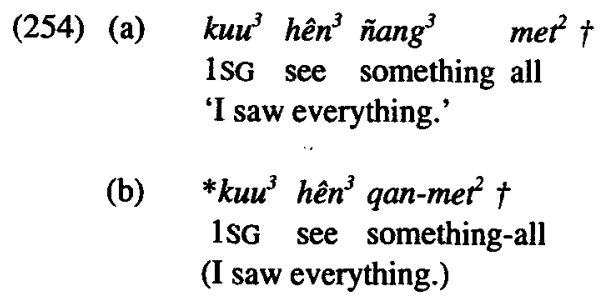

(255) (a) phaj met $^{2}$ huu qan-nil $^{4}+$ someone all know thing-this 'Everyone knows this.'

(b) *phu-met ${ }^{2} \quad h u u^{4} \quad q a n-n i i^{4}+$ someone-all know thing-this (Everyone knows this.)

Negation may be added to such a construction to give 'nobody' (i.e. not anybody). Note that this cannot be read as 'Not everyone knows this'.

(256) phaj $^{3} \quad \mathrm{met}^{2} b \dot{o}^{0} \quad h u u^{4}$ qan-nit ${ }^{4}$ someone all NEG know thing-this

'No-one knows this.' (i.e. 'Anyone doesn't know this.')

With negation, and an interrogative/indefinite pronoun like phaj ${ }^{3}$ SOMEONE, it is common to use the focus particle $k a^{\circ}$, which rules out an interrogative meaning and gives a reading 'nobody', as in (257). With neither met $^{2}$ ALL nor the focus particle $k a^{0}$, the combination of negation and the indefinite/interrogative pronoun phaj ${ }^{3}$ SOMEONE/WHO remains ambiguous as in (258). 
(257) $p h a j^{3} \quad k a^{0} \quad b o^{o} \quad h u u^{4} \quad q a n-n i^{4}+$ who FOC.PCL NEG know thing-this 'No-one knows this.'

(258) phaj $^{3} \quad$ bò $\grave{o}^{\circ} u^{4} \quad q a n-n i i^{4}+$ who NEG know thing-this i. 'No-one knows this.' ii. 'Who doesn't know this?'

\subsection{Evaluators}

The stative verbs $d i i^{3}$ GOOD and $b \grave{d} . d i i^{3}$ BAD may be used both attributively and predicatively, with nominal subjects, or even clausal subjects. Morphologically, the expression translated here as BAD looks on the surface like it should mean NOT GOOD - i.e. a combination of the negative marker $b \grave{o}^{\circ}$ and $d i i^{3}$ GOOD. However, there is no doubt that $b \grave{o} \cdot d i i^{3}$ does mean BAD rather than simply NOT GOOD. Proper negation of either GOOD or BAD involves not just the negative marker $b \grave{o}^{o}$ but a more complex expression $b \grave{o}^{0}$ mè̀n ${ }^{l}$ [NEG be.the.case]. Thus, $B A D$ and NOT GOOD may be contrasted as follows:

(259) qan-nii ${ }^{4}$ bò.dii ${ }^{3} \dagger$ thing-this bad 'This is bad.'

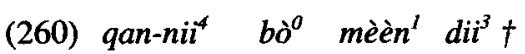
thing-this NEG be good 'This is not good.'

The idea 'this is not good', as expressed in (260), contradicts 'this is good', but since NOT GOOD does not entail BAD, it does not contradict 'this is not bad':

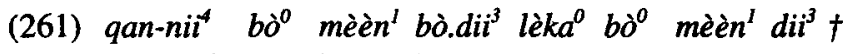
thing-this NEG be bad and NEG be good 'This is not bad, and not good.'

The copula mè̀n ${ }^{l}$ 'be the case' is obligatory in genuine negation of either GOOD or BAD, as illustrated by the following ungrammatical attempt to paraphrase example (261): 


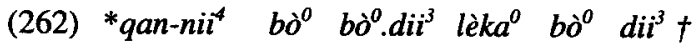
thing-this NEG bad and NEG good (This is not bad, and not good.)

The first two of the following examples show $d i i^{3}$ GOOD and $b \grave{d} . d i i^{3}$ BAD as attributives. The second two show them as predicatives.

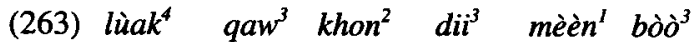
choose take people good be.so PCL.Q '(They) select good people, right?'

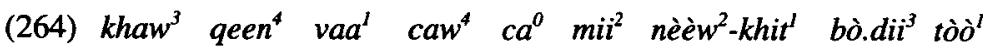
3PL call COMP 2SG IRR have way-think bad connect - tòò $\grave{o}^{l} \quad$ saat ${ }^{4} \cdot \grave{e} e ̀ w^{4}$ connect nation PFV

'They'd say you would have a bad attitude towards - towards the nation.'

(265) phèèn ${ }^{I}-\operatorname{din}^{3} d i i^{3}-$ puuk $^{5}$ long $^{2}$ daj phon $^{3}$ earth/land good plant descend receive reward '(If) the soil is good, (you) plant things, and get rewards.'

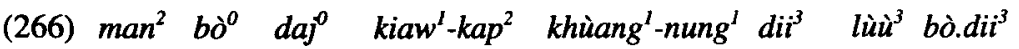
3SG NEG ACHV about stuff-wear good or bad mèèn ${ }^{l} \quad b \grave{o} \grave{o}^{3}$ be.so PCL.Q

'It's got nothing to do with (whether your) clothes are good or bad, right?'

Another common function of $d i i^{3} \mathrm{GOOD}$ and $b \dot{\partial} . d i i^{3} \mathrm{BAD}$ is adverbial. The following example contains three instances of $d i i^{3}$ GOOD, two of which are adverbial (the second is attributive):

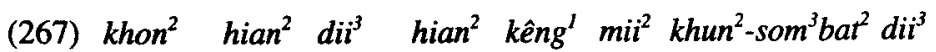
people study good study adept have attributes good qòòk hèèng ${ }^{2}$-ngaan ${ }^{2}{d i i^{3}}^{3}$

exit strength-work good

'someone who studies well, studies adeptly, has good attributes, and works well'

It is common for $\mathrm{dii}^{3}$ GOOD to have an inchoative reading 'become good' (i.e. 'good-en'), and more specifically of an ill person or a disease to 'get better': 
(268) qòò $k^{5}$ phansaa $^{3} \quad l \grave{e ̀ w^{4}} d i i^{3}$, phañaat nan $^{4}$ exit rainy.season $\mathrm{PFV}$ good illness that 'Once the rainy season was over, (it) came good, that illness.'

One important use of GOOD in NSM formulas is as a kind of clausal evaluative 'It is good/bad if/that $p$ '. A common idiomatic structure along these lines in Lao involves combination of $d i i^{3}$ GOOD and $t \grave{e} \grave{e}^{l}$ 'only', with a clausal complement $p$, giving a meaning 'It's (at least) good that $p$ ':

(269) $d \ddot{i l}^{3}$ tè̀ $\grave{m a n}^{2} b \grave{o}^{o} k h a a^{5} h a w^{2}$ good only 3PL NEG kill 1PL 'It's (at least) good that they didn't kill us.'

However, this seems to contain more in its semantics than a mere 'It is good that...', and furthermore bò.dii ${ }^{3}$ BAD cannot be used in this frame. Less idiomatic, but more along the lines of the required NSM "clausal evaluative" expression is the following structure, in which the clause being evaluated (by $\mathrm{dit}^{3} \mathrm{GOOD}$ or bo.dii ${ }^{3} \mathrm{BAD}$ ) is in the left (topic) position, and the evaluative predicate is the comment:

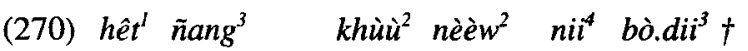
do something like manner this bad 'It is bad to do something like this.'

It seems to me, however, that this kind of construction may not be the clearest way to express this idea, and may not be necessary for NSM formulas anyway. Perhaps the idea expressed in (270) would be better put as follows:

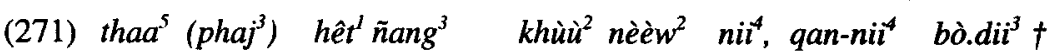
if someone do something like manner this thing-this bad 'If someone does something like this, this (thing) is bad.'

It is possible in Lao to differentiate between something GOOD or BAD happening to a person (for undergoers of HAPPEN and DO), and something (an event or state of affairs) being GOOD or BAD for a person. In the former case, the undergoer is marked with kap $^{2}$ 'with' (as described in section 3.3.4 above on hêt ${ }^{\prime}$ DO and keet ${ }^{5} . k h u ̀ n^{5}$ HAPPEN), while the connector samlap ${ }^{2}$ 'for, in order to' is used in the latter case, as shown in the following examples: 
(272) man $^{2}$ hêt $t^{\prime}$ qan-nùng ${ }^{l} d i i^{3} \quad$ samlap $^{2}$ mùng ${ }^{2}$ diaw $^{3} . n i i^{4}+$ 3SG do something-one good for 2SG now 'S/he is doing something good for you now.'

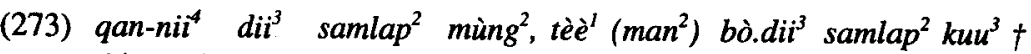
thing-this good for 2SG but (it) bad for 1SG 'This (thing) is good for you, but it's bad for me.'

\subsection{Descriptors}

As stative/adjectical verbs, $\tilde{n} a j^{l}$ BIG and $n \grave{o} j^{4}$ SMALL display the same attributive and predicative behaviour as $d i i^{3}$ GOOD and $b \grave{o} . d i i^{3} \mathrm{BAD}$, above:

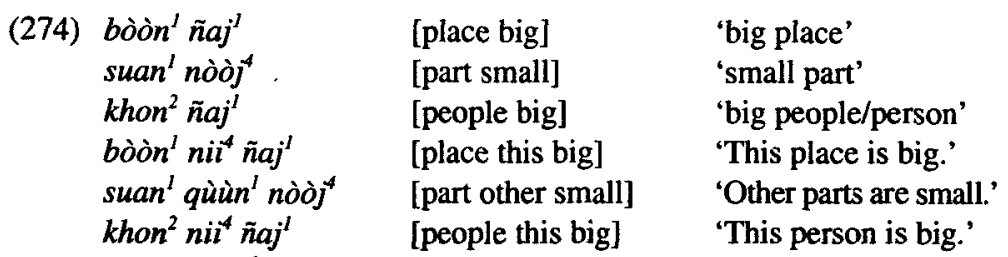

There may be specific restrictions in the NSM system on what can be modified by BIG and SMALL. For example, while we can use BIG and SMALL with PART, we cannot say *'big time' or *'small time'. Note also that unlike GOOD/BAD, predicative BIG/SMALL cannot take a 'clausal subject' (i.e. it makes no sense to say 'It is big for you to do this'). (275) gives examples of $\tilde{n} a j^{l}$ BIG and nòo $\jmath^{4}$ SMALL as attributives. (276) shows $\tilde{n} a j^{l}$ BIG as a predicative element:

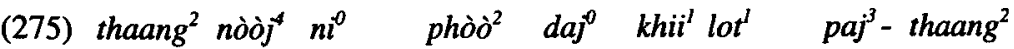
road small TPC.PCL enough ACHV ride vehicle go road $\tilde{n} a j^{l} p a j^{3} \quad b \grave{o}^{0} d a j^{4}-j a a n^{4}$

big go NEG can afraid

'Small roads are right for me to ride (my) bicycle on - big roads (I) can't go (on) - (I'm) scared.'

(276) $k h a n^{2} k_{a j}{ }^{I} \quad \tilde{n} a j^{I} l a a j^{3} l e ̀ e w^{4} h a w^{2} k a^{0} \quad k h a a j^{3}$ qòòk ledêê if chicken big very PFV 1PL FOC.PCL sell exit PCL 'If the chickens are already very big, then we sell them off.'

The contrast between adults and children often makes reference to BIG and SMALL: 
(277) $q a w^{3}$ ngua $a^{2}$ nò̀j to-nùng ${ }^{4}$ take cattle small CLF-one '(We) took one calf.'

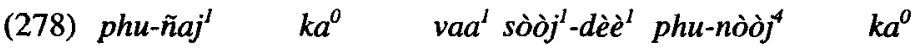
someone-big FOC.PCL say help-PCL someone-small FOC.PCL $v a a^{I} \quad s \grave{o ̀ j}{ }^{l}-d \grave{e} \grave{e}^{I}$ say help-PCL

'The adults were saying "Help!", the children were saying "Help!"”

The following examples show that $\tilde{n} a j^{I}$ BIG and nòoj $j^{4}$ SMALL can have nonphysical readings, referring to status, extent, or importance. These do not appear to be "extensions" from the physical meanings of BIG and SMALL, but are apparently part of the natural semantic range of these concepts.

(279) $\mathrm{paj}^{3}$ beng ${ }^{1}$ hua ${ }^{3}-n a a^{5} \tilde{n a j} j^{I} \mathrm{ka}^{0} \quad \operatorname{san}^{1} j \mathrm{ju}^{0}$ go look head-face big FOC.PCL shake PCL thùk $k^{l}$-thùk $k^{I}$-thùk $k^{l}$-thùk ${ }^{\prime} \quad k h a j{ }^{j}$ onm-onm-onm-onm fever

'Go and look at (our) big boss, he's shaking thùk-thùk-thùk-thùk with fever.'

(280) phit $^{2}$ kan $^{3}$ jaang $^{1} \tilde{n a j}{ }^{l} \mathrm{kap}^{2} \mathrm{cêk}^{2}$ wrong RCP way big with Chinaman '(He) had a big disagreement with the Chinaman.'

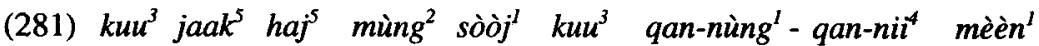
1SG want give 2SG help 1SG thing-one thing-this be lùangl nòòj sù-sùŭ $^{4} \dagger$ matter small that's.all 'I want you to help me (with) something - this thing is just a small matter.'

\subsection{Time}

\subsection{1 $\operatorname{tò̀n~}^{3}$ TIME/WHEN, diaw $^{3} \cdot$ nil $^{4}$ NOW}

The Lao exponent for TIME is $t \grave{o ̀ n} \mathbf{n}^{3}$. Another common term with similar meaning and usage (although less versatile, and stylistically less basic) is vêlaa (of Sanskritic origin). Tòòn $n^{3}$ TIME may combine with any verbal predicate in NSM formulas. 
Temporal adjuncts using $t \grave{o} o n^{3}$ TIME/WHEN are usually placed before the clause they mark, essentially in the topic position, as in (282). (See Haiman 1985:39ff for a detailed discussion of the expression of subordinate semantic relations through syntactic coordination.) They may also appear either finally or medially, as in the subsequent two examples.

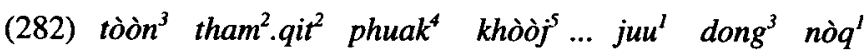
time at.first group 1SG be.at forest PCL

'At first, we were living in the forest, right?'

(283) tamluat $^{5} \quad b^{0} \quad \operatorname{than}^{2} \quad d a j^{0} \quad$ maa $^{2}$ tòòn ${ }^{3}$ nan $^{4}$ police NEG yet ACHV come time that 'The police had not yet arrived, (at) that time.'

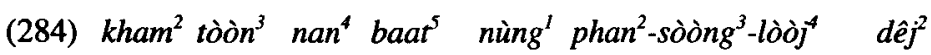
gold time that $15^{1} / 2 \mathrm{~g}$ one thousand-two-hundred PCL 'Gold at that time was 1200 per baht, you know.'

Tòo $n^{3}$ TIME may be used to link two clauses. Usually the first clause is marked, as in the first two examples below; but occasionally, as shown in the third example, it is the second clause which is marked by $t \grave{\partial} \dot{n}^{3}$ TIME/WHEN:

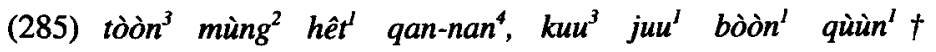
time 2SG do thing-that $1 \mathrm{SG}$ be.at place other 'When you did that, I was in another place.'

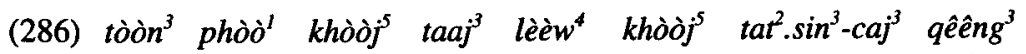
time father 1SG die PFV 1SG decide-heart self $k h \grave{o} \dot{j}^{5} \quad p a j^{3} \quad$ mùang ${ }^{2}-t h a j^{2}$ 1SG go country-Thai

'When my father was dead, I decided myself (that) I'd go to Thailand.'

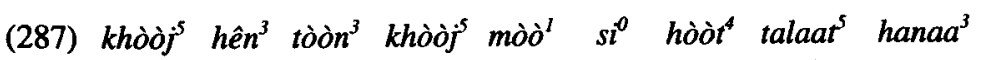
1SG see when 1SG almost IRR reach market PCL 'I saw (it) when I had almost reached the market.'

Tòòn ${ }^{3}$ TIME/WHEN may also appear as a substantive nominal head referring to a period of time, an era, or a period of the day ('morning', 'afternoon', 'evening'): 


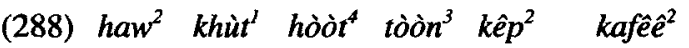
1SG think reach time harvest coffee 'I miss the time (I was) harvesting coffee.'

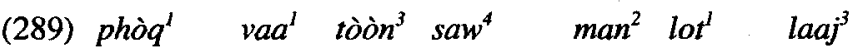
because COMP time morning 3PL vehicle many 'Because in the morning there are lots of vehicles (on the road).'

"Occurrence time" - i.e. countable 'times' as in 'John sneezed three times' does not use tòòn ${ }^{3}$, but thùa ${ }^{I}$ 'instance', as follows:

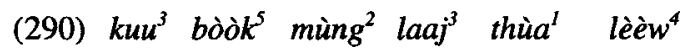
1SG tell 2SG many instance PFV '(I've) told (you) many times aready.'

NOw is expressed by $d i a w^{3} \cdot n i i^{4}$, which morphologically includes diaw 'single/lone/same' and nit $i^{4}$ THIS. However, semantically, it is not a combination of these two. It appears clause-initially or clause-finally, although the former is preferred, cf. (266) and (386).

(291) diaw $\cdot n i i^{4} \tilde{n} a n g^{2} p e ̂ n^{3} h i i n^{3}$ now still be stone 'Now, (that snake) is still stone.'

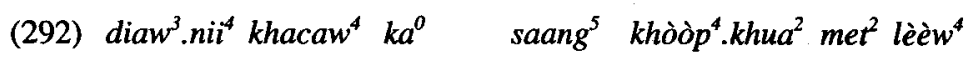
now 3PL FOC.PCL build family all PFV 'Now they have all got families.'

\subsection{2 lang $^{3}$. caak $^{5}$ AFTER, kòòn ${ }^{i}$ BEFORE}

Both kòòn BEFORE and lang $^{3} \cdot$ caak $^{5}$ AFTER function to locate two clauses in time relative to each other, and it is usually the first clause that is marked:

(293) kòòn $\mathrm{ca}^{0}$ qè̀m ${ }^{4} \quad c a^{0} \tilde{n} a n g^{3} \quad$ haw $^{2} \quad \tilde{n} a n g^{2}$ daj $^{0}$ before IRR put.on.walling IRR something IPL still must hêt ${ }^{\prime}$ han $^{4}$ haj $^{5}$ man $^{2}$

make platform give $3 \mathrm{SG}$

'Before we put the walls on and whatever, we still must make them some platforms.' 
(294) lang $^{3} \cdot$ caak $^{5}$ qaw $^{3}$ saw $^{3}$ fang $^{3}$ lèèw haw $^{2} k^{0} \quad$ tòo $k^{5} k_{h a a n g}{ }^{3}$ after take post bury PFV 1PL FOC.PCL nail crossbeam 'After we plant the posts, then we nail on the crossbeams.'

In the following example, $k \grave{o} o n^{1}$ BEFORE takes a nominal complement khaw ${ }^{3}$ '3PL', but I presume this is elliptical (as indicated by the translation):

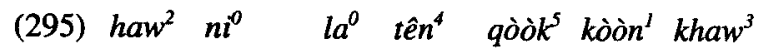

1SG TPC.PCL, PCL jump exit before 3PL

'I jumped out (of the boat) before they (did).'

In the next examples, $k \grave{o o ̀ n}{ }^{l}$ BEFORE is used adverbially (i.e. without an overt complement), and corresponds to English 'first':

(296) haw $^{2} \quad \mathrm{ka}^{0} \quad$ beng $^{1} \mathrm{juu}^{1} \ldots \mathrm{khaw}^{3}$ qaw $^{3}$ nang ${ }^{3}$ kòòn

1SG FOC.PCL look be.at 3PL take what before

'I was watching (them) - (to see) what would they take first.'

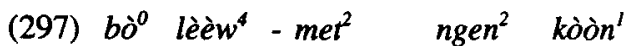

NEG finish exhausted money before

'(It's) not finished - (I) ran out of money first.'

A similar adverbial function is observed for AFTER, but in Lao this does not involve lang $^{3}$.caak ${ }^{5}$. Rather, for the adverbial sense of AFTER, where no overt complement appears, Lao speakers use a different construction nam $^{2}$-lang ${ }^{3}$, literally 'going after the back of'.

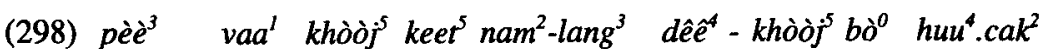
translate COMP 1SG born go.after-back PCL 1SG NEG know 'I mean, I was born afterwards - I don't know (about that).'

$K \grave{\partial} \partial n^{3}$ BEFORE and $l a n g^{3} . c a a k^{5}$ AFTER can be used freely with temporal

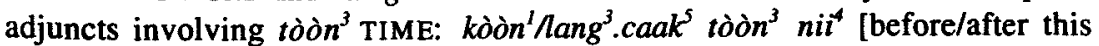
time] 'before/after this time'. Expression of 'before now' or 'after now' are

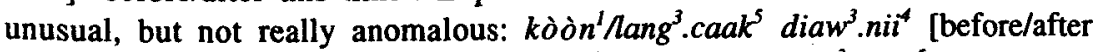
now] 'before/after now'. In narratives, kò̀n ${ }^{l}$ BEFORE and lang ${ }^{3}$. caak $^{5}$ AFTER have no entailments as to any relationships other than temporal ones (such as causal or conditional) between events. 
3.11.3 don ${ }^{3}$ A LONG TIME, $b \grave{o}^{0}-d o n^{3}$ [?] A SHORT TIME, $l a j^{2} . \tilde{n} a q^{l} n u ̀ n g^{l}$ FOR SOME TIME A LONG TIME is expressed in Lao by an adverbial element ${d n^{3}}^{3}$ :

(299) laaw $w^{2}$ nang $^{1}$ juu $^{l}$ don $^{3} \quad l \grave{e ̀ s} w^{4}$ 3SG sit be.at long.time PFV 'He had sat there for a long time already.'

(300) $s a j^{4}$ vêlaa ${ }^{2}$ vêlaa $a^{2} d o n^{3} \quad$ dêj $^{2}$ cùng ${ }^{1} d a j^{0} k \hat{e} p^{2}$ use time time long.time PCL so ACHV collect 'It takes time - a long time, you know, until you can harvest (them).'

Another word for A LONG TIME heng $^{3}$ does not seem to differ semantically from $d o n^{3}$, but is more common in Southern dialects of Lao:

(301) huaj suu $^{3}$ phat $^{1} \mathrm{maa}^{2}$ heng $^{3}$ paan ${ }^{3}-d a j^{3} \quad n i^{0}$ INTJ 2PL PCL come long.time extent-which PCL 'Well! How long have you been here?!'

To say 'I did it for a long time', it is sufficient to simply add $d o n^{3}$ A LONG TIME to the sentence 'I did (it)', as in (302). However, when the main predication is more bulky, a complex construction pên ${ }^{3}$ velaa ${ }^{2}$ don $^{3}$ [be time long.time] is required (note that the other 'time' expression tòòn ${ }^{3}$ does not occur here):

(302) $k u u^{3} h e t^{l} d o n^{3} \dagger$

1 sG do a.long.time

'I did (it) for a long time.'

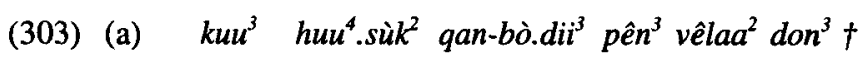
ISG feel thing-bad be time a long time 'I felt something bad for a long time.'

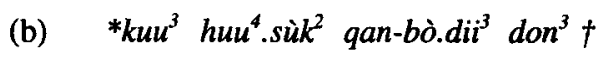
1sG feel thing-bad a long time (I felt something bad for a long time.)

For 'I did it a long time ago', the perfective marker lèèw' may be added, as in (304). It is not really clear, however, that this pattern properly distinguishes 'did (it) for a long time' from 'did (it) a long time ago'. (304) could also be construed to mean 'I have been doing (it) for a long time' (i.e. since a long time ago). It is 
not clear whether the two meanings can be clearly separated. The solution may be associated with a more general solution to problems of verb aspect in Lao.

$$
\begin{aligned}
& \text { (304) } k u u^{3} \text { hêt' } \text { don }^{3} \text { lèèw }{ }^{4}+ \\
& \text { ISG do a.long.time PFV } \\
& \text { 'I did (it) a long time ago.' }
\end{aligned}
$$

The notion A SHORT TIME is most idiomatically rendered as $b \grave{o}^{\circ}-d o n^{3}$ 'not a long time', but may also be expressed using $p e \hat{n} n^{3} v e ̂ l a a^{2} \operatorname{san}^{5}$ [be time short] 'for a short time' (although this construction is only limited to delineating duration of some ongoing event, cf. (308) below):

(305) khon ${ }^{2} \quad n i^{4} \quad v a w^{4} b \grave{o}^{0} \quad d o n^{3} \dagger$ people this say NEG a.long.time 'This person didn't talk for a long time.'

(306) khon ${ }^{2}$ nit $^{4}$ vaw $^{4}$ pên $^{3}$ vêlaa $\operatorname{san}^{5}+$ people this say be time short 'This person spoke for a short time.'

Future reference, 'in a short/long time' (i.e. a short/long time after now), is relatively straightforward, involving the temporal expression in combination with the augmentor qiik' 'more, another':

$$
\begin{aligned}
& \text { (307) } \text { qiik }^{5} \text { don }^{3}, \quad q a n-n i i^{4} \quad \mathrm{ca}^{0} \text { keet }^{5} . \mathrm{khùn}^{5}+ \\
& \text { more/another long.time thing-this IRR happen } \\
& \text { 'In a long time, this thing will happen.' }
\end{aligned}
$$

The expression $p \hat{e} n^{3} v e ̂ l a a^{2} \operatorname{san}^{5}$ 'for a short time' cannot be used in an expression like this, throwing further doubt on its status as the putative prime, though $b \dot{o}^{0}-d o n^{3}$ 'NEG-long.time' may be used just as easily here:

$$
\begin{aligned}
& { }^{*} q i i k^{5}\left(p e n^{3}\right) v \hat{e l a a^{2}} s a n^{5} q a n-n i i^{4} c a^{0} k e e t^{5}-k h u ̀ n^{5}+ \\
& \text { more/another be time short thing-this IRR happen } \\
& \text { ('In a short time, this thing will happen.') }
\end{aligned}
$$

(309) qiik

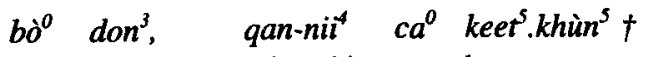
more/another NEG long.time thing-this IRR happen 'In not a long time, this thing will happen.' 
Thus, it is unclear as to how A SHORT TIME is best expressed. Vêlaa ${ }^{2} \operatorname{san}^{5}$ seems to do the job, but cannot be used in expressions referring to 'a short time in the future'.

Finally, we may note a further durational expression useful in NSM formulas, namely FOR SOME TIME (neutral as to whether the time period is long or short).

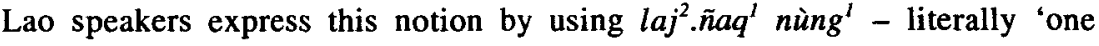
time.period' - as an adverbial:

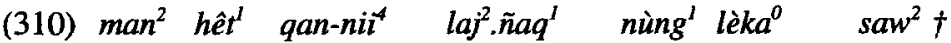 3SG do thing-this time.period one CLS.LNK cease 'S/he did this for some time, and then stopped.'

\subsection{4 bùt' ${ }^{2}$ nùng ${ }^{I}$ MOMENT}

It has recently been suggested that the NSM inventory of universal and indefinable concepts should include MOMENT. This notion does not equate to 'a short time' in which things may happen, but literally to a point in time at which things may happen. While the NSM system already includes TIME - in expressions like 'It happened at this time', 'He did this at the same time' - this is a rather elastic notion which may refer to periods of time rather than to points in time. However, it appears that the notion of a non-extended "point in time" is necessary in the analysis of some aspects of verb semantics. Those who have set up verb class categories based on logical and aspectual distinctions (e.g. Vendler 1967, Dowty 1979, Foley and Van Valin 1984) have shown that the notion of momentary change of state is an important semantic feature of certain classes of verbs (e.g. among "achievement" verbs such as realise). There are other phenomena involving aspect, such as the lexical classes of aspect in Slavic languages (cf. Wierzbicka, this volume, section 2.8), as well as the semantics of particular aspectual markers (especially perfective), which apparently include a notion MOMENT as opposed to TIME. Expressions such as 'suddenly' and 'just now' also seem to demand this notion. Consider, for example, the idiomatic Lao portmanteau vang. $\mathrm{kil}^{4} \mathrm{nil}^{4}$ 'just a moment ago', in (311). Another example is the coordinative expression involving joined clauses each marked by pap 'immediately', as in (312).

(311) $k u u^{3} h e n^{3}$ phu-nan ${ }^{4} \quad$ vang.kii nit $^{4}+$ 1SG see someone-that 'just a moment ago' 'I saw that person just a moment ago.' 


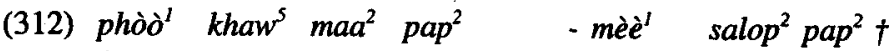
father enter come immediately mother faint immediately 'Right when father came in - mother fainted right then.'

It would be expected that MOMENT should be able to combine at least with the determiner THIS, as in the following rendition of (312) using bùt ${ }^{2}$ MOMENT (also allowing an alternative form $b a t^{2}$, related to $b a a t^{5}$ 'occasion'):

(313) phòò khaw $^{5}$ maa $^{2}-n a j^{2} b \grave{u} t^{2}-n i i^{4} \quad m \grave{e} \grave{e}^{l} \quad s a l o p^{2} \dagger$ father enter come in moment-this mother faint 'Father came in - at this moment, mother fainted.'

It may also be possible in NSM syntax to use MOMENT in combination with the relative temporal elements BEFORE and AFTER:

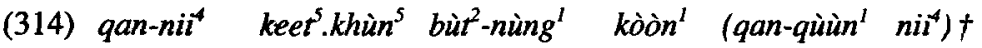
thing-this happen moment-one before thing-other this 'This thing happened (at) a moment before (this other thing).'

(315) bùt ${ }^{2}$-nùng ${ }^{1} \quad$ lang $^{3} \cdot$ caak $^{5}$ qan-nii ${ }^{4}$ keet $^{5}$. khùn $^{5}$, khon $^{2} \quad n i i^{4}$ taaj $^{3} \dagger$ moment-one after thing-this happen person this die 'A moment after this thing happened, this person died'

It is unclear whether a wider range of expressions involving MOMENT, e.g. 'at the same moment', are possible.

\subsection{Space}

\subsection{1 bòòn ${ }^{1}$ PLACE and $p h i i^{4}$ HERE}

Bòòn' '(IN A) PLACE' may be used to locate events and actions, speech, and 'seeing'. (Other cognitive predicates such as KNOW, WANT, THINK, and probably FEEL do not seem inherently locatable in a PLACE; cf. section 3.3.2.) In NSM expressions, bòòn ${ }^{l}$ PLACE appears either in a clause adjunct, as a core clausal element, or as a topic, as in the following examples, respectively.

(316) $k u u^{3} h e t^{\prime}$ juu $u^{l}$ bòòn' diaw'.kan ${ }^{3} \dagger$

1SG do be.at place same

'I did it at the same place.' 
(317) tòòn ${ }^{3} \mathrm{nan}^{4} \mathrm{kuu}^{3}$ juul bò̀n ${ }^{l}$ qùùn ${ }^{l}+$ time that 1SG be.at place other

'(At) that time, I was at another place.'

(318) (juu ) bòòn ${ }^{l} n i i^{4}$ mii $^{2}$ sòòng ${ }^{3}$ khon $^{2}+$ be.at place this there.is two people 'In this place, there are two people.'

Other examples of bòòn ${ }^{l}$ PLACE as nominal head can be found at (234) and (324a). It is also common as a relative clause head, '(the place) where $p$ ':

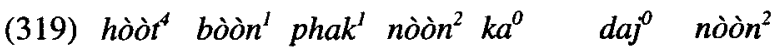
reach place rest sleep FOC.PCL ACHV sleep '(When he'd) reach somewhere to rest and sleep, then (he'd) sleep.'

The non-specific/interrogative marker $-d a j^{3}$ 'any/which/whichever' is commonly added to bòòn ${ }^{l}$ for expressions such as 'where', 'where?', 'anywhere' or 'wherever', as in (320) and (321). But the same meanings are more commonly expressed using $\mathrm{saj}^{3}$ ' where', as in (322) and (323).

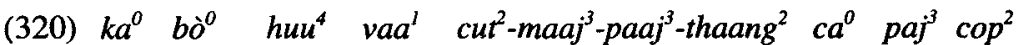
IRR NEG know COMP point-aim-end-way IRR go finish juul ${ }^{l} \quad b \grave{o ̀ n}{ }^{l}-d a j^{3}$ be.at place-which

'(I) didn't know where the eventual destination (of my life) would end up.'

(321) mùng ${ }^{2} i^{0}$ paj bòòn daj $^{3}+$ 2SG IRR go place which 'Where are you going?'

(322) $\mathrm{ca}^{0} \mathrm{saw}^{2} \mathrm{juu}^{l} \mathrm{saj}{ }^{3}-h e q^{l}-\mathrm{ca}^{0} \mathrm{saw}^{2} \mathrm{juu}^{l} \mathrm{vang}^{2}$-viang ${ }^{2}$ IRR stop be.at where INTJ IRR stop be.at V. 'Where will (we) stop? Hmm! We'll stop at Vang Vieng.'

(323) $j u u^{I} \quad s a j^{3} \quad k a^{0} \quad b \dot{o}^{0} \quad h e \hat{n} n^{3}$ be.at where FOC.PCL NEG see

'(They) couldn't see (them) anywhere.'

Thus, $s a j^{3}$ PLACE(/WHERE) is in the same relation to bò̀ $n^{l}$ PLACE as $\tilde{n} a n g^{3}$ SOMETHING/WHAT and $p h a j^{3}$ SOMEONE/WHO are to qan-THING and phuSOMEONE, respectively. 
HERE is unequivocally expressed in Lao by $p h i i^{4}$, although $b \grave{o ̀ n} n^{1} n i i^{4}$ [place this] THIS PLACE often effectively means the same (due simply to the default deictic reference of 'this' being the location of the speech event). However, bòòn ${ }^{l} n i i^{4}$ THIS PLACE may also function (unlike phit HERE) anaphorically, referring to some place previously mentioned in the discourse. Text examples of phii ${ }^{4}$ HERE can be found at (212) and (215).

The following examples show that $p h i i^{4}$ HERE - unlike $b \partial \partial n^{I} n i i^{4}$ [place this] THIS PLACE - cannot appear as the complement of $\mathrm{paj}^{3}$ ' $\mathrm{go}$ ':

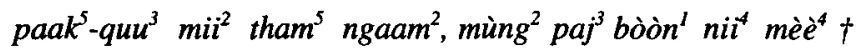

$$
\begin{aligned}
& \text { P. have cave lovely 2SG go place this PCL } \\
& \text { 'Paak-Ou has lovely caves, you should go there (to this place).' }
\end{aligned}
$$

(b) ${ }^{*}$ paak ${ }^{5}-q u u^{3}$ mii $^{2} \quad$ tham $^{5}$ ngaam $^{2}$, mùng $^{2}$ paj $^{3}$ phil $^{4}$ mè̀ $\grave{4}^{4}$ P. there.is cave lovely 2SG go here PCL

(Paak-Ou has lovely caves, you should go here.)

Further, as noted earlier, $n i i^{4}$ THIS alone can also mean 'here' in certain contexts (specifically, as complement of $j u u^{l}$ 'be at' or $\mathrm{maa}^{2}$ 'come').

It is worth noting that the concepts HERE and NOW are apparently more restricted syntactically in the NSM system than the sometimes equivalent complex expressions THIS PLACE and THIS TIME.

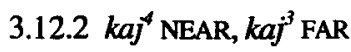

The Lao exponents for NEAR and FAR are verbs $k a j^{4}$ and $k a j^{3}$, respectively. These are most generally used as formally transitive verbs, as follows:

(325) $k a j^{4} b o^{\circ} \quad d a j^{4}$ near NEG can '(You) can't (come) near (him).'

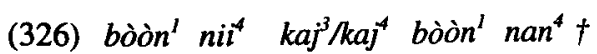
place this far/near place that 'This place is far (from)/near (to) that place.'

In the case of $\mathrm{kaj}^{3}$ FAR (but never with $\mathrm{kaj}^{4}$ NEAR), the object may be marked by caak $^{5}$ 'from': 


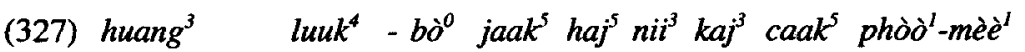
protective.of children NEG want let flee far from father-mother '(They're) protective of (their) children - (they) don't want to let (them) go far from (their) parents.'

(328) baan khòoj $j^{5}$ man $^{2}$ haangl $\mathrm{kaj}^{3} \mathrm{caak}^{5}$ viang ${ }^{2} \cdot \mathrm{can}^{3}$ pamaan $^{3}$ home 1SG 3SG separated far from V. approx. cêt $t^{2}-\operatorname{sip}^{2} \quad k u a^{l} \quad k i l o o^{2}$ seven-ten more.than $\mathrm{km}$ 'My home is far from Vientiane, approximately over 70 kilometres.'

An alternative is to use $k a p^{2}$ 'with' to mark the object, and this appears with either $k a j^{3}$ FAR or $k a j^{4}$ NEAR (as in (329)). A further alternative is for $k a p^{2}$ 'with' to link the two locations, with $\mathrm{kaj}^{3} / \mathrm{kaj}^{4} \mathrm{FAR} / \mathrm{NEAR}$ appearing as a main predicate combined with the reciprocal particle $\mathrm{kan}^{3}$ 'together' (along the lines of 'A and B are near/far from each other'), as in (330).

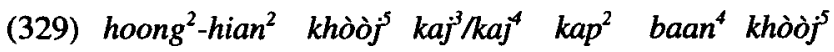
school 1SG far/near with home 1SG 'My school was far from my home.'

(330) hoong ${ }^{2}-\operatorname{hian}^{2} k h \grave{o ̀ j}{ }^{5} \mathrm{kap}^{2} \mathrm{baan}^{4} \mathrm{khòjj}^{5} \mathrm{kaj}^{3} / \mathrm{kaj}^{4} \mathrm{kan}^{3} \dagger$ school 1SG with home 1SG far/near RCP 'My school and my home were far (from)/near (to) each other.'

In the next two examples, $\mathrm{kaj}^{3}$ FAR is used as an intransitive predication and as an attributive verb/adjective, respectively. $\mathrm{KaJ}^{4} \mathrm{NEAR}$ shows the same behaviour:

(331) hùan ${ }^{2}$ phen $^{1} k a j^{3}$ dêj house 3HON far PCL

'His house was far (away), you know.'

(332) phùan' sahaaj ${ }^{3}$ thaang ${ }^{2} \mathrm{kaj}^{3}$ friend comrade way far 'comrades (from) afar'

An adverbial function is illustrated in the following example, in which $\mathrm{kaj}^{3}$ FAR appears following the verb-phrase without a complement. Again, kaj NEAR shows the same behaviour: 


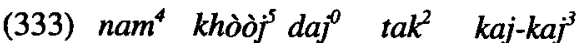
water 1SG ACHV scoop far-RDP 'Water, I had to collect (from) far (away).'

Used with no explicit reference to any entity or location of comparison, $\mathrm{kaj}^{3}$ FAR and $k^{4} j^{4}$ NEAR are generally elliptical for 'far from here' or 'near to here', or some understood place (unless some point of reference is already contextually given):

(334) sùang ${ }^{I} \quad b \grave{o}^{0} d a j^{0} \quad k a j^{3} \quad d e \hat{j}{ }^{2} \quad n i^{0}$ conceal NEG ACHV far PCL PCL '(He) concealed (it) not far (away).'

(335) khon $^{2} \operatorname{nan}^{4}\left(j u u^{l}\right) k a j^{4} / \mathrm{kaj}^{3} \dagger$ people that be.at near/far 'That person is near (to here)/ far (from here).'

There are naturally some non-physical uses of these two words. In the next example, the speaker is terrified that he will be selected to compete in a baldhead butting contest, and uses $k a j^{3}$ FAR to express the idea of being 'unqualified' or 'incapable', in the sense of being 'far from' what is required. In the second example, kaj' NEAR is used in the 'temporal domain'.

(336) qoj khanòòj hè̀̀ng ${ }^{4} \quad k a j^{3}$ lèèw $v a-s a n^{4}$ INTJ 1SG especially far PFV say-thus "'Oh, I'm very far from it!", he said.'

(337) $k a j-k a j^{4} \quad s i^{0}$ hòot fang nan $^{4}$ nan $^{0} \quad \mathrm{ka}^{0} \mathrm{lom}^{4} \quad h \grave{u} a^{2} \mathrm{kan}^{3} \mathrm{saa}^{2}$ close-RDP IRR reach bank that TPC.PCL IRR tip.over boat RCP PCL '(When they're) nearly at that bank, then (they'd) tip over the boat.'

\subsection{3 lum $^{\prime}$ BELOW, theng ${ }^{2}$ ABOVE}

The other pair of relational/spatial concepts $l u m^{1}$ BELOW and $t$ theng ${ }^{2}$ ABOVE may be used to locate things, people, and places. These are nominals which may appear on their own, or may be used in combination with some other directional or locative head such as thaang 'direction, way', as in the following examples: 
(338) thaang ${ }^{2}$ lum $^{1} \quad \mathrm{ka}^{0} \quad$ têm $^{3}$ theng $\mathrm{ka}^{2} \quad \mathrm{têm}^{3}$ direction below FOC.PCL full above FOC.PCL full 'The below (storey of the house) was full (of people), the above (storey of the house) was full (of people).'

(339) tat $^{2}$ thaang ${ }^{2}$ theng $\mathrm{ka}^{0} \quad k h u q^{2}-a a^{4}$ long $^{2}$ thaang lum $^{1} \mathrm{nit}^{4}$ cut direction above IRR EXPR descend direction below here '(When they) cut (the fruit) above, (it) went khu-aa, down here to below.'

The next examples show theng ${ }^{2}$ ABOVE and lum $^{l}$ BELOW used as relational predicates, in combination with the locative verb juu 'be.at':

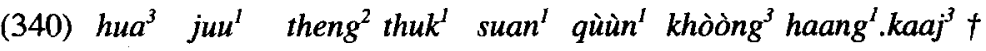
head be.at above every part other of body 'The head is above all the other parts of the body.'

(341) tiin $^{3}$ juul lum thuk $^{l}$ suan $^{l}$ qùùn ${ }^{l}$ khòòng ${ }^{3}$ haang ${ }^{l} \cdot$ kaaj $^{3} \dagger$ foot be.at below every part other of body 'The feet are below all the other parts of the body.'

The relational nominals $t a j^{4}$ 'South, downstream, underneath' and nù $a^{3}$ 'North, upstream, over' are also often used for ABOVE and BELOW. As relative spatial terms, these are limited to a condition of strict verticality, as in the following proverb, a figurative expression of being under an oppressive regime:

(342) daap ${ }^{5}$ juul nùa ${ }^{3}$ khòò ${ }^{2}$ juu taj $^{4}+$

sword be.at over neck be.at under

'The sword above, the neck below.' (i.e. a situation with a sword hovering above one's neck; under the constant threat of punishment and death)

Clearly, this cannot be interpreted in terms of upstream/downstream or cardinal directions 'North' and 'South'. When the two entities being located are not vertically aligned, nù $a^{3}$ 'over' and $t a j^{4}$ 'under' cannot be used. If A's house is further up the hill than B's, the locative relationship could be expressed by theng ${ }^{2} \mathrm{ABOVE}$, but not nù ${ }^{3}$ 'over'. However, if A's room were on the second floor, directly above B's, either theng ${ }^{2}$ ABOVE or nù $a^{3}$ 'over' could be used.

Another word for expressing 'under' is kòong ${ }^{4}$, which suggests some kind of covering - possibly entailing that if one were above $\left(j u u^{l}\right.$ theng $^{2}$ ), one wouldn't see the entity being located. 


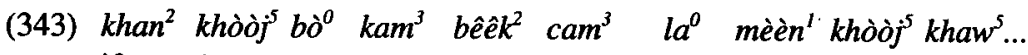
if $1 \mathrm{SG}$ NEG grasp brake to.limit PCL be.so $1 \mathrm{SG}$ enter khaw ${ }^{5}$ kòòng $^{4}$ khaw ${ }^{5}$ kòòng ${ }^{4}$ lot $^{1}-\tilde{n} a j^{l}$ enter under enter under vehicle-big

'If I (had) not put on the brakes hard, I (would have) gone in... gone into the underneath, gone into the underneath of (that) truck.'

\subsection{4 bùang ${ }^{4}$ SIDE}

$B$ ùang ${ }^{4}$ expresses the relational concept 'to the side of' as required for NSM expressions. It may also be used to refer to a 'place', namely the side. The next examples show that bùang ${ }^{4}$ SIDE is a nominal which may appear with modifiers like $k h u a^{3}$ 'right', saaj 'left', as well as determiners like diaw $w^{3} . k a n^{3}$ THE SAME: ${ }^{2}$

(344) phuuk khèèn ${ }^{3}$ khua ${ }^{3}$ paj bùang $^{4}$ khua $a^{3}$-phuuk khèèn $^{3}$ saaj $^{4}$ tie arm right go side right tie arm left paj $^{3}$ bùang saaj $^{4}$ go side left '(They) tied (his) right arm off to the right side - and tied (his) left arm off to the left side.'

(345) $k u u^{3}$ juu ${ }^{l}$ bùang diaw $^{3} \cdot \mathrm{kan}^{3} \mathrm{kap}^{2}$ mùng ${ }^{2} \dagger$ 1SG be.at side same with 2SG 'I was on the same side as you.'

The full three-slot expression of bùang ${ }^{4}$ SIDE parallels English ' $\mathrm{A}$ is at side $\mathrm{X}$ of B' (Wierzbicka 1996:136), where the third argument is marked by the possessive particle $k h \grave{o ̀ n g}{ }^{3}$ 'of':

(346) phen ${ }^{l}$ juul bùang ${ }^{4}$ qùùn ${ }^{l}$ khòòng ${ }^{3}$ hoong $^{2}-$ hian $^{2} \dagger$ 3HON be.at side other of school 'He is at another side of the school.'

(347) mùng $^{2}$ juul bùang ${ }^{4}$ diaw $^{3} \cdot$ kan $^{3}$ khòòng $^{3}$ qan-nil ${ }^{4} \dagger$ 2SG be.at side same of thing-this 'You are at the same side of this thing.'

Here we see a good example of difficulty in evaluating the naturalness of NSM expressions. As with other two- and three-place predications, it is difficult to find natural examples with all three places overtly filled. It is a rare thing in 
natural discourse for more than one full noun phrase to appear in a single clause, let alone three, and anaphora in Lao usually involves mere ellipsis.

Another word often translated by 'side' in English is khaang', which unlike bùang ${ }^{4}$ SIDE can refer to the side part of the body (e.g, kaduuk $k^{5}-k h a a n g^{5}$ [boneside] 'ribs', literally, 'side bones'), or can predicate a relationship of 'being to the side of'. The following example shows both buang ${ }^{4}$ and khaang $^{5}$ expressing the relational sense of SIDE (rather than 'the side' as a body-part): ${ }^{3}$

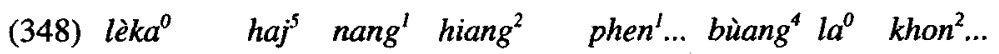
CLS.LNK give sit alongside 3 HON side per people

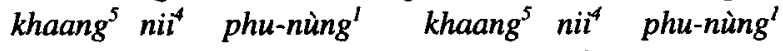
side this someone-one side this someone-one 'And so (he) got (them) to sit alongside of him... one person to each side... someone (on) this side, someone on this (other) side.'

$3.12 .5 n a j^{2} \mathrm{INSIDE}$

$\mathrm{Naj}^{2}$ INSIDE is another of many relational nominals. $\mathrm{Naj}^{2}$ can mean 'insides', specifically referring, for example, to seeds found inside fruit or pods. As a relational locative term, it co-occurs with $j u u^{l}$ 'to be at (a place)', in line with the claim that INSIDE is "a special case of "being somewhere"” (Wierzbicka 1996:137). $\mathrm{Naj}^{2}$ INSIDE can be used to simply state location of entities, or it may appear in an adjunct to a distinct main clause (which in the NSM system may involve tiing ${ }^{3}$ MOVE, hêt ${ }^{l}$ DO or keet ${ }^{5}$.khùn ${ }^{5}$ HAPPEN).

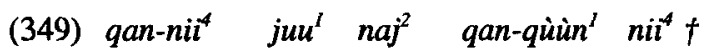
thing-this be.at inside thing-other this 'This thing is inside this other thing.'

(350) mii $^{2}$ qan-daj-nùng ${ }^{I} \quad$ tiing $^{3}$ juu $^{l} \quad n a j^{2} \quad$ qan-nil ${ }^{4} \dagger$ there.is something-which-one move be.at inside thing-this 'Something moved/is moving inside this thing.'

In example (351), naj ${ }^{2}$ INSIDE marks a destination for the theme argument of $s a j^{I}$ 'put'. In the next two examples naj ${ }^{2}$ INSIDE marks simple location 'inside', where the main verb is the locational juu' 'be at'.

(351) phen $^{I}$ qaw $^{3} \tilde{n} a n g^{3} \mathrm{saj}^{I} \mathrm{naj}^{2} \mathrm{kap}^{2} \mathrm{han}^{5} \quad \mathrm{ka}^{\circ} \quad \mathrm{bò}^{\circ} \mathrm{huu}^{4}$ 3HON take what put inside box TPC.PCL FOC.PCL NEG know 'What he put in that box, (I) don't know.' 
(352) $\mathrm{mii}^{2} \quad \cot ^{2}-\mathrm{maaj}^{3} \quad j u u^{l} \quad n a j^{2} \quad h u ̀ a n^{2} k h o ̀ \partial n g^{3} \quad$ laaw $^{2}$ there.is letter be.at inside house of $3 \$$ 'There was a letter in his house.'

(353) $k h u a m^{2}-$ cing $^{3}$ man $^{2}$ mii $i^{2} \quad k h o ̀ o ̀ n g^{3}-d i i^{3} j u u^{1} n a j^{2} n i i^{4}$ dêê $\hat{e}^{4}$ NSR-true $3 S G$ there.is stuff-good be.at inside here PCL 'In fact, there was something good in here.'

When $n a j^{2}$ INSIDE is used to express the location of an action expressed by the main verb, juu' 'be at' still appears, though here as a 'verb-preposition':

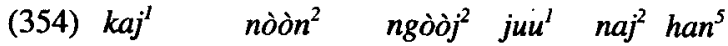
chicken lie/sleep perch be.at in there 'The chickens sleep perched in there (i.e. in nests nailed to the wall of the pen).'

\subsection{Logical concepts}

3.13.1 Interclausal linkers: ñòòn ${ }^{4}$ BECAUSE, thaa ${ }^{5}$ IF

BECAUSE is expressed by a clause linker ñò ${ }^{4}$, whose complement is often marked by the complementiser $v a a^{l}$ :

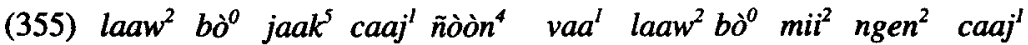
3SG NEG want pay because COMP 3SG NEG have money pay 'He didn't want to pay because he didn't have the money to pay.'

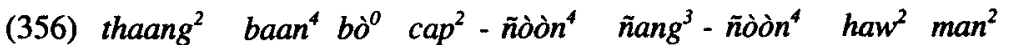
direction home NEG catch because what because 1SG 3SG $k_{h o n^{2}} k_{h e e j}{ }^{2} \mathrm{juu}^{l} \mathrm{nam}^{2} \quad \mathrm{kan}^{3} \mathrm{laaj}^{3} \mathrm{pii}^{3} \mathrm{lèè}^{4}$ people ever be.at together RCP much year PFV 'The village didn't capture (me) - why? - because I am someone who they have lived together (with) for many years already.'

$\tilde{N} \partial \grave{\partial} n^{4}$ BECAUSE may also directly mark a nominal, as follows:

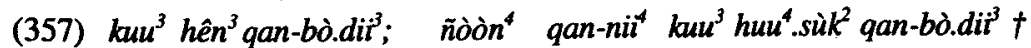
2SG see something-bad because thing-this 1SG feel something-bad 'I saw something bad; because of this (thing), I feel something bad.' 
Example (357) shows that the nominal qan-nit THIS THING - a nominal complement of ñòo $n^{4}$ BECAUSE - in fact stands anaphorically for a preceding clause (i.e. 'You did something bad'). The following example is also elliptical, with 'you' in 'because of you' referring, presumably, to some event or action on behalf of 'you' (i.e. 'This happened because you did/said something'):

(358) qan-nii' keet $^{5}-k h u ̀ n{ }^{5}$ ñòòn ${ }^{4}$ mùng ${ }^{2}+$ thing-this happen because 2SG

'This (thing) happened because of you.'

Another common word for BECAUSE is phò $q^{l}$. It apparently does not differ in meaning with $\tilde{n} \grave{o} o n^{4}$, and has much the same distribution:

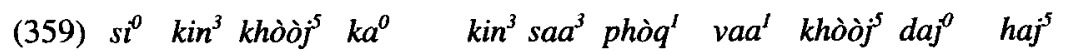
IRR eat ISG FOC.PCL eat PCL because COMP 1SG ACHV give

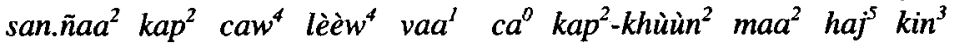
contract with $2 \mathrm{SG}$ PFV COMP IRR return come give eat '(If) you're going to eat me, then do it, because I did give you a promise that (I) would come back and let (you) eat (me).'

In ordinary Lao discourse, conditional meanings often arise with no morphosyntactic marking at all. The order of clauses in such cases is with protasis preceding. (Other orders are possible, but require marked intonation, i.e. strong de-stressing of the protasis showing that it has been "moved" into an afterthought position.) Example (359) shows an unmarked conditional construction. Other examples can be found at (2), (207) and (265).

The following example shows a concessive meaning 'even if arising in context, with no overt marking of the protasis:

(360) $b \grave{o}^{0}$ nòòn $k a^{o} \quad b \grave{o}^{0} h a j^{5} l u k^{l} \quad p a j^{3} s a j^{3}$ NEG sleep FOC.PCL NEG give get.up go anywhere '(Even if) you didn't sleep, (they) wouldn't let (you) get up and go anywhere.'

Haiman (1985) has documented this iconic ordering in a number of languages. The protasis provides the setting or background, 'conditions' for the clause that follows, and is thus functionally (and structurally) a topic (Haiman 1978, 1985:61ff), the initial element in a formally co-ordinate structure. Despite this co-ordinate syntactic structure, the semantic structure is clearly one of subordination. 
It is also common in Lao to overtly mark the protasis (prepositionally) with a word meaning IF. Both thaas and $k_{h a n^{2}}$ mean IF, and display no identifiable semantic or grammatical differences (but certainly are distinct stylistically). I have identified thaa $a^{5}$ as the basic exponent of IF: ${ }^{4}$

(361) thaa kaj $^{l} \quad h^{2} w^{2} l a a j^{3} h_{a w^{2}} k^{0} \quad h \hat{e}^{\prime}$ khuam $^{2}-k u a n g^{4}$ if chicken 1PL many 1PL FOC.PCL do NSR-wide khuam $^{2}-\tilde{n} a j^{l}$ laaj $^{3}$ nòq ${ }^{l}$

NSR-big very PCL

'If our chickens are many, then we'd make the width and size (of the pen) great, wouldn't we?'

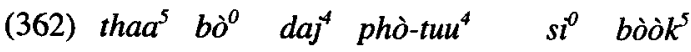

if NEG can grandfather IRR tell

'If (you) can't (read it), I'll tell you.'

The next example shows that the reverse order is also possible. And as (364) shows, it is also common for thaa $a^{5}$ IF to combine with the complementiser $v a a^{l}$ :

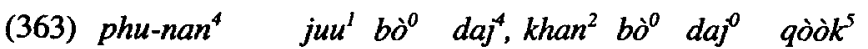
someone-that live NEG can, if NEG ACHV exit 'She couldn't live, if she didn't get out (of there).'

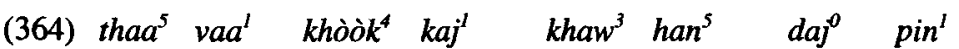
if COMP pen chicken 3PL TPC.PCL ACHV turn $n a a^{5}$ paj $^{3}$ thaang ${ }^{2}$ thit $^{l}$ tavên $^{2}-q \grave{o} o k^{5}$ han $^{0} \quad \mathrm{ca}^{0}$ face go direction face sun-emerge TPC.PCL IRR

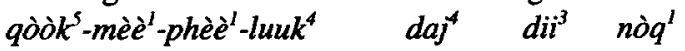
exit-mother-propogate-child ACHV good PCL

'If their chicken pen is turned to face the East, then (they'll) propagate well, won't they.'

Counterfactual expressions in Lao are not formally distinguished from conditionals in general, and specific counterfactual readings are pragmatically determined (based on tense/aspect reading of the predicate, and real-world knowledge of whether or not the protasis has happened or is the case). A text example can be found at (343). In the following example, the relationship between two unmarked coordinate clauses has several readings out of context: 


$$
d a m^{3} p a j^{3} t \hat{e} q^{2}-b a a n^{3}, l u u k^{4} \quad \operatorname{com}^{1}
$$

D. go kick-ball children complain

i. '(If) Dam goes to play soccer, his kids complain.'

ii. '(Even if) Dam goes to play soccer, his kids complain.'

iii. '(If) Dam has gone to play soccer, his kids will be complaining.' (i.e. I don't know what the situation is right now).

iv. '(If) Dam had gone to play soccer, his kids would have complained.' (i.e. I know that Dam didn't go.)

While these distinctions need not be formally marked in Lao, speakers nevertheless may distinguish between these meanings by using more explicit locutions if necessary.

\subsubsection{Clause Operators: baang $^{3} \cdot$ thii $^{2}$ MAYBE, $b \grave{o} \grave{o}^{l} / b \grave{o}^{\circ}$ NOT}

Baang ${ }^{3}$.thii ${ }^{2}$ MAYBE is morphologically analysable into baang ${ }^{3}$ SOME and thii ${ }^{2}$ 'instance', and is often translated into English as sometimes. (Accordingly, a common mistake for Lao speakers of English is to use sometimes for 'maybe', as in Sometimes it will rain today.) For example:

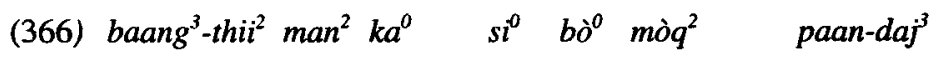
maybe 3SG FOC.PCL IRR NEG appropriate particularly 'Maybe it would be not very appropriate (to build a chicken pen, when you have as many as 20 chickens to house).'

The following example shows the expression baang ${ }^{3}$-thù ${ }^{l}$ performing an equivalent function (where thùa ${ }^{l}$ also means 'instance'). The speaker is not sure whether the facility at Chernobyl involved gas or nuclear energy:

(367) baang ${ }^{3}$-thù $a^{l} s \iota^{0}$ mè̀̀n ${ }^{l}$ niw $^{2} k h i a^{2}$ maybe IRR be nuclear 'Maybe it was nuclear.'

Example (368) has both baang ${ }^{3}$-thù $a^{1}$ and baang ${ }^{3}-$ thii $^{2}$ meaning 'sometimes':

(368) baang ${ }^{3}$-thùa $a^{1} k^{0}$ mùa $a^{2}$ thiaw ${ }^{5}$ lèèng ${ }^{2}$ baang $^{3}$-thii ${ }^{2}$ sii $^{4}$ sometimes IRR go trip afternoon/evening sometimes four moong ${ }^{2} k_{\text {heng }}{ }^{\prime}$ cùng ${ }^{I}$ qòo $k^{5} k a^{0} \quad$ mit $^{2}$ hour half so exit FOC.PCL there.is

'Sometimes (I) go on the evening flight, sometimes they have (flights which) leave at half past four.' 
Another common (and often more idiomatic) expression for MAYBE (or better, 'might') is $q a a t^{5}$ - $c a^{0}$, again morphologically analysable, as qaat 'to be possible' and $c a^{o}$, a future-oriented irrealis particle. This future orientation (although not necessarily with the speech event as the tense locus) renders the particle unsuitable for certain expressions of MAYBE (i.e. those without future orientation from at least some locus). Compare (369a) and (369b):

(369)
(a) baang ${ }^{3}$ thii ${ }^{2}$ laaw $^{2}$ hêt $t^{1} \dagger$ maybe $3 \mathrm{SG}$ do
'Maybe s/he (would) have done it/ did it/ will (would) do it.'

(b) $\quad l a a w^{2} q a a t^{5} . c a^{0} h e \hat{t} t^{l}+$

3SG maybe do

'Maybe s/he would have done it/ will (would) do it.'

* 'Maybe s/he has done it/did it.'

Baang ${ }^{3} . t h i i^{2}$ MAYBE operates over the whole clause, while $q a a t^{5}-c a^{0}$ works directly on the verb. The combinability of $b a a n g^{3} \cdot$ thil $^{2}$ MAYBE as a clause operator is broad, with one possible restriction on occurrence with first person present-tense mental predicates. (Wierzbicka (1996:140) notes this restriction for English; Evans (1996) describes similar grammatical effects of "private" predicates and their inherent association with the first person.) Thus:
(370) (a) baang thii $^{2} \quad q a n^{3} \quad n i i^{4} d i i^{3} \dagger$ maybe thing this good 'Maybe this thing is good.'
(b) baang.thii $i^{2}$ mùng ${ }^{2} \quad k h u ̀ t^{l} \quad v a a^{l} \quad q a n^{3} \quad n i i^{4} \mathrm{dit}^{3} \dagger$ maybe 2SG think say(COMP) thing this good 'Maybe you think this (thing) is good.'

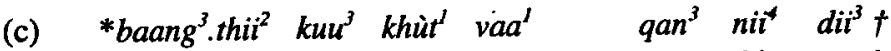 maybe 1SG think say(COMP) thing this good (Maybe I think this thing is good.)

The marker of negation $b \grave{o}^{0}$ or $b \grave{o} \grave{o}^{l}$ NOT, is a clausal operator, placed in a preverbal position. (Dozens of text examples appear throughout this chapter). Negation appears in the centre of the preverbal aspect-modality complex, with some aspectual-modals (including irrealis particles) preceding, and other aspectual-modals and directional particles following (Enfield 2002:140). 
Note also a "negative imperative" marker jaa $a^{l}$ 'don't':

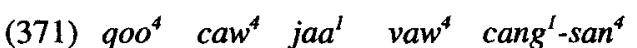
INTJ 2SG don't speak like.that

'Oh, don't you speak like that!'

Negation may involve complex scope relationships, as well as complex interaction with phrases of varying discourse status, e.g. SOMETHING and SOMEONE (cf. section 3.3.1 above for description of the interaction between negation, discourse status of arguments, and allolexy of SOMETHING/SOMEONE/SOMETIME exponents). Lao seems to display similar complications to English where more than one predicate is involved, such as with complement-taking predicates like WANT, or auxiliary predicates like CAN (see next section). Consider negation in a multi-predicate expression including WANT and DO. We can imagine two readings 'I don't want to do it' (WANT is negated) and 'I want to not do it' (WANT is asserted). The matter may require further investigation.

\subsubsection{Metapredicate: daj $^{4} \mathrm{CAN}$}

CAN is expressed by postverbal modal daj (cf. Enfield 2002 for a detailed description):

(372) qaan $^{1} \quad b \grave{o}^{0} d a j^{4}$ read NEG can

'(He) couldn't read (it).'

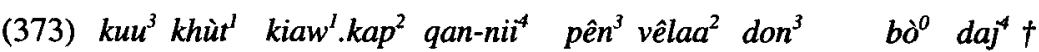
1SG think about thing-this be time long.time NEG can 'I can't think about this thing for a long time.'

(374) $b \grave{o}^{o} \quad l u k^{l} k a^{o} \quad b \grave{o}^{o} \quad d a j^{4}$ NEG arise FOC.PCL NEG can '(We) couldn't not get up.' (i.e. 'We had to get up')

Example (374) shows that double negation of CAN is a legitimate means of paraphrasing modal notions like obligation and necessity in Lao renditions of NSM formulas.

$\mathrm{Daj}^{4} \mathrm{CAN}$ allows non-personal arguments preverbally:

(375) qan-nit tiing $^{3}$ daj $^{4} \dagger$ thing-this move can 'This thing can move.' 


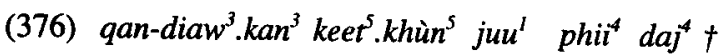
thing-same happen be.at here can 'The same thing can happen here.'

An important set of logical possibilities to be formally distinguished in the NSM system arise from possible relative scopes of negation and modality, as follows:

(i) $\quad$ can $\langle q\langle a\rangle>\quad$ ' $a$ can $q$ '

(ii) $\sim$ can $\langle q<a\rangle>$ ' $a$ can-not $q$ '

(iii) can $<\sim q<a>>$ ' $a$ can not $-q$ ' (e.g. 'John can swim') (e.g. 'John cannot swim') (e.g. 'John can not swim';

'It's okay/possible for John not to swim')

(iv) $\sim$ can $<\sim q<a>>$ ' $a$ can-not not- $q$ ' (e.g. 'John cannot not swim'; 'John must swim'.)

If these are to be recognised as conceptually distinct, their expression should be formally distinguishable in all languages. The tricky distinction is between (ii) and (iii). In Lao, the normal expression of the (ii) pattern involves direct negation on the post-verbal modal daj $^{4} \mathrm{CAN}$, as follows in (377). Negation of the first verb (i.e. scoping over the whole verb-plus-modal combination) suggests the (iii) reading, and insertion of the focus particle $k a^{0}$ before $d a j^{4}$ CAN forces this reading, as in (378). Thus, the four distinctions are formally made in Lao.

(377) $\operatorname{man}^{2} l \grave{o} \dot{j}^{2}-n a m^{4} \quad b \grave{o}^{0} d a j^{4}+$

3SG swim-water NEG can

'He can't swim.'

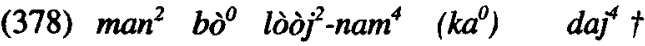

3SG NEG swim-water FOC.PCL can

'It's okay/possible for him to not swim.' ('He can not-swim.')

With respect to the basic modal CAN, NSM theory rejects traditional distinctions such as "permission", "ability", and "possibility". Wierzbicka regards CAN in 'I can't move' (e.g. 'of a baby, tightly held') and 'You can't do this' (a 'social rule') as having one and the same meaning, with the "social" or "physical" angle emerging from context (Wierzbicka 1996:104-105). While distinctions such as "permission", "ability", and "possibility" may be relevant to the meanings of more semantically elaborate/specific modals and modal idioms or collocations, it is the case that no instance of a simple $\mathrm{daj}^{4} \mathrm{CAN}$ expression inherently produces any one of these more specific readings. Context-situated examples of $\mathrm{daj}^{4} \mathrm{CAN}$ naturally give one reading or another, but when context is removed or altered, the other readings are always possible. There are no semantic subtypes of CAN. 


\subsection{Augmentor}

A common pattern for expression of $q i i k^{5}$ MORE is as a kind of adverb, corresponding to English another, usually coming before the nominal head (i.e. classifier) it refers to:

(379) khian $^{3}$ saan $^{3} \quad$ qiik' phèèn' nùng'

write official.letter more CLF one

'(They) wrote another official letter.'

In the next example, qiik ${ }^{5}$ MORE appears after the nominal it refers to:

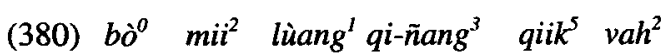

NEG have story something more PCL

'Don't (you) have any more stories?'

In the following example, qiik ${ }^{5}$ MORE refers exclusively to the action predicated by the intransitive verb $\mathrm{maa}^{2}$ 'come' (in the last clause):

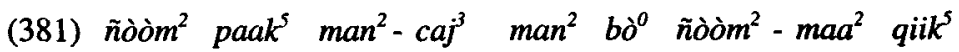
yield mouth 3SG - heart 3SG NEG yield come more '(They) yielded by mouth [and agreed to not come again] - (but) their hearts didn't yield - (they) came again.'

MORE seems to be inherently vague as to whether it refers to an activity or a participant in that activity. Thus, if Mary says 'John ate more pizza', it makes no sense to ask whether MORE refers to 'the pizza' or to 'the eating'. The following two examples demonstrate the point:

(382) $\mathrm{khon}^{3} \quad \mathrm{khaam}^{5} \mathrm{paj}^{3} \mathrm{cak}^{2} \cdot$ nòjj $^{5} \mathrm{la}^{0}$ khaam $^{5} \mathrm{maa}^{2} \mathrm{qaw}^{3}$ qiik transport cross go short.time PCL cross come take more '(They'd) transport (people) across there, and before long (they'd) cross back and take more (people).'

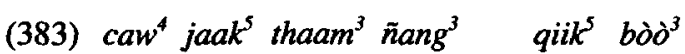

2SG want ask something more PCL.Q

'Do you want to ask anything more?'

In NSM formulas, $q i i k^{5}$ MORE combines unproblematically with the range of predicates - keet ${ }^{5}$.khùn ${ }^{5}$ HAPPEN, hêt ${ }^{l}$ DO, tiing ${ }^{3}$ MOVE, huu ${ }^{4} \mathrm{KNOW}, h \hat{e} n^{3}$ SEE, and $d a j^{4} . \tilde{n}$ in $^{2}$ HEAR. Here are a few examples: 


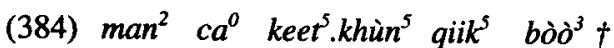

3SG IRR happen more PCL.Q

'Will it happen more/again?'

(385) $\mathrm{kuu}^{3}$ jaak $^{5}$ tiing $^{3} \mathrm{hêt}^{l} q i i k^{5} \dagger$

1sG want move/do more

'I want to move/do (it) more.'

(386) $d i a w^{3} . n i i^{4} k u u^{3} j a a k^{5} h u u^{4} / h \hat{e n}^{3} / d a j^{4} . \tilde{n} i n^{2} q i i k^{5} \dagger$

now 1SG want know/see/hear more

'Now I want to know/see/hear more.'

Comparative expressions in Lao do not involve qiik $k^{5}$ MORE. Instead, Lao uses $k u a^{l}$ 'exceed'/'more.than', as in the following examples:

(387) $k u u^{3}$ nang ${ }^{2}$ thaw $^{5}$ kual $^{l} \quad$ mùng $^{2}$ phun $^{4}-q a h^{o}$

1SG still old more.than 2SG PCL

'I'm older than you!'

(388) saam $^{3}$ phan $^{2} \quad k u a^{l} \quad k h o n^{2}$

three thousand more.than people

'(There were) more than three thousand people.'

\subsection{Intensifier}

The Lao exponent for VERY is the same stative verb $l a a j^{3}$ which has been described above (section 3.8.2) as having the meaning MUCH/MANY. Before we consider making the distinction between these meanings, let us first consider examples of $l a a j^{3}$ as a post-clausal adverbial element (coming after the object in transitive clauses), meaning VERY. See also (276) and (361).

(389) $l a a w^{2} d i i^{3}-c a j^{3} \quad l a a j^{3}$

3SG good-heart very

'He was very glad.'

(390) $\operatorname{man}^{2} h_{a k}{ }^{l} \cdot s a a^{3} \quad \tilde{n} a a k^{4} \cdot l a a j{ }^{3}$

3SG take.care.of difficult very

'He's very difficult to take care of.' 
In Lao renditions of NSM formulas, $l a a j^{3}$ means VERY in combination with

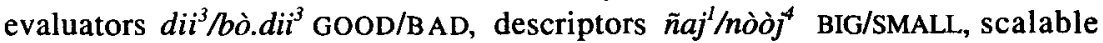
distance and duration expressions $\mathrm{kaj}^{3} / \mathrm{kaj}^{-4} \mathrm{FAR} / \mathrm{NEAR}$ and $\mathrm{don}^{3}$ A LONG TIME. Here are a few examples:

(391) khon $^{2}$ nan $^{4} \mathrm{dil}^{3} \quad \mathrm{laaj}^{3}+$ people that good very

'That person is very good.'

(392) $q a n-n i i^{4} \quad \tilde{n} a j^{l} l a a j^{3}+$ thing-this big very

'This thing is very big.'

(393) bòòn $n^{1} i^{4} \mathrm{kaj}^{3} \mathrm{caak}^{5}$ bò̀n ${ }^{1} \mathrm{nan}^{4} \mathrm{laaj}^{3} \dagger$ place this far from place that very 'This place is very far from that place.'

As described above in section 3.8.2, in combination with nominal elements, laaj $j^{3}$ behaves syntactically as a verb (following the nominal), and corresponds in translation to English much or many as in the following examples. In combination with classifiers (such as the all-purpose classifier $q a n^{3}$ THING), $l a a j^{3}$ usually precedes the element it modifies, as in (395):

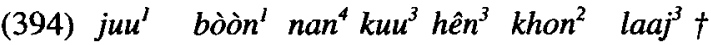
be.at place that $15 \mathrm{Sg}$ see people many 'At that place I saw many people.'

(395) $j u u^{\prime} \quad n a j^{2} \quad q a n-n i^{4} \quad m i^{2} \quad$ qan-qùùn' ${ }^{2} a a j^{3} \quad q a n^{3}+$ be.at inside thing-this there.is thing-other many thing 'Inside this thing there are many other things.'

However, a distinction between VERY and MUCH/MANY is required within the NSM to handle at least the notion of VERY MANY (as opposed to just MANY). In Lao, this requires a combination of $l a a j^{3}$ MUCH/MANY and $l a a j^{3}$ VERY, and it depends on these two meanings being formally distinct. There are three cases in which $l a a j^{3}$ may occur in direct combination with $l a a j^{3}$. The first two are constructions involving reduplication of $l a a j^{3}$ MUCH/MANY, and these both have specific constructional meanings beyond the simple combination of VERY and MANY. First, with stative verbs (or 'adjectives', including laaj ${ }^{3}$ MUCH/MANY), a syllable is repeated, with stress on the second of the pair. The meaning is 'V/adj- 
ish': 'more V/adj than others'. The following examples show that $l a a j$ as an attributive verb MANY enters into this construction in analogous manner to $\tilde{n} a j^{l}$ BIG:

(396) mii $^{2} \quad$ khon $^{2} \quad \tilde{n} a j-\tilde{n} a j^{1} \dagger$

there.is people RDP-big

'There were rather large people (there).'

(397) $\mathrm{mii}^{2} \quad \mathrm{khon}^{2} \quad l a j-l a a j^{3}+$

there.is people RDP-many

'There were rather a lot of people (there).'

A second kind of reduplication, also applicable specifically to attributive stative verbs ('adjectives'), puts stress on the first of the two syllables resulting from reduplication, and changes the tone of that first syllable to tone 2 (high rising), with emphatic meaning 'really, truly' (again, $l a a j^{3}$ MANY is analogous in behaviour to other 'adjective' type verbs such as $\tilde{n} a j^{l}$ BIG):

(398) $m i^{2} \quad k h o n^{2} \quad \tilde{n} a j^{2}-\tilde{n} a j^{1} \dagger$

there.is people big-RDP

'There were really large people (there).'

(399) mii $^{2} \quad$ khon $^{2} \quad$ laaj $^{2}-$ laaj $^{3}+$

there.is people many-RDP

'There were really a lot of people (there).'

A third situation in which $\mathrm{laaj}^{3}$ appears twice is with even stress on both - in this case, they are separate constituents and not part of any special reduplication construction, and this case represents the simple combination of VERY and MUCH/MANY as required for NSM expressions:

(400) $\mathrm{mii}^{2} \quad$ khon $^{2} \quad \mathrm{laaj}^{3} \quad \mathrm{laaj}^{3}+$

there.is people many very

'There were very many people.'

In the two distinct slots - main verb and post-verbal adverbial modifier - $l a a j^{3}$ carries two distinct meanings (MUCH/MANY, and VERY, respectively). Accordingly, another word which cannot perform those two roles - such as ñaj ${ }^{l}$ BIG - cannot appear in this kind of expression (i.e. with separate and even stress on adjacent instances): 
(401) $* m i i^{2} \quad$ khon $^{2} \tilde{n} a j^{l} \tilde{n} a j^{1}+$ there.is people big big

(There were really?/very? large people (there).)

\subsection{Taxonomy and partonomy}

The Lao expression for KIND (OF) is sanit ${ }^{I}$, syntactically a classifier. Compare the contrast with the individuating classifier $t o o^{3}$ 'body' in the following:

(402) $\mathrm{juu}^{l} \mathrm{suan}^{3} . \mathrm{sat}^{2} \mathrm{mii}^{2} \quad \mathrm{cia}^{3}$ sòòng $\mathrm{too}^{3} \dagger$ be.at zoo there.is bat two CLF('body')

'At the zoo there are two bats.'

(403) $\mathrm{juu}^{t} \mathrm{suan}^{3} . \mathrm{sat}^{2} \mathrm{mii}^{2} \quad \mathrm{cia}^{3}$ sòòng $^{3}$ sanit $^{1} \dagger$ be.at zoo there.is bat two kind 'At the zoo there are two kinds of bat.'

The following examples show that $\operatorname{sanit}^{l}$ KIND (OF) may be combined, as a nominal head, with any of the "determiners":

\begin{tabular}{|c|c|c|c|}
\hline (404) & $\begin{array}{l}\text { sanit }^{I} \text { nii }^{4} \\
\text { sanit }^{\prime} \text { diaw }^{3} . \text { kan }^{3} \\
\text { sòòng }^{3} \text { sanit } \\
\text { laaj }^{3} \text { sanit } \\
\text { sanit }^{I} \text { qùùn }\end{array}$ & $\begin{array}{l}\text { [kind this] } \\
\text { [kind same] } \\
\text { [two kind] } \\
\text { [many kind] } \\
\text { [kind other] }\end{array}$ & $\begin{array}{l}\text { 'this kind' } \\
\text { 'the same kind' } \\
\text { 'two kinds' } \\
\text { 'many kinds' } \\
\text { 'other kinds' }\end{array}$ \\
\hline
\end{tabular}

Expressions along the lines of ' $\mathrm{X}$ is a kind of $\mathrm{Y}$ ' involve the structure ' $\mathrm{X}$ is a Y (of) one kind':

(405) maj-khèèn ${ }^{2}$

pên ${ }^{3} \quad$ ton $^{4}$. maj $^{4}$ sanit ${ }^{1}$ nùng ${ }^{I} \dagger$ wood/tree-K.(Hopea sp.) be tree kind one 'Maj-khèen is a kind of tree.'

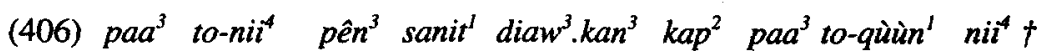
fish CLF-this be kind same with fish CLF-other this

'This fish is of the same kind as this other fish.'

PART is expressed by the nominal suan ${ }^{l}$ or the synonym compound phaak ${ }^{4}$-suan ${ }^{I}$. In some contexts, the bisyllabic phaak $k^{4}-\operatorname{suan}^{I}$ is idiomatically preferred, especially 
with reference to parts of non-physical things, such as organisations. ${ }^{5}$ As a nominal, suan $^{l}$ PART may take any of the determiners, as we saw for sanit ${ }^{\prime}$ KIND, above:

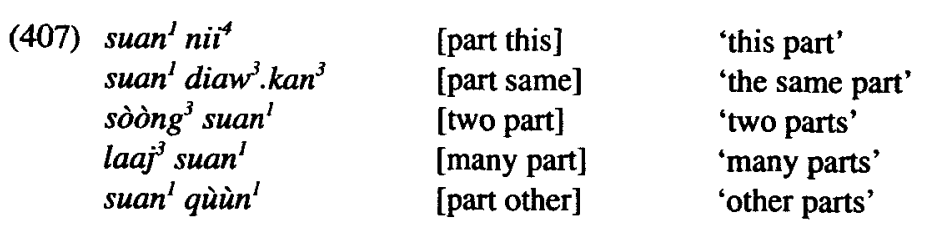

A common idiomatic use of suan ${ }^{l}$ PART is in the adverbial expressions suan ${ }^{l}$ nòòj [part small] 'least, the minority (of)', suan' ${ }^{l} a j^{l}$ [part big] 'mostly, the majority (of)', and $\operatorname{suan}^{1} \mathrm{laaj}^{3}$ [part much/many] 'mostly, the majority (of)'.

A more complex expression of PART - ' $X$ is a part of $Y$ ' - involves the possessive linker khòng 'of', in much the same role as English of in the translations:
(408) mù̀ ${ }^{2}$ pên ${ }^{3}$ suan' $^{\prime}$ nùng $^{I}$ khòòng ${ }^{3}$ khèèn ${ }^{3}+$ hand be part one of arm
'The hand is a part of the arm.'
(409) hòòng $-k h u a^{2}$ pên ${ }^{3}$ suan $^{1}$ nùng ${ }^{1}$ khò̀ng ${ }^{3}$ hùan ${ }^{2} \dagger$ room-kitchen be part one of house 'A kitchen is a part of a house.'

\subsection{Similarity}

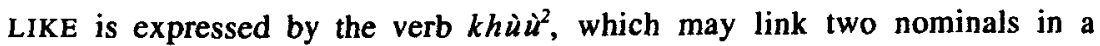
predicative construction (i.e. saying that one thing is like another thing):

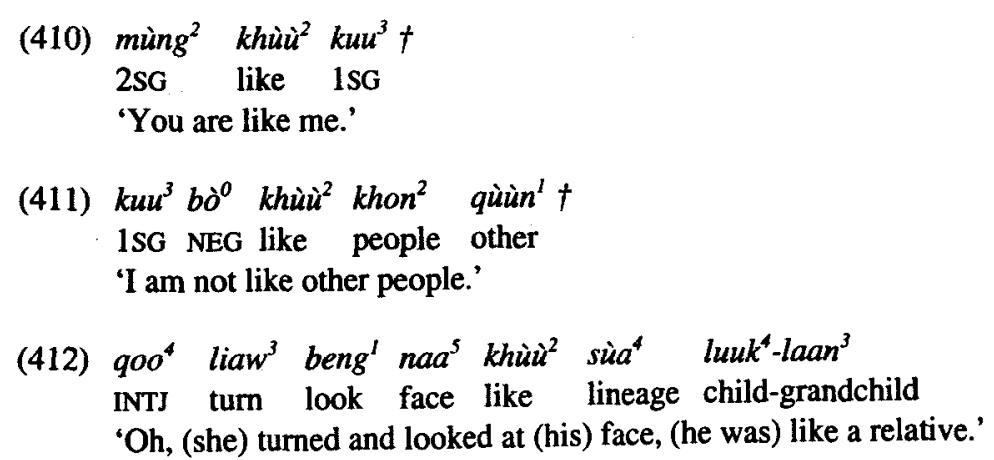


In the following common construction, the things being compared are in subject position, with $k h \grave{u} \grave{u}^{2}$ LIKE as a main verb taking the reciprocal marker $\mathrm{kan}^{3}$ (cf. English alike):

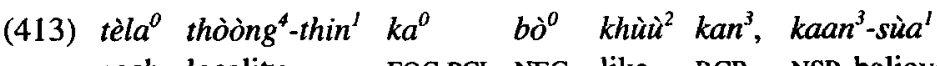
each locality FOC.PCL NEG like RCP NSR-believe 'Each of the localities are not alike, (with respect to people's) beliefs.'

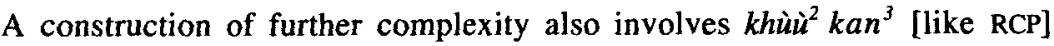
'alike', with addition of the preposition $\mathrm{kap}^{2}$ 'with', retaining the constituent order of (410-412), above:

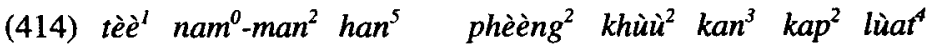
but liquid-oily TPC.PCL dear like RCP with blood 'But fuel was dear, like blood.'

The following examples show khùù ${ }^{2}$ LIKE forming the head of an adverbial adjunct, taking either a nominal complement, or a clausal complement:

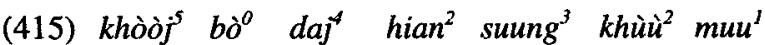
ISG NEG ACHV study high like peers 'I didn't study (to a) high (level) like (my) peers.'

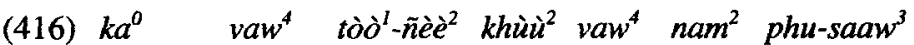
FOC.PCL speak flirting like speak with unmarried.girl

'(He) spoke flirtingly, like (he was) speaking to an unmarried girl.'

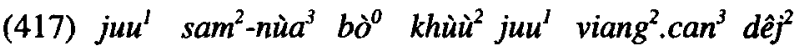
be.at S. NEG like be.at V. PCL

'(Living) in Sam Neua was not like (living) in Vientiane.'

$K h \grave{u} \grave{u}^{2}$ LIKE may also function as an attributive linker in a relative clause:

(418) tò̀n ${ }^{3}$ khùù ${ }^{2}$ tòòn ${ }^{3}$ nii ${ }^{4}$ mùng ${ }^{2}$ bò $\grave{o}^{0}$ khuan ${ }^{2}$ pên ${ }^{3} . h u a n g^{1}+$ time like time this 2SG NEG should worry

'(At) a time like this you shouldn't worry.'

(419) phuak ${ }^{4}-$ haw $^{2}$ tòòng kaan $^{3}$ khon $^{2}$ khùù $^{2}$ mùng ${ }^{2} \dagger$ group-1SG require people like $2 \mathrm{SG}$ 'We need people like you.' 
The common expression LIKE THIS may be expressed by overtly combining

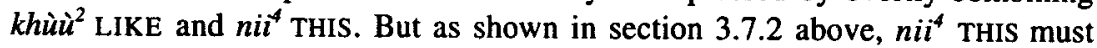
appear bound to a classifier, and for this particular expression the best candidate is nèè $w^{2}$ 'manner, way':

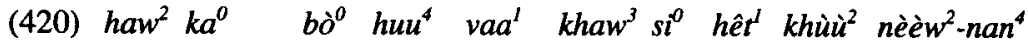
ISG FOC.PCL NEG know COMP 3PL IRR do like manner-that 'I didn't know they were going to do (something) like that.'

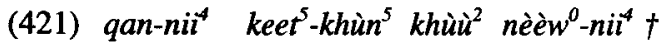
thing-this happen like manner-this 'This thing happened like this.'

A common adverbial expression cang.sit ${ }^{4}$ also means LIKE THIS (usually used with reference to an explicit visual demonstration):

(422) laaw $^{2}$ vaw ${ }^{4}$ cang.sili $\dagger$

3SG say like.this

'S/he spoke/said it like this.'

(423) man $^{2}$ keet $^{5}-k h u ̀ n^{5}$ cang.sii ${ }^{4}+$

3SG happen like.this

'It happened like this.'

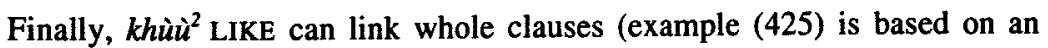
example in Wierzbicka 1996:144):

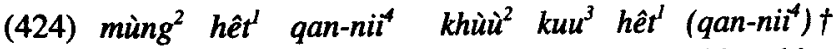
2SG do thing-this like $1 \mathrm{SG}$ do thing-this

'You did this thing like I did (it).'

(425) mùng ${ }^{2}$ jaak ${ }^{5}$ het qan-dii ${ }^{3}$ samlap ${ }^{2}$ haw ${ }^{2}$ khùù ${ }^{2} h_{a w^{2}}$ jaak 2SG want do thing-good for 1PL like 1PL want $h e \hat{t} t^{\prime}$ qan-diì ${ }^{3}$ samlap ${ }^{2} l u u k^{4} \quad k u u^{3}+$

do thing-good for child 1SG 'You want to do good things for me, like (as) we want to do good things for our children.' 


\subsection{On two recently proposed semantic primes: BODY and TOUCHING}

BODY is referred to in Lao by haang ${ }^{2}-k_{a a j} j^{3}$. This would be required for reference to body parts (cf. examples (340) and (341) above), and to bodily conditions or events, as for example in concepts of illness or emotional states:

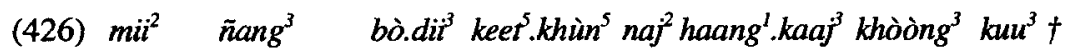 there.is something bad happen in body of 1SG 'Something bad is happening inside my body.'

TOUCHING, in the relational sense of 'be in contact with', is expressed in Lao by the verb $t i t^{2}$. The grammar of this word overlaps with certain uses of the relational predicate LIKE (cf. section 3.17 above). Tit $^{2}$ TOUCHING may be a transitive verb as in (427), or may take a reciprocal particle $\mathrm{kan}^{3}$, with the two touching participants expressed as a compound subject joined by the conjunctive particle $k_{a p}{ }^{2}$, as in (428):

(427) qan-niti $\quad t i t^{2} \quad$ qan-qùùn ${ }^{2} n i i^{4}+$ thing-this touching thing-other this

'This thing is touching this other thing.'

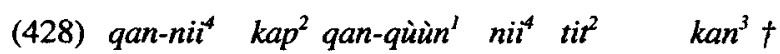
thing-this and thing-other this touching RCP 'This thing and this other thing are touching.'

Further, expression of $t^{2} t^{2}$ TOUCHING as a main verb may involve a complex combination of the reciprocal particle $k_{a n}{ }^{3}$ and the conjunctive particle $k a p^{2}$, apparently putting the non-subject argument into a more oblique grammatical status (as reflected in the English translation):

(429) qan-nii tit $^{2} \quad \mathrm{kan}^{3} \mathrm{kap}^{2}$ qan-qùùn ${ }^{1} \mathrm{nil}^{4} \dagger$ thing-this touching RCP with thing-other this

'This thing is touching with this other thing.'

It is not clear whether there is any semantic contrast between (429) and the simpler example (427). 


\subsection{Discussion and concluding remarks}

Goddard (1997) has argued that if one establishes the range of mechanisms required in a single language for expression of all semantic and combinatoric distinctions in the NSM system, one establishes the fundamental grammatical profile of that language. Indeed, in the above description of combinatoric properties of NSM expressions in Lao, most of the essentials of Lao grammar are revealed. We observe important general facts about typological parameters such as constituent structure, word order, phrase headedness, classifier constructions, and so on. It is also notable, however, that some highly salient features of Lao grammar do not emerge at all in NSM expressions, such as the inherently pragmatic/interactional systems of expressives and sentence-final particles. While the system of expressives is more or less context-specific and somewhat restricted (Chapman 1996, Wayland 1996), the grammatical use of sentence-final particles is one of the most salient and important parts of Lao grammar. It is their interactional status which makes them, on the one hand, unlikely to occur in impersonalised formal expressions such as NSM formulations, yet on the other hand extremely likely to occur in most real language use. Examples drawn from texts, as provided in this work, are peppered with interactional sentence-final particles but these. would never be required in "pure" NSM expressions. Thus, while a significant proportion of this language's "core grammar" is indeed revealed in its mechanisms for expressing NSM formulas, there are salient and important features of the grammar which are overlooked in the metalanguage, due to its formal and context-specific nature.

In closing, I would like to address some issues which have arisen, not directly from the Lao data, but in view of the general exercise being undertaken here. This set of studies represents a comprehensive response to constructive criticism of the NSM approach from various quarters over the years. It is now no longer possible to claim that the NSM system lacks explicit principles for combination of the primes (McCawley 1983). There remains, however, a further level (among others, perhaps) in the task of uncovering universal syntax. "Syntax" has been used here to refer to general principles of combinatorial organisation and composition of semantic primes in the NSM system. However, in this system (as in natural language) "combinatorial organisation" extends beyond the level we have discussed here. It extends beyond the clause and beyond the sentence.

NSM explications are typically large and structurally complex, virtual texts in themselves (see Appendix 3.1), with numerous predicates, numerous propositions, and numerous references and cross-references to a number of various participants, events, and situations. If an NSM explication is to be offered as a cohesive whole, equivalent to the speaker's own conceptual representation, then the relationships 
between all of these elements should be clear and unequivocal. Ambiguity may be a common decoding problem, but it cannot be an encoder's problem; for example, hearers may sometimes not know what a particular THIS is intended to refer to, but speakers surely must know. Thus, for any use of THIS (or other co-referring expression, such as THE SAME), the speaker's representation of reference should be unambiguous. But in NSM explications, the reference of THIS is generally left to sort itself out, and proposals to explicitly mark coreference have been dismissed due to their artificial nature (Wierzbicka 1980:15). In more recently addressing this problem, Wierzbicka (1996:146-7) has acknowledged a reliance on devices such as "a system of pauses and some nudimentary intonational contrasts" for spoken versions of NSM formulas, and "special spacing and indentation" for written versions. These "devices", while different in nature to familiar artificial notations, nevertheless perform explicit indexical functions, and the average NSM explication would hardly be interpretable without them (i.e. if the primes were simply written out in an unbroken string, or pronounced with identical intonation on every element). What then is the status of these devices in the NSM system? Pauses and intonational contrasts are not only formal diacritics, but more importantly they are meaningful, and if they are to be relied upon to resolve semantic problems, then they cannot go unaccounted for. Thus, still on the list of things to do is the challenge of attempting a description of universal grammar beyond the level of the clause.

Another issue which deserves comment concerns the tension between the status of the NSM as a "formal" system, on the one hand, and as a "natural" system on the other. The data provided in this chapter have demonstrated that the individual elements of the proposed NSM system are richly represented in naturally occurring discourse in Lao. Embedded in natural contexts (i.e. alongside semantically complex expressions and idioms), the meanings of these semantically basic elements are clear, simple, and perfectly idiomatic. However, it remains the case that the kind of complex NSM formulas found in standard NSM descriptive work (e.g. Wierzbicka 1996) are distinctly unidiomatic (despite their meanings being clear). At one important level however, style is irrelevant in a formal descriptive metalanguage. The real issues are semantic clarity, exactness, discreteness, verifiability, and lack of ambiguity.

NSM researchers prioritise the expressibility of their formal metalanguage via natural language because it is always through (our own) natural language that the ultimate interpretation of formal semantic description is made. Thus, formal semantic metalanguages which are expressed in highly abstract terms (e.g. Katz 1972, Jackendoff 1990), are so obscure at face value as to be opaque to the untrained observer. For the initiate or expert, these technical formulas may be interpretable, but nevertheless only interpretable to the extent that they continue 
to be privately paraphrased into natural language. Without principles explicitly mapping these formulas onto natural language, these other more abstract formal approaches are inherently indeterminate. The greater formal precision implied by their mathematical style is an illusion - because the abstract is ultimately interpreted in terms of the more immediate (Fraser 1996). NSM, on the other hand, routinely obscures its formal precision (at least in the eyes of those who desire mathematical rigour) by insisting that semantic explications be made in terms of natural language, with all the "surface" variation that natural languages necessitate (as described throughout this two-volume set).

The Natural Semantic Metalanguage is surely the only formal semantic metalanguage which tolerates - indeed encourages - context-dependent variation (allolexy) in the symbols for its primitive elements. This creates a number of misunderstandings for observers. First, some do not realise that the NSM approach entails a fundamental distinction between surface form and underlying content. The explications are intended to represent an underlyingly "pure" system, one which is nonetheless directly expressible via natural language. Natural language structures "host" these underlying conceptual structures, and this more often than not involves a range of variations not typical of formal languages, such as apparently arbitrary grammatical machinery, context-specific indexical variation, and multiple meanings of single symbols (distinguishable by grammatical context). These phenomena of surface variation in the rendering of the underlying NSM system have been explicitly defined in NSM theory by terms such as "allolexy" (where a single meaning is realised by more than one form, often serving the function of indexing a conceptual distinction in the context), and "polysemy" (where a single form expresses more than one meaning). Phenomena such as synonymy and polysemy are traditionally not permissible in formal descriptive systems (cf. Apresjan 2000), but this is essentially an aesthetically motivated prohibition. No compromise of rigour results from permitting such surface variation, just so long as the variation is contextually predictable and explicitly statable.

That this surface variation is not considered inherent to the "true" NSM metalanguage means that the true system is theoretically a stable and contextfree formal system, with no necessary departure from satisfying the condition of biuniqueness with respect to the symbols and the ideas they signify. It is at this "deep" level that the NSM would look like a formal semantic metalanguage (if it could be observed at this level). In collaboration with Chris Manning, I have attempted to demonstrate this by arguing that a "deep" representation of the system as a context-free formal grammar is possible (Enfield and Manning 1997). The apparent increase in formal rigour is of course only apparent, since as NSM researchers rightly point out, semantic description is ultimately always 
interpreted via natural language anyway. All the same, "formalisation" of the NSM (or even just remembering to think of the NSM as a formal system) remains a worthwhile exercise, and one that complements the current preoccupations of the research program, for at least three reasons. First, it makes explicit to non-initiates that the NSM as a descriptive metalanguage possesses all the qualities of a formal semantic system. This fact is not apparent to the casual observer. For all their fine qualities, NSM explications appear to the general linguistic community neither as formalisms nor as natural language descriptions - they conform to the idiom of neither, and yet ironically they satisfy the criteria of both. ${ }^{6}$ Put off by the fact that NSM conforms to no conventional idiom (be it colloquial speech, literary depiction, linguistic parlance, or the idiom of formalism), some linguists are unable to appreciate its unique achievement of unifying formalism and naturalism in a single descriptive and analytical system.

A second reason for formalising the NSM system is to demonstrate to formal semanticists in terms they can understand (or at least in terms which suit their tastes), that a true formal metalanguage can be based on maximally natural categories, and can be mapped explicitly and directly onto natural language. A third and important reason would be to enable the direct application of NSM semantics in natural language processing.

The merits of the NSM system need not be defined by the extent to which it is judged to approximate a "true" formally statable discrete universal conceptual system underlying the semantics of natural language(s), or whether it represents anything cognitively real or innate. Many scholars in this (post?)modern age are apparently unable at some personal or philosophical level to stomach the reductionist flavour of the system, or the failure of NSM explications to qualify as either literary form or logical formalism. But one need not commit to the putative universality or basicness of the system to use it to great advantage - one can always read 'universal' as 'maximally universal', 'simple' as 'maximally simple', as far as can be expected in a formal metalanguage. We are more likely to make progress in semantics by attempting explicit definitions in simple and cross-linguistically comparable terms, than by engaging in the esoteric abstraction of formal and semi-formal approaches, or in the woolly speculative psychology of some recent work in cognitive linguistics. The Natural Semantic Metalanguage provides a stable and methodologically useful cross-linguistic frame of reference for discovering and stating meaning, both in the laboratory and in the field. As the descriptive chapters in this set of studies demonstrate, the NSM provides a genuine solution to a fundamental problem of linguistics and anthropology - where to begin in describing what things mean. 


\section{Appendix 3.1: Two natural semantic metalanguage texts in Lao}

Following are two 'semantic texts' devised by the editors as an exercise in cross-linguistic comparability of complex NSM formulas. There are no significant problems with the Lao version, but a few points are worth mentioning.

First (as in Malay, see Goddard, vol. I, chapter 3), the "low"-form pronouns $k u u^{3}$ I and mùng $^{2}$ you would be considered inappropriate for this kind of impersonal text, i.e. a text which is not situated in some interactional context, and which, more importantly, appears in writing. While speakers would probably prefer the more polite forms $k h \dot{\partial} \dot{\partial} \dot{f}^{s}$ 'I' and $\mathrm{caw}^{4}$ 'you', it would be a simple matter to brief people on the reasoning behind the highly informal style (i.e. that the forms are more "basic", semantically more simple). However, as Goddard suggests for Malay, it may prove more practical simply to use the less distracting polite forms.

Second, there is a problem in Text 1 with translating the following: 'If you can do it, it is good if you do it.' (The expression is not even particularly clear in English.) My translation appears in line (c) simply as 'if you do this, this is good'. The problem seems to lie in the embedding of the paratactic "clausal evaluator expression" (it is good if you do it') within a hypothetical construction ('if you can do it, _'). The original construction does not seem to be possible in Lao, and one would hope that a suitable paraphrase could be worked out.

Third, the high number of clausal evaluator expressions ('It is good/bad if...') in these texts sounds rather clumsy overall, since this kind of construction is not particularly idiomatic in Lao. I do not regard this as a major concern, since (as should be quite obvious) NSM explications in any language do not have to sound "natural". It should never be overlooked that the NSM is a formal and semi-artificial metalanguage, and as such, cannot be expected to be idiomatic.

I would also like to point out that lines (a) and (c) of Text 2 illustrate the use of $m i i^{2}$ 'there is' as an obligatory grammatical mechanism to mark the non-specific nominal subject SOMETHING (i.e. in this position, mii $^{2}$ does not mean THERE Is; cf. Sect. 3 above).

Text 1: The "Good Samaritan" script

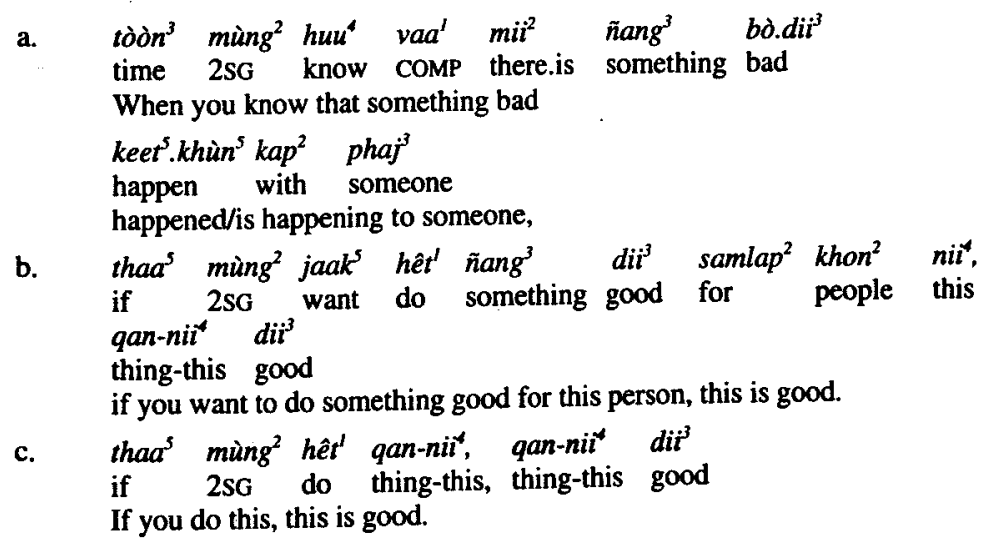




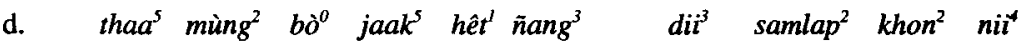
if 2SG NEG want do something good for people this If you do not want to do something good for this person,

qan-nii ${ }^{4}$ bò.dii

thing-this bad

this is bad.

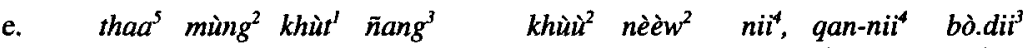
if 2sG think something like manner this thing-this bad If you think something like this, this is bad:

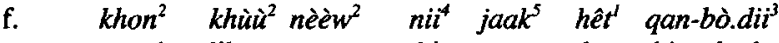
people like manner this want do thing-bad "People like this want to do bad things

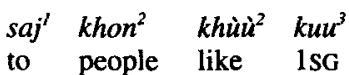

to people like me.

g. $\tilde{n} \dot{o} \partial n^{4} \quad q a n-n i i^{4} \quad k u u^{3} \quad b \partial^{o} \quad j a a k^{5} \quad h e t^{\prime} \quad \tilde{n} a n g^{3} \quad{d i i^{3}}^{3}$ because thing-this ISG NEG want do something good Because of this I don't want to do good things

samlap $^{2}$ khon $^{2}$ nit $^{4}$

for people this

for this person."

h. phacaw jaak hêt qan-dii ${ }^{3}$ samlap ${ }^{2}$ phaj ${ }^{3} \quad m e t^{2}$ God want do thing-good for someone all God wants to do good things for everyone.

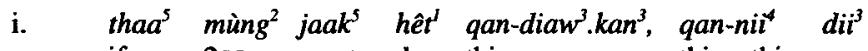
if 2SG want do thing-same thing-this good If you want to do the same thing, this is good.

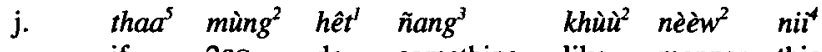
if 2SG . do something like manner this If you do things like this,

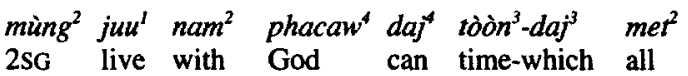
you can live with God at all times.

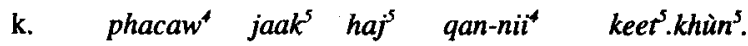
God want give thing-this happen

God wants this to happen.

Text 2: Part of the Chinese "Philosophy of the Middle Way"

a.
tò̀on ${ }^{3} \quad m \ddot{i}^{2}$
$\tilde{n} a n g^{3}$
bò.dii ${ }^{3} \quad l a a j^{3} \quad$ keet ${ }^{5} . k h u ̀ n^{5}$
kap ${ }^{2} \quad k u u^{3}$
time there.is something bad
When something very bad happens to me,
with $1 \mathrm{SG}$ 


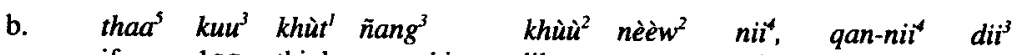
if 1SG think something like manner this thing-this good If I think something like this, this is good:

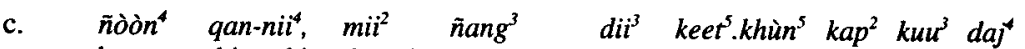
because thing-this there.is something good happen with 1 SG can "Because of this, something good can happen to me

$\left(\right.$ lang ${ }^{3} \cdot$ caak $^{5}$ tòòn $\left.{ }^{3} \quad n i^{*}\right)$

after time this

(after this time)"

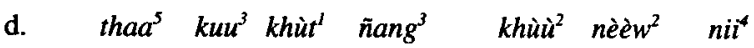
if 1sG think something like manner this If I think something like this,

e. $\quad k u u^{3} b \grave{o}^{o} \quad h u u^{4} \cdot s \grave{s u k} k^{2} \quad \tilde{n} a n g^{3} \quad b \grave{o} \cdot d i i^{3} l a a j^{3}$ 1SG NEG feel something bad very I will not feel something very bad.

f. $\quad$ qan-nit $\quad d i i^{3}$ thing-this good This is good.

g. $\quad t \partial \partial n^{3} \quad \operatorname{mit}^{2} \quad \tilde{n} a n g^{3} \quad d i i^{3} \quad l a a j^{3} \quad k e e t^{5} . k h u ̀ n^{5} \quad k a p^{2} \quad k u u^{3}$ time there.is something good very happen with 1SG When something very good happens to me,

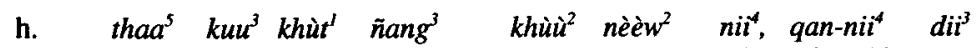
if 1SG think something like manner this thing-this good if $I$ think something like this, it is good:

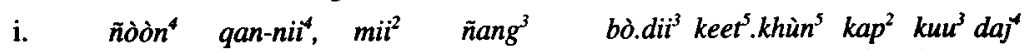
because thing-this there.is something bad happen with 1 sG can "Because of this, something bad can happen to me

$\left(\right.$ lang $^{3} \cdot$ caak $\left.^{5} \operatorname{tòòn}^{3} \quad n i^{4}\right)$

after time this

(after this time.)"

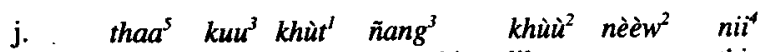
if ISG think something like manner this If I think something like this

k. $\quad k u u^{3} \quad b \dot{o}^{0} \quad h u u^{4} . s u ̀ k^{2} \quad \tilde{n} a n g^{3} \quad{d i i^{3}}^{3} \quad l a a j^{3}$ 1SG NEG feel something good very I will not feel something very good.

1. qan-nii $\mathrm{dii}^{3}$

thing-this good

This is good. 
Appendix 3.2: Exponents of semantic primes in Lao

\begin{tabular}{|c|c|}
\hline Substantives & Evaluators and Descriptors \\
\hline I $k u u^{3}$ & GOOD $d i i^{3}$ \\
\hline YOU mùng ${ }^{2}$ & BAD bò.diti \\
\hline SOMEONE $p h a j^{3} / p h u-$ & BIG $\tilde{n} a j^{l}$ \\
\hline SOMETHING $\tilde{n}$ ang ${ }^{3} / q a n-$ & SMALL $n \grave{\partial} \jmath^{\star}$ \\
\hline $\begin{array}{l}\text { PEOPLE } \text { khon }^{2} \\
\text { BODY haang }{ }^{1} \cdot \text { kaaj }^{3}\end{array}$ & Time \\
\hline Mental Predicates & $\begin{array}{l}\text { TIME/WHEN } t \grave{\partial o ̀ n} n^{3} \\
\text { NOW } d i a w^{3} \cdot n i i^{4}\end{array}$ \\
\hline THINK $k h u ̀ t^{l} / k h i t^{2}$ & BEFORE $k \dot{d} n^{\prime}$ \\
\hline KNOW huu & AFTER lang $^{3} \cdot$ caak $^{5}$ \\
\hline WANT jaak ${ }^{5}$ & A LONG TIME $d o n^{3}$ \\
\hline FEEL huu $u^{4} . s u ̀ k^{2}$ & A SHORT TIME $b \grave{\partial}^{0}-d o n^{3}[?]$ \\
\hline $\mathrm{SEE} h e n^{3}$ & FOR SOME TIME $l a j^{2} \tilde{n} a q^{\prime} \cdot$ nùng $^{\prime}$ \\
\hline HEAR daj.ñin & MOMENT but.nung $/$ bat \\
\hline Speech & Space \\
\hline $\begin{array}{l}\text { SAY } v a w^{4} \\
\text { WORDS } k^{2} a m^{2} . s a p^{2}\end{array}$ & $\begin{array}{l}\text { WHERE/PLACE } s a j^{3} / b o ̀ o ̀ n ' \\
\text { HERE } p h i i^{\prime}\end{array}$ \\
\hline Actions, Events, Movement & ABOVE theng $g^{2}$ \\
\hline HAPPEN keet. khüns & $\begin{array}{l}\text { BELOW lum } \\
\text { INSIDE } n a i^{2}\end{array}$ \\
\hline DO hêt ${ }^{\prime}$ & SIDE bùang ${ }^{4}$ \\
\hline MOVE nêng $g^{3} /$ tiing $^{3}$ & NEAR $k a j^{\circ}$ \\
\hline Existence, Possession & FAR $k a j^{3}$ \\
\hline THERE IS $m i i^{2}$ & Logical Concepts \\
\hline HAVE $m i^{2}$ & BECAUSE $p h \grave{o} q^{1} / \tilde{n} \partial \grave{o} n^{4}$ \\
\hline $\begin{array}{l}\text { Life and Death } \\
\text { LIVE } j u u^{I} \\
\text { DIE } t a a j^{-3}\end{array}$ & $\begin{array}{l}\text { IF thaa'khan } \\
\text { NOT bod } \dot{d}^{\prime} \\
\text { MAYBE baang }{ }^{3} \cdot \text { thii }^{2} \\
\text { CAN } d a j^{4}\end{array}$ \\
\hline $\begin{array}{l}\text { Determiners } \\
\text { THIS } \text { nit }^{*} \\
\text { THE SAME } \text { diaw }^{3} \cdot \mathrm{kan}^{3} \\
\text { OTHER qüùn' }\end{array}$ & $\begin{array}{l}\text { Intensifier, Augmentor } \\
\text { VERY } \text { laaj }^{3} \\
\text { MORE } q i i k^{5}\end{array}$ \\
\hline $\begin{array}{l}\text { Quantifiers } \\
\text { ONE nùngl } \\
\text { TWO sò̀ng }\end{array}$ & $\begin{array}{l}\text { Taxonomy and Partonomy } \\
\text { KIND (OF) sanit' } \\
\text { PART (OF) suan' }\end{array}$ \\
\hline MUCH/MANY $l a a j^{3}$ & Similarity \\
\hline $\begin{array}{l}\text { SOME baang } \\
\text { ALL } \text { met }^{2}\end{array}$ & 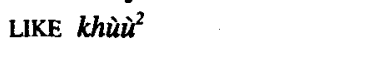 \\
\hline & $\begin{array}{l}\text { Newly proposed: } \\
\text { TOUCHING } t i t^{2}\end{array}$ \\
\hline
\end{tabular}


Abbreviations and conventions

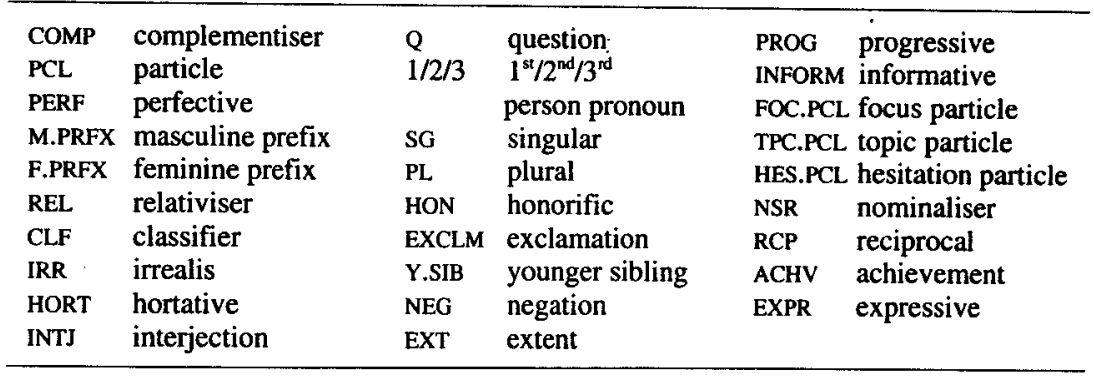

Small caps are used for NSM primes, italics for mentions, bold for emphasis, single capital letter with period (e.g. D.) for gloss of proper names, period between morphemes to indicate semantically unanalysable morphology (e.g. THERE.IS). ${ }^{*}(x)$ and $\left({ }^{*} x\right)$ indicate that the example is ungrammatical if $x$ is excluded, and included, respectively. $f$ indicates that the sentence is elicited or constructed. All other examples are from natural spoken texts.

There is no standard romanisation of Lao. The system used in this chapter (like the Lao orthography itself) does not feature sentence-based punctuation such as capital letters and periods. This is primarily to index their spoken (not written) source.

\section{Transcription}

\begin{tabular}{|c|c|c|c|c|c|c|c|c|}
\hline \multicolumn{5}{|c|}{ Consonants } & \multicolumn{3}{|c|}{ Vowels } & \multirow{2}{*}{$\begin{array}{l}\text { Tones } \\
1.132 /\end{array}$} \\
\hline$b$ & $d$ & & & & $i$ & & $u$ & \\
\hline$p$ & $t$ & $c$ & $k$ & $q$ (glottal stop) & & & $\grave{u}$ (unrounded) & 2. $/ 35 /$ \\
\hline$p h$ & th & & $k h$ & & $\hat{\boldsymbol{e}}$ & $e$ & $o$ & $3 . / 13 /$ \\
\hline$m$ & $n$ & $\tilde{n}$ & $n g$ & & & & & $4.151 /$ \\
\hline & $s$ & & & $h$ & $\grave{e}$ & $a$ & $\grave{o}$ & $5 . / 31 /$ \\
\hline$v / w$ & $l$ & $j$ & & & & & & 0. /unstressed/ \\
\hline
\end{tabular}

\section{Acknowledgements}

I gratefully acknowledge comments from Felix Ameka, Adam Chapman, Mark Durie, Nick Evans, and Catherine Travis on early versions of this work. I am especially indebted to Cliff Goddard and Anna Wierzbicka for their generosity, and their ongoing careful and detailed consultation. I am also grateful to Latsamay Sylavong, Syban Khoukham, Thongsvaat Thipphalangsy, and Pitsana Vayaphanh for their patient consultation concerning Lao grammar. 


\section{Notes}

1. The transcription used is described in Abbreviations and Conventions. There is no standard Romanisation of Lao. Most of the examples in this chapter are drawn from a corpus of spontaneous texts (including personal narratives, procedural description, folk tales, conversations, and the like) collected in Vientiane in 1996-1997. The examples marked with a cross $\dagger$ were constructed in consultation with informants.

2. Note that when buang' SIDE combines with qùùn' OTHER, the result is not the natural English rendition 'the other side' (presupposing just two sides), but 'another side'. The combination of OTHER and SIDE in NSM formulas should not be rendered in English by the other side.

3. This example illustrates well the distinction between the use of a locational nominal as a spatial relational concept, as opposed to a 'place' or a 'part' of something. Thus, in example (348) the girls did not sit 'on the man's sides' (i.e. on a part of his body), but rather 'to his sides', i.e. 'beside him'. In some recent discussion of the linguistic expression of space, it has been claimed that there is no such distinction. Best known perhaps are the claims by Claudia Brugman (1983) with regard to Mixtec, discussed by Lakoff (1987:316 and passim), and referred to by Strauss and Quinn (1997:81), and Bowerman (1996), who writes that "Mixtec has no prepositions or other morphemes dedicated to spatial relations. Instead, it expresses locations by metaphorically viewing the ground as an animal or a person and assigning a body part to the region in which the figure is located" (Bowerman 1996:158). Whatever kind of "extension" is involved, the usage remains relational and not nominal. Whatever "conceptual motivation" may be perceived (i.e. metaphor or metonymy) concerns a relationship between distinct senses of a word, not between two interpretations of a single meaning. It is important to note that for all the relational spatial concepts in Lao - cf. bùang ${ }^{4}$ (TO THE) SIDE (OF), naj ${ }^{2}$ INSIDE, theng ${ }^{2}$ ABOVE, lum ${ }^{3}$ BELOW - there are (a) nominal usages, where the term refers to a 'place' or a 'part', and has a grammatical role as the argument of a verb, and (b) relational usages, where the term predicates a relationship between two entities. These are conceptually and formally distinct.

4. I want to raise an issue here with respect to IF expressions (especially in combination with 'can'), and a problematic logical entailment which can arise. According to the mode of reasoning known as modus tollens, if the apodosis of an If construction is known to be false, then it follows that the protasis must also be false:

(i) Implicational statement $p \rightarrow q$ :

(ii) Falsity of the apodosis $q$ :

If John has five beers, he gets drunk.

(iii) Valid conclusion that protasis $p$ is false: John hasn't had five beers.

Occasionally, NSM formulas include IF constructions along the following lines:

(i) If I can do something good, I want to do it.

(ii) If you can do it, it is good to do it.

Consider (i) - by modus tollens, if it were true that 'I don't want to do something good' then it would follow that 'I can't do something good'. And of (ii), if it were true that 'It is not good to do this', then one would have to conclude that 'You can't do this'. Neither of these conclusions would seem to fit with the meanings intended by the two formulas. This suggests either (a) a problem with the modus tollens reasoning, (b) a problem in the phrasing of the formulas in (i-ii), and/or (c) a qualitative distinction between 'logical if 
and 'natural if. The problem would not arise if the 'if' clauses in these two formulas were removed - it may be that they are simply not necessary.

5. There is one issue to consider with regard to the semantics of part, and this concerns its relation to nominals describing non-countable masses such as 'rice', 'corn', or 'water', which do not have inherently identifiable 'parts'. The following example shows suan' part referring to a given portion of a mass, rather than to a "component/part":

(i) $\mathrm{kin}^{3} \mathrm{khaw}^{5} \mathrm{ni}^{\mathrm{D}} \mathrm{khaw}^{5} \mathrm{ni}^{\theta}$ sòòng suan' tòòng ${ }^{4} \mathrm{saj}^{\mathrm{l}} \mathrm{pon}^{3}$ eat rice TPC.PCL rice TPC.PCL two PART must put mix

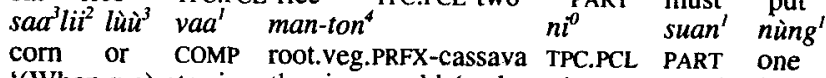
'(When we) ate rice, the rice would (make up) two parts, (and you'd) have to mix in one part of corn or cassava.'

[i.e. '... two parts rice, one part corn or cassava...']

While suan ${ }^{l}$ PART is used in Lao to express the idea of a portion of some mass, the equivalent in English involves not part but some:

(ii) $k h a w^{5}$ suan $^{\prime}$ nùng' tok $^{2}$-hia' $\dagger$

rice part. one fall-spill

'Some of the rice spilt.' ( = ?'Part of the rice spilt.')

The Lao word baang ${ }^{3}$ SOME cannot be used in such an expression, since it is restricted to use as a determiner with countable things:

(iii) *baang ${ }^{3}$ hhaw $^{5}$ tok ${ }^{2}-h i a^{l}+$

some rice fall-spill

(Some of the rice spilt.)

It is not clear how the semantic problems illustrated in these examples are to be handled in the NSM system. Perhaps English some of the rice should be defined as 'part of the rice' in the NSM.

6. It is on the level of idiomaticity that different linguistic/conceptual systems are incommensurable, yet commensurability is a fundamental aim of the NSM system. NSM is claimed to represent (ideally) the level at which different semiotic systems are commensurable, and this can be jarring since it entails an unidiomatic level of representation. Thus, while commensurability is virtually possible, it comes at a price. Complex ideas encoded in one language are unlikely to find idiomatic expression in another, especially when dismantled and reduced to the conceptual nuts and bolts.

\section{References}

Apresjan, Juri D. 2000. Systematic Lexicography. Translated by Kevin Windle. Oxford: Oxford University Press.

Brugman, Claudia. 1983. The use of body-part terms as locatives in Chalcatongo Mixtec. In A. Schlichter et al. (eds.), Survey of California and other Indian languages, Report No.4, 235-290.

Bowerman, Melissa. 1996. The origins of children's spatial semantic categories: Cognitive versus linguistic determinants. In J. J. Gumperz and S. C. Levinson 
(eds.), Rethinking Linguistic Relativity. Cambridge: Cambridge University Press, 145-167.

Carroll, John B. 1953. The Study of Language: A survey of linguistics and related disciplines in America. Cambridge, MA: Harvard University Press.

Chafe, Wallace. 1994. Discourse, Consciousness, and Time: The flow and displacement of conscious experience in speaking and writing. Chicago: University of Chicago Press.

Chapman, Adam. 1996. The Syntax of Lao Expressives. BA (Hons) Thesis. Australian National University.

Diller, Anthony. 1994. Thai. In C. Goddard and A. Wierzbicka (eds.), Semantic and Lexical Universals - Theory and Empirical Findings. Amsterdam: John Benjamins, 149-170.

Dixon, R. M. W. 1991. A New Approach to English Grammar, On Semantic Principles. Oxford: Clarendon Press.

Dowty, David R. 1979. Word Meaning and Montague Grammar: The semantics of verbs and times in generative semantics and in Montague's PTQ. Dordrecht: Kluwer.

Du Bois, John W. 1987. The discourse basis of ergativity. Language 63(4):805-855.

Enfield, N. J. 1999. Lao as a national language. In Grant Evans (ed.), Laos: Culture and society. Chiang Mai: Silkworm, 258-290.

Enfield, N. J. 2000. The cultural logic of personal reference in Lao. Paper Presented at the Workshop on Ethnopragmatics, Australian Linguistic Institute, July 2000. Melbourne University.

Enfield, N. J. 2002. Linguistic Epidemiology: Semantics and grammar of language contact in Mainland Southeast Asia. London: Routledge.

Enfield, N. J. and Christopher D. Manning. 1997. Towards a formal grammar for NSM. Paper Presented at The Annual Conference of the Australian Linguistics Society. University of New England.

Evans, Nicholas. 1996. Grammaticizing the Knower: Towards a partial typology of person effects on predicates. Plenary Paper, Third Australian Linguistic Institute, July 1996. Australian National University.

Foley, William A., and Robert D. Van Valin, Jr. 1984. Functional Syntax and Universal Grammar. Cambridge: Cambridge University Press.

Fraser, Helen. 1996. The Subject in linguistics. In K. Simms (ed.), Language and the Subject. Amsterdam: Rodopi, 115-125.

Givón, Talmy. 1984. Syntax: A functional-typological introduction. Volume 1. Amsterdam: John Benjamins.

Goddard, Cliff. 1989. Issues in natural semantic metalanguage. Quaderni di Semantica 10(1):51-64.

Goddard, Cliff. 1997. The concept of a 'core grammar' from a semantic point of 
view (with special reference to Malay). Linguistics seminar, May 1997. University of Melbourne.

Goddard, Cliff. 2002. Semantic primes and universal grammar in Malay (Bahasa Melayu). In C. Goddard and A. Wierzbicka (eds.), Meaning and Universal Grammar - Theory and Empirical Findings. Volume I. Amsterdam: John Benjamins, 87-172.

Goddard, Cliff, and Anna Wierzbicka. 1994. Introducing lexical primitives. In C. Goddard and A. Wierzbicka (eds.), Semantic and Lexical Universals Theory and Empirical Findings. Amsterdam: John Benjamins, 31-54.

Goddard, Cliff, and Anna Wierzbicka. 2002. Semantic primes and universal grammar. In C. Goddard and A. Wierzbicka (eds.), Meaning and Universal Grammar - Theory and Empirical Findings. Volume I. Amsterdam: John Benjamins, 41-85.

Goddard, Cliff, and Anna Wierzbicka. (eds.), 1994. Semantic and Lexical Universals - Theory and Empirical Findings. Amsterdam: John Benjamins.

Haiman, John. 1985. Natural Syntax. Cambridge: Cambridge University Press.

Haiman, John. 1978. Conditionals are topics. Language 54:564-589.

Hoshino, T. and R. Marcus. 1981. Lao for Beginners: An introduction to the spoken and written language of Laos. Rutland/Tokyo: Tuttle.

Huffman, Franklin E. 1970. Modern Spoken Cambodian. Ithaca, NY: Comell University, Southeast Asia Program.

Jackendoff, Ray. 1990. Semantic Structures. Cambridge, MA/London: MIT Press.

Katz, Jerrold J. 1972. Semantic Theory. New York: Harper and Row.

Lakoff, George. 1987. Women, Fire, and Dangerous Things. Chicago: University of Chicago Press.

Langacker, Ronald W. 1991. Foundations of Cognitive Grammar. Volume 2. Stanford: Stanford University Press.

Li, Charles N. and Sandra A. Thompson. 1976. Subject and Topic: A new typology of language. In C. N. Li (ed.), Subject and Topic. New York: Academic Press, 457-489.

Li, Charles N. and Sandra A. Thompson. 1979. Third-Person pronouns and zeroanaphora in Chinese discourse. In T. Givón (ed.), Syntax and Semantics, Volume 12: Discourse and syntax. New York: Academic Press, 311-335.

Li, Charles N. and Sandra A. Thompson. 1981. Mandarin Chinese. Berkeley: University of California Press.

Matthews, Stephen and Virginia Yip. 1994. Cantonese: A comprehensive grammar. London: Routledge.

McCawley, James D. 1983. Review of Anna Wierzbicka's Lingua Mentalis: The semantics of natural language. Language 59(3):654-659.

Morev, Lev N., Aleksej A. Moskalev and Yuri Ya Plam. 1972. The Lao Language. Moscow: Nanka (Glavnaja Redakcija Vostochnoj Literatury). [In Russian.] 
Onishi, Masayuki. 1994. Semantic primitives in Japanese. In C. Goddard and A. Wierzbicka (eds.), Semantic and Lexical Universals - Theory and Empirical Findings. Amsterdam: John Benjamins, 361-385.

Pawley, Andrew. 1994. Kalam exponents of lexical and semantic primitives. In C. Goddard and A. Wierzbicka (eds.), Semantic and Lexical Universals Theory and Empirical Findings. Amsterdam: John Benjamins, 387-421.

Reinhorn, Marc. 1980. Grammaire de la Langue Lao. Paris: Institute National des Langues et Civilisations Orientales, Université de la Sorbonne Nouvelle.

RLG (Royal Lao Government) 1972. Lao Grammar. (4 vols.). Vientiane: Royal Academy, Ministry of Education. [In Lao language.]

Roffe, G. Edward and Thelma W. Roffe. 1958. Spoken Lao. New York: American Council of Learned Societies.

Strauss, Claudia and Naomi Quinn. 1997. A Cognitive Theory of Cultural Meaning. Cambridge: Cambridge University Press.

Trudgill, Peter. 1974. Sociolinguistics: An introduction. England: Penguin.

Unicef Lao, 1991. Muun-sùa Tukataa. ['The Tukata (puppet) Tradition']. Video Production. Vientiane: Unicef Lao.

Van Valin, Robert D., Jr. 1993. A synopsis of Role and Reference Grammar. In Robert D. Van Valin Jr. (ed.), Advances in Role and Reference Grammar. Amsterdam/Philadelphia: John Benjamins, 1-164.

Van Valin, Robert D., Jr. and Randy LaPolla. 1997. Syntax: Structure, meaning, and function. Cambridge: Cambridge University Press.

Vendler, Zeno. 1967. Linguistics in Philosophy. Ithaca, New York: Cornell University Press.

Wayland, Ratree. 1996. Lao expressives. Mon-Khmer Studies 26:217-231.

Werner, Klaus. 1992. Learning Lao for Everybody. Vientiane: Peter Rump.

Wright, P. S. 1994. A Lao Grammar for Language Learners. (Special edition of Joumal of Language and Linguistics, 13). Bangkok: Thammasat University.

Wierzbicka, Anna. 1972. Semantic Primitives. Frankfurt: Athenäum Verlag.

Wierzbicka, Anna. 1980. Lingua Mentalis: The semantics of natural language. Sydney: Academic Press.

Wierzbicka, Anna. 1994. Semantic primitives across languages: A critical review. In C. Goddard and A. Wierzbicka (eds.), Semantic and Lexical Universals Theory and Empirical Findings. Amsterdam: John Benjamins, 445-500.

Wierzbicka, Anna. 1996. Semantics: Primes and universals, Oxford: Oxford University Press.

Wierzbicka, Anna. This volume. Semantic primes and universal grammar in Polish.

Yates, W. G. and S. Sayasithsena. 1970. Lao Basic Course. (2 Vols.) Washington DC: Foreign Service Institute. 